Florida International University FIU Digital Commons

11-20-1985

\title{
Effective energy conservation and management in the building sector : the answer to the energy predicament
}

Jorge C. Cano

Florida International University

DOI: $10.25148 /$ etd.FI14052559

Follow this and additional works at: https://digitalcommons.fiu.edu/etd

Part of the Environmental Engineering Commons, and the Other Civil and Environmental Engineering Commons

\section{Recommended Citation}

Cano, Jorge C., "Effective energy conservation and management in the building sector : the answer to the energy predicament" (1985). FIU Electronic Theses and Dissertations. 1995.

https://digitalcommons.fiu.edu/etd/1995 


\title{
EFFECTIVE ENERGY CONSERVATION AND MANAGEMENT
}

\author{
IN THE BUILDING SECTOR:

\section{THE ANSWER TO THE ENERGY PREDICAMENT}

By

\author{
Jorge C. Cano, P.E.
}

Modern civilization has developed principally through man's harnessing of forces. For centuries man had to rely on wind, water and animal force as principal sources of power. The advent of the industrial revolution, electrification and the development of new technologies led to the application of wood, coal, gas, petroleum, and uranium to fuel new industries, produce goods and means of transportation, and generate the electrical energy which has become such an integral part of our lives.

The geometric growth in energy consumption, coupled with the world's unrestricted growth in population, has caused a disproportionate use of these limited natural resources. The resulting energy predicament could have serious consequences within the next half century unless we commit ourselves to the philosophy of effective energy conservation and management.

National legislation, along with the initiative of private industry and growing interest in the private sector has played a major role in stimulating the adoption of energy-conserving laws, technologies, measures, and practices. It is a matter of serious concern in the United States, where ninety-five percent of the commercial and industrial facilities which will be standing in the year 2000 - many in need of retrofit - are currently in place.

To conserve energy, it is crucial to first understand how a facility consumes energy, how its users' needs are met, and how all internal and 
external elements interrelate. To this purpose, the major thrust of this report will be to emphasize the need to develop an energy conservation plan that incorporates energy auditing and surveying techniques. Numerous energy-saving measures and practices will be presented ranging from simple no-cost opportunities to capital intensive investments. 


\section{EFFECTIVE ENERGY CONSERVATION AND MANAGEMENT \\ IN THE BUILDING SECTOR:}

THE ANSWER TO THE ENERGY PREDICAMENT

by

$$
\text { Jorge C. Cano, P.E. }
$$

A report submitted in partial fulfillment of the requirements for the degree of

MASTER OF SCIENCE

in

ENVIRONMENTAL AND URBAN SYSTEMS

at

FLORIDA INTERNATIONAL UNIVERSITY

Committee in charge:

Professor

Chairperson

Professor

Professor

Professor 
To Professors

This report, having been approved in respect to form and mechanical execution, is referred to you for judgment upon its substantial merit.

The report of Jorge C. Cano is approved.

Professor

Professor

Major Professor

Date of Examination: November 20, 1985 
EFFECTIVE ENERGY CONSERVATION AND MANAGEMENT

IN THE BUILDING SECTOR:

THE ANSWER TO THE ENERGY PREDICAMENT

by

Jorge C. Cano, P.E.

A report submitted in partial fulfillment of the requirements for the degree of

MASTER OF SCIENCE

in

ENVIRONMENTAL AND URBAN SYSTEMS

at

FLORIDA INTERNATIONAL UNIVERSITY

1985 


\section{ACKNOWLEDGEMENT}

My thanks and sincere appreciation to Dr. Jose T. Villate,

P.E. for his constant interest, encouragement and support. 
TABLE OF CONTENTS

I. INTRODUCTION

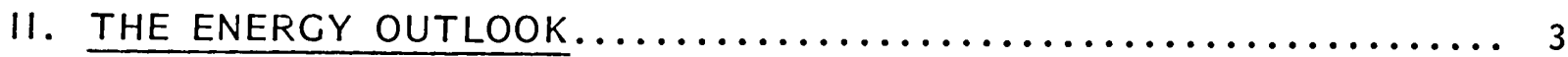
A. WORLD ENERGY RESOURCES
B. THE ENERGY SITUATION IN THE UNITED STATES

III. THE ROLE OF CONSERVATION

A. CONSERVATION DEFINED

B. CONSERVATION OPPORTUNITIES IN EXISTING FACILITIES

C. CONSERVATION IN THE RESIDENTIAL SECTOR

I. General

2. Legislation and the Government's Role

3. State Responsibility

D. CONSERVATION IN THE COMMERCIAL/INDUSTRIAL SECTOR

I. General

2. Direction of Commercial/Industrial Conservation

3. Legislation and the Government's Role

4. Industrial Conservation and the Economy

IV. DEVELOPING AN ENERGY CONSERVATION PLAN

A. A BASIC APPROACH 
1. Purposes and Goals

2. The Energy Audit

B. CONDUCTING THE ENERGY AUDIT

I. Collecting Background Data

2. Performing On-Site Survey

3. Identifying Retrofit Options

C. ECONOMIC EVALUATION AND IMPLEMENTATION OF RETROFIT PROJECTS

1. Simple Payback

2. Life Cycle Costing

3. Establishing Priorities

4. Implementing Conservation Opportunities

D. ESTABLISHING EFFECTIVE ENERGY OPPORTUNITIES

I. Initial Management Effort

2. Obtaining Personnel Cooperation

3. Monitoring

V. ENERGY CONSERVATION OPPORTUNITES IN THE

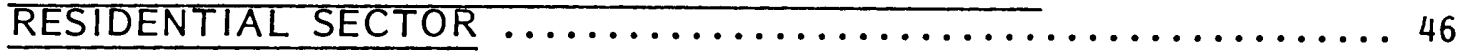
A. THE MOTIVATIONAL FACTOR
B. RESIDENTIAL CONSERVATION SERVICES
C. ENERGY CONSERVATION MEASURES
D. ENERGY EFFICIENT APPLIANCES
E. LANDSCAPING

VI. ENERGY CONSERVATION OPPORTUNITIES IN THE COMMERCIALIINDUSTRIAL SECTOR.................. 55 
A. GENERAL

B. STRUCTURAL

1. Background

2. Guidelines to Reduce Energy

C. VENTILATION

1. Background

2. Guidelines to Reduce Energy

D. HEATING AND COOLING

1. Background - Heating

2. Background - Cooling

3. Guidelines to Reduce Energy - Heating and Cooling

E. LIGHTING

I. Background

2. Guidelines to Reduce Energy

F. DOMESTIC HOT AND COLD WATER

I. Background

2. Guidelines to Reduce Energy

G. COMMERCIAL REFRIGERATION

I. Background

2. Guidelines to Reduce Energy

H. POWER

I. Background

2. Guidelines to Reduce Energy

I. CENTRAL CONTROL SYSTEMS

I. Background

2. Basic Functions 
VII. ENERGY LEGISLATION AND PROGRAMS.
A. GENERAL
B. METROPOLITAN DADE COUNTY ENERGY CONSERVATION PROGRAMS
C. FLORIDA POWER AND LIGHT CO. ENERGY CONSERVATION PROGRAMS
I. General
2. Residential Programs
3. Commercial/Industrial Program
4. Passive Construction Program
5. Appliance Efficiency Program

VIII. FUTURE FRAMEWORK

IX. APPENDECES...
A. GLOSSARY
B. CONVERSION FACTORS
C. ENERGY COST COMPARISON
D. ENERGY USE AUDIT FORM
E. UTILITY RATE SHEETS
F. INSULATING MATERIALS
G. ENERGY SURVEY REPORT FOR SUPERMARKET
H. LAMP REPLACEMENT CHART
I. ENERGY EFFICIENCY LABELING
J. RESIDENTIAL WEATHERIZATION
K. PASSIVE CONSTRUCTION DESIGN

$X$. LIST OF REFERENCES. 
In ancient times there was no energy predicament for man. His needs were limited to food, clothing, and shelter, and none of these required consumption of the earth's non-renewable energy resources. Although the discovery of fire allowed the development of manufacturing, it was not until after the Industrial Revolution that seeds were sown for the energy predicament, for it was then that man began burning vast quantities of non-renewable fossil fuels. The trend become an explosion, and by 1975 the United States, with just 6\% of the world's population, was consuming one third of the energy being used worldwide (Aadland 1980).

In the last decade, we have bequn facing, however reluctantly, some facts about energy. The plentiful supplies of inexpensive fuels that have helped build the American way of life as we know it, the energy sources that have spurred an economy and standard of living envied the world over, are not proving finite, not boundless as we had earlier imagined.

It has not been until recently - when prompted by government acknowledgement of our energy problems - that we have become somewhat more responsible for the use of our resources. However, this does not help to recover the incredible amount of energy that we squander through inherent inefficiencies in the residential, commercial, and industrial sectors of the society that we live in. A study by the National Academy of Sciences indicates that the energy potentially recoverable from these existing inefficiencies could add up to almost half our total energy consumption by the year 2010 (Miller 1980). 
Nevertheless, as bleak as the energy situation may seem, numerous ways exist by which we can reduce our increasing dependence on foreign, non-renewable energy resources. The approach is mainly through energy conservation and effective energy management.

Energy conservation is synonymous with eliminating energy waste no more and no less. The first step to discovering and eliminating waste is to understand how energy is used. Only then is it possible to evaluate waste that may be present in a system.

The objectives of this paper will deal with promoting energy conservation while underscoring the value of the energy survey as an indispensable tool for achieving energy conservation goals and developing effective energy management strategies.

Special emphasis will be placed in the identification of energysaving opportunities in existing residential and industrial/commercial facilities. 


\section{THE ENERGY OUTLOOK AND CONSERVATION}

\section{A. WORLD ENERGY RESOURCES}

All activities known to humans depend on energy in one of its forms. Solar energy is the force responsible for driving the great global weather and water cycles and supporting the earth's natural ecosystems. Energy in the form of fossil fuels, uranium, and hydropower turn the wheels of cities and machines. Human social history has developed in parallel with the development of sources of energy. Plentiful and affordable supplies of energy have released humans from many physical constraints in developing civilizations.

But energy has generallv remained an unseen, unthought of resource, unrecognized for its importance to human continued existence. Until recently, energy and its role in society were taken for granted; energy was available by merely driving up to the aasoline pump, flicking a switch, or shopping for food at the supermarket.

When referring to global energy supplies and consumption, the "quad" is the term most widely used by the energy accountant. A quad is a quadrillion $(1,000,000,000,000,000)$ British thermal units (Btu). One quad equals 180 million barrels of petroleum; 42 million tons of bituminous coal; 0.98 trillion cubic feet of natural gas; or 293 billion kilowatt hours of electricity. It takes 170 supertankers to haul one quad of oil (Miller 1981).

Of all the common fuels, oil is the most portable, the most convenient for transportation, the most versatile. It has seemed endlessly abundant. Above all, it was cheap until the 1973-74 Organization of Petroleum Exporting Countries (DPEC) oil embargo. With oil having been so relativelv inexpensive in the past, developing 
countries turned to it to fuel the economic systems and to provide the necessities of life such as food, clothing, and shelter. Meanwhile, industrialized countries, particularly in Western Europe, turned to oil to meet the demands of the industrialized age. Oil thus became the "growth" fuel of the 20 th century.

In 1979, oil, coal, gas and uranium accounted for about 94 percent of the world's energy production - 279 quads. Of the proved world energy reserves, coal represents the greatest percentage (69\%), followed by oil (16\%), gas (11\%) and uranium (4\%) (Weaver 1981). It is alarming to note that the greatest percentage of energy production is derived from oil, a reserve which may be depleted by the early part of the next century.

Long term energy issues are now only beginning to emerge and these problems appear to be as much conceptual as technical or economic in nature.

As energy resources rise in value, they gravitate mostlv to the developed nations, where a minority of the world's people enjoy a majority of its wealth. The growing disparity between the "more developed" nations and the "poorer" ones has spawned a dichotomy in world politics.

Pressures are mounting to reduce resource consumption of the industrialized nations. The less-developed countries claim the right to share in the world's resources and concern is increasing over the legacv to be left for future generations. Since the industrial nations are growing more dependent on lesser developed countries to help supply their resource needs, such pressures could take the form of economic and trade reprisals. Also, the lesser developed nations may select to husband their resources for use in their own countries. 
At this point in history there is sudden concern and apprehension over a developing energy crisis. The explanation for this situation includes the growing demand for greater amounts of energy, the diminishing quantities of remaining petroleum, and the time delays and limitations of alternative energy sources.

In light of the apparently impending energy crisis, noted energy expert O'Leary (1981) has not lost hope for solution:

\footnotetext{
"Enormous opportunities exist for expansion of conventional as well as unconventional resources in this hemisphere and in other parts of the world, if the technology and funding can be made available. The major remaining task of the U.S. is to find the political and financial mechanisms that will permit these resources to be applied to resolving the global energy dilemma."
}

Assuming slower world economic growth (3.5\% per vear) and less energy intensity, compared to the pre-energy crisis period before 1973 , $\mathrm{Hu}$ (1983a) predicts that the 1990 world energy supply would be about 270 quadrillion Btu. He adds that oil will still contribute about one-half of the 1990 world energy need; coal will contribute 20\%; and natural gas will provide $18 \%$. This projection indicates a slight increase in the share of coal and a significant reduction in the share of oil, which is forecast to be replaced by nuclear energy and synthetic fuels. 
During the 1970's - the decade of OPEC - Americans became acutely aware, as never before, of the extent to which their lifestyles and jobs depended on oil and other forms of energy. Twice in this period imported supplies of oil were seriously disrupted. Before that time availability of cheap energy was simply taken for granted.

Under the best of conditions, the energy outlook for the next two decades must be viewed with concern. The bonanza of low-cost petroleum and natural gas, a mainstay of the industrial world for most of this century, is over even though prices may temporarily be reduced. Great uncertainty exists concerning energy supplies. Yet if recent trends continue, by the year 2000 the United States could consume 50\% more energy than it does now (Hu 1983a). Consumption of all primary energy resources - the sum of coal, natural gas and oil, uranium and hydro - used in generating electricity could more than double.

Meloe (1981) reports that in the decade of the 1970s, energy requirements increased by nearly a third, while oil prices today are almost 30 times the level they were at the end of the 1960 decade. In real terms, after inflation has been wrung out, thev are probably many times that level. This development - and the prospect of even higher real energy prices in the decades ahead - is bound to have more of an impact on economic growth and the energy/GNP ratio in the future than any other single factor.

The U.S. still possesses extensive deposits of coal and uranium which can begin to substitute for oil and natural gas. However, there are obstacles which make it difficult to rapidly substitute these resources. Rising production costs, distance of the resources from eventual points of use, lack of sufficient transportation, restoration and maintenance of environmental quality, the lead times required to fully develop 
production facilities, and some technological problems must be accommodated or resolved before the promise of these resources is fulfilled.

The concept of diminishing returns helps explain the rising costs of producing domestic oil and natural gas. Most of the shallow and easily accessible on-shore domestic oil and natural gas fields have already been found and exploited. The location of new finds will increasingly occur at much greater depths in the ground, in distant off-shore waters or in extremely hostile environments such as Alaska. The costs to explore, produce, and deliver future oil and gas supplies under such conditions will be significantly higher than those of the past.

To counter this rate of depletion, we must discover similar reserves in the scale of Prudhoe Bay in Alaska. Yet most experts fear that few large fields remain to be found. More wells have been drilled in the U.S. than in the rest of the world combined. In 1980, Gore (1981) reports that drillers sank a record 60,000 domestic oil and gas wells, a fifth more than in the previous vear and most of them deeper and far more costly than ever before. The investment in this urgent search reached billions of dollars that year alone. Yet new finds still fall short of the depletion rate.

The general public, however, cannot afford to ignore the need for nuclear power to smooth the transition from gradually depleting resources of fossil fuels to new technologies whose potentials are not now fully developed or assessed and whose costs are generally nonpredictable.

Renewed interest in nuclear energy may be spurred when the public begins increasingly to realize that the energy crisis is real and cannot be overcome by relying solely on development of costly synthetic production. This development may indeed intensify the confrontation 
between environmentalists and those more interested in the growth of the economy and employment. But America's energy future may be untenable without nuclear energy.

Nuclear energy probably will not contribute its projected share of energy needs because of the recent Three-Mile Island accident. The prospect of the nuclear industry depends entirely on the public's attitude toward nuclear safety and waste disposal, and the effort of the industry and government to reduce the public's suspicions.

It has been estimated that energy consumption in the United States will double in approximately 20 years ( $\mathrm{Hu} \mathrm{1983a).} \mathrm{This} \mathrm{means} \mathrm{that} \mathrm{truly}$ huge quantities of energy and electricity will be needed. Considering that supplies of fossil fuels - coal, oil and natural gas - are limited, it is important to consider the expansion on nuclear generating facilities for their only use - generating electricity. This could free more of the remaining fossil fuels which are used to produce many vital products, such as plastics and fertilizer. These fuels need to be used for these higher purposes, for which there are no substitutes.

The Edison Electric Institute (EEI) (1979) has identified four important reasons why nuclear power is needed:

I. For the sake of reducing our dependence on foreign oil.

2. For the sake of economy in serving our expanding population.

3. For the sake of the environment.

4. For the sake of preserving remaining natural resources. Significant potential also exists from the development of "svnfuels". Synfuels are crude-oil substitutes derived from the liquefaction of coal and shale rock of which the United States is fortunate to have enormous reserves - the greatest in the world (Canby 1981). However, according to Barker and Lindgren (1979), the transformation of coal by liquefaction 
and gasification techniques looks promising if it can be made clean enough, cheap enough, and in sufficient quantities to meet projected needs.

However, ongoing research and development indicate that synfuels may not be commercially available until the end of this century. Currently, the Electric Power Research Institute, the Federal government, and several companies are developing synfuel pilot plants. When the pilot plants are built and have completed two years of operating experience, researchers will have the information necessarv to step up to a 30,000 ton-a-day commercial coal refinerv (EEI 1978).

The electric utilitv industrv is vitally concerned with this process because petroleum fuels are going to become less available and the industry is dependent on petroleum for certain generating uses, such as meeting the peak demands of a hot summer day when the use of air conditioning increases significantly.

Synthetic fuels, nevertheless, face barriers including uncertain environmental effects, commercially unproven technologies, multibilliondollar investments for each of dozens of facilities, and long times required for design and construction. Like solar energy, their contribution by the end of this century may be uncertain.

Most probably, America will not be self-sufficient in energy this century. However, we could alleviate the problem only through the large use of both coal and nuclear power combined with the application of effective energy conservation strategies in all phases of our lives.

Unfortunately, McKetta (1983) reports that over 300 new electrical generating plants have been cancelled during the past 9 years. Although 300 appears to be a small number. McKetta adds that there are less than 700 large electric generating plants in the United States. Over 
half of these plants are small compared to the plants of 1,000 megawatt capacity that have been cancelled.

Discoveries of significant offshore fields, further nuclear development, dramatic improvements in recovering oil from currently producing wells, rapid development of oil shales and tar sands, and the liquefaction of coal will be needed to halt this decline in energy resources - unless we learn to live on less and more efficiently through conservation. 


\section{THE ROLE OF ENERGY CONSERVATION}

\section{A. CONSERVATION DEFINED}

The simplest definition of energy conservation is to reduce the waste of energy by eliminating its unnecessary use - whether it be oil, gas, coal or electricity.

By extension, energy conservation can also be defined as the substitution of energy with capital, labor, or material and time. This definition also covers the substitution of scarce types of energy (e.g., oil) with abundant types of energy (e.g., coal) or the substitution of energy with time, convenience, labor and capital.

One substitutes time when waiting a little longer to plan a trip so that many shopping trips can be combined into one. One substitutes convenience when having the patience to carpool with others. One substitutes labor when using a hand opener instead of an electric opener to open a can. Finally, one substitutes capital when replacing an old, low-efficient residential air conditioner with a new one having a high E.E.R. (energy efficiency ratio) rating (See Appendeces A \& C).

Conservation has usually been interpreted as a sacrifice in standard of living, but that is an incorrect interpretation. Conservation can both increase productivity and maintain our standard of living because more time and convenience are used for production. Conservation is thus a way of using energy more efficiently.

In particular, conservation in industry may mean making new investments in more efficient equipment to replace old, inefficient facilities or retrofitting existing facilities. Thus, conservation investments have the same results as other investments that bring more 
jobs, lower costs, better products, and more competition, if the investments are well planned.

Finally, energy conservation can also be defined as the substitution of this generation's energy with that of future generations. This is called "intertemporal substitution" ( $\mathrm{Hu}$ 1983b). In this sense of energy conservation, $\mathrm{Hu}$ states the need to consider the following two points before demanding more conservation efforts:

- Whether the depletion of the given resource can be offset by new explorations and findings. That is, is the resource really limited and hard to replace in a short time?

- The intertemporal welfare of consuming this type of energy. That is, is the marginal utility of consuming this energy in this generation larger than the utility of consuming it in the next generation?

The United States' use of the world's resources is well known. This imbalance is summarized by the often quoted statistic that the United States with only six percent of the world's population uses over thirty percent of the energy consumed in the world (Sheathen 1978).

At the same time, while wrestling with finding ways to produce more energy, we have in the past overlooked the need to use this energy more efficiently. Miller (1980) points to a widely-praised 1979 Harvard Business School report which said that reclaiming this waste would give us "the cheapest, safest, most productive energy alternative readily available in large amounts, the equivalent of the elimination of all imported oil - and then some". 
There is encouraging evidence that new values are challenging traditional national goals such as material growth. The concepts of progress and improved quality of life are becoming less associated with consumptive lifestyles. The concern over such issues as the amount of energy the society should plan for in the future and the nation's choice of future energy sources are examples of a fundamental rethinking of "where are we going?" and "where do we want to be?". Increasing energy prices and limits to energy availability may encourage widespread adoption of these new values.

In 1980 alone, conservation efforts combined with effects of the recession reduced our annual oil imports by nearly 20 percent, with daily shipments dropping from 7.9 million barrels in January to 6.5 in December of the same year (Gore 1981).

Study after study reaches the same conclusion: The cleanest, least expensive, and least vulnerable energy option today is to use less by being more efficient. Only conservation can be implemented quickly enough to make a substantial difference.

If an attempt to achieve energy conservation is to be successful, it must be made in full light of the many factors which affect energy consumption. Unless these factors are known and understood, changes made may result in achievements far short of expectations or may actually do more harm than good.

\section{B. CONSERVATION OPPORTUNITIES IN EXISTING FACILITIES}

Until the early 1970's, many persons in the United States considered energy to be both inexhaustible and expendable. These assumptions were seemingly verified by the relatively low cost of most energy forms. The problems fostered by such attitudes are manifested in commercial 
buildings. Typically, most such buildings were designed and constructed with initial costs in mind. The result has been creation of a vast inventory of commercial buildings which - by todav's standards utilize excessive amounts of energy.

Buildings being designed now and those to be designed in the future will utilize many new techniques and systems which can lead to maximum energy efficiency. But the National Electrical Contractors Assoc. (NECA) (1979) reports that the present building inventory is being replaced at the rate of only 2-3\% per year. As a result, for many years to come, the majority of existing commercial buildings will be those designed without energy conservation in mind.

Because of this situation, conservation of energy in existing commercial buildings has become a matter of serious concern. Because energy is critical to the functioning of our nation, the federal government has become involved through the Department of Energy and many other departments and agencies. The government also has been working with organizations in the private sector to develop ways to help spur energy conservation in existing structures.

Ninety-five percent of the commercial and industrial structures which will be standing in the United States in the year 2000 are currently in place (Munk 1980). These structures use over 60 percent of our current energy supply, with environmental conditioning systems heating, ventilating, and air conditioning (HVAC) - using over 50 percent of that amount. The national energy objective of conservation can best be served with eneray-efficient heating, ventilating, and air conditioning systems.

To conserve energy one first must understand how the building consumes energy, how users' needs are met, how the systems and their 
elements interrelate, how the external environment affects the building, and other factors. By understanding how a specific building consumes energy, energy conservation improvements can be made which can be integrated into the system itself. Then, when the system is used, it runs efficiently and uses the least amount of energy to get the job done.

To conserve energy, we first have to know how we are using it. To find this out, we have to "audit" the use of energy at a facility to determine how it is being used. In many instances, a comprehensive energy audit will be the first major step of a comprehensive energy conservation program.

Energy auditing provides a detailed examination of the energy flows in a building's heating, cooling, ventilating, and lighting facilities; it determines ways to measure the efficient use of energy within a property, complex or industry; and then decides whether energy is being used efficiently. Using the audit, recommendations can be made for the most appropriate solutions to a particular energy consumption problem.

\section{CONSERVATION IN THE RESIDENTIAL SECTOR}

1. General. All Americans are part of the residential sector. No other sector can boast such participation. A spirited enerqy management consciousness is likely to start at home and then spread to our places of occupation. Residential energy use, which consumes 20 percent of the energy consumed in this country (Aadland 1980), may be more prone to efficient modification and adaptation than industrial or commercial.

2. Legislation and the Government's Role. Perhaps the most promising vehicle for the promotion of energy conservation in the residential sector is the National Energy Conservation Policy Act 
(NECPA) of 1978. NECPA is an example of governmental recognition that American homes are extremely important in our nation's energy picture.

NECPA has created a major program called Residential Conservation Services (RCS). Title 11, Part 1, of the RCS Program, Public law 95-619, requires that electric utilities selling to retail customers 750 million kilowatt hours or more annually and gas utilities selling to retail customers one billion cubic feet or more annually provide a comprehensive energy management package for all residential customers living in one-to-four-household units ( $\mathrm{Hu}$ 1983d). Standards for classifying energy-efficient residences have not been specified by the legislation or the regulations. These standards will have to be determined before the potential for conservation can be known.

It is estimated that many of the 33 million residences which are potential targets for RCS are in poor structural condition, and little can be done to make them energy efficient (Baker 1981). However, others offer the potential for retrofitting with a resulting energy reduction of up to $50 \%$. Since audits will be requested and must be provided to households that are already energy efficient, the number of audits will be greater than the number of audited customers taking action.

Thus, qualified auditors and inspectors are required for the good recommendations necessary for both the utility and the household to gain a reasonable return on investments. Inspectors will likely be employed by state and local governments while auditors will be representatives of utilities or private consulting firms. However, inspectors must understand the intent of auditors to judge installations fairly. Both auditors and inspectors must be well trained and certified to ensure good performance. 
The service package to be offered by the covered utilities includes the following (Aadland 1980):

- An announcement brochure which explains the program and invites them to participate. It lists measures and practices which have proven to be effective in saving energy and it indicates the level of savings for each that can generally be expected. It provides information on tax credits, weatherization assistance, and benefits of RCS.

- An on-site inspection of the home (Class A energy audit) by a qualified auditor. The auditor will make an analysis of the home's energy picture. He will further analyze the potential energy impact and cost effectiveness of applicable measures. The audit will provide instruction and information to the homeowner on practices and projects for saving energy and the use of renewable resources.

- Lists of qualified suppliers, contractors, and lenders whose services may be utilized by the homeowner in his energy projects.

- An offer to help in the arranging for installation and financing of energy conserving measures.

- Attention to quality control including a warranty on products, requirements according to Department of Energy standards for safety and effectiveness of products and materials, and D.O.E. standards for installations. In addition, inspections of some installations are required.

- Access to conciliation conferences and redress procedures.

3. State Responsibility. States are to ensure the success of the RCS Program by overseeing and enforcing the program according to their State Plans. Although State participation is not required, those States 
that choose to participate will be able to tailor the RCS Program to their own needs to integrate the Program with existing conservation activities. The State Plan will govern the RCS activities of all regulated utilities in the State and, at the Governor's discretion, may include non-regulated utilities and home heating suppliers. NECPA authorizes the Department of Energy (DOE) to develop and implement an RCS plan for utilities in States which have not submitted their own plans (Anderson 1979).

Governmental jurisdictions throughout the United States have begun to address energy efficiency through the use of building codes. Many if not all of the codes have set limits on the amount of energy expected to be consumed through end-use. The State of Florida, for example, has enacted laws which set standards relative to building energy efficiency through The Model Energy Efficiency Code for Building Construction (State of Florida 1984). The intent of Florida's energy code is to regulate the design of building envelopes for adequate thermal resistance and low air infiltration. The code also addresses the design and selection of electrical, mechanical, and illuminating systems. It is further intended that the provisions set forth by the code provide for the flexibility to permit the use of innovative approaches and techniques to achieve effective utilization of energy.

The code is based on a point system, which assigns to point values based on such factors as wall area, insulation values, window areas and other physical characteristics particular to the given structure. The total number of base points are then multiplied by a factor which has been derived using mechanical air conditioning efficiency as its basis. Once the total Energy Performance Index (EPI) is found and is within an acceptable range, the structure, be it residential, commercial or 
industrial, is certified as being energy efficient (Metropolitan Dade County OEM 1982).

\section{CONSERVATION IN THE COMMERCIAL/INDUSTRIAL SECTOR}

1. General. Energy conservation in industry is nothing new. The effective use of labor and materials - including energy - has been an important tool in cost control for many years. In fact, DeKoker (1979) reports that General Motors has been comparing its manufacturing plants' energy consumption and efficiency of steam generating facilities on a monthly basis since 1929. Extensive data was collected on steam generating facilities in order to compare efficiency of operation from plant to plant and to encourage adoption of the most cost efficient operating practices.

In the past, industry as well as government, has focused on retrofitting and bookkeeping, auditing, and data collection in conservation. The success of these efforts has been limited because resulting energy savings have not been substantial. Therefore, replacement of old facilities in the energy-intensive industries with new energy-efficient processes should be the new direction of conservation. Furthermore, new efficient processes that can also conserve petroleum should be the first priority for investment.

Based upon a survey conducted among the readers of Heating/Piping/Air Conditioning magazine, it is known that on the average, a 10-year old building wastes 40 percent of the energy delivered to that building, as verified by the National Bureau of Standards (Roose 1978). It is also known from the survey that over 50 percent of the existing industrial, commercial, institutional, and public 
buildings are over 10 years old. Of these buildings, over 100,000 are of the industrial type and over 400,000 are of the commercial, institutional, and governmental type representing over 4,000,000 square feet of space. To further confirm these findings, the Mechanical Contractors Association of America estimates that these buildings, on the average, waste between 40 and 50 percent of the energy consumed in the existing commercial, institutional, industrial, and government buildings.

It is also estimated that there are about 100,000 old, inefficient boilers and approximately 200,000 out-dated burners in these commercial, institutional and governmental buildings, and millions of miles of uninsulated piping; all of these installed when energy was cheap and thought to be plentiful and inexhaustible. Much of this equipment operates at 60 to 70 percent inefficiency and consumes millions of gallons of oil and millions of cubic feet of natural gas more than is necessary (Roose 1978). By renovating these and other systems and processes, such as the application of insulation, installing solar heating panels and high efficiency air conditioners, the total energy consumption could be reduced bv significantly.

Industry plays the key role to the nation's enerqy conservation efforts. However, government needs to be a catalyst that basically supports industry in replacing old facilities with new energy-efficient processes. These efficient processes will produce energy-efficient products and services at lower costs.

Because of industry's attention to costs and profits, continuing rising energy prices and uncertainty in energy supply may finally induce investment in conservation technologies when the cost of capital declines. Conservation investment is one of many ways in which industry can choose to spend its capital. Industry needs to carefully evaluate all 
alternative investments for conservation and non-conservation technologies and choose the investments that will provide efficient processes to produce more efficient and better quality goods and services.

A concerted effort in industrial energy conservation will become more and more important if stable economic growth is to be maintained.

2. Direction of Industrial Conservation. Hu (1983c) in his Handbook of Industrial Energy Conservation, makes the following four important observations about industrial energy conservation:

- Competition will increase because of the more energy-efficient production equipment installed in conservation programs.

- In order to justify expenses for energy conservation measures, industry must be able to expect an appropriate level of energy prices.

- Industry needs a constructive and cohesive government energy policy.

- Coordination among various federal, state, and local agencies, both energy and non-energy related, is essential for the success of the nation's energy conservation efforts.

Although numerous factors affect the implementation of energyefficient production equipment, usually the most critical factor is to have a technology - a piece of equipment, a process, or a method - that is attractive to the customer. In industry, the customer can include top management, the financial staff, as well as the engineers concerned with plant operation and production.

Once the technology is accepted and the proper systems implemented, the resulting processes will increase competition by producing energy-efficient products and services at lower costs. For example, if 
the automobile industry can produce cars that get $30 \%$ better mileage, the nation's energy savings will be substantial. In addition, many of these cars will be used to produce other goods and services.

Although some generalizations can be made about the overall acceptability of a new technology to an industry group, it must be remembered that purchase decisions are made at the level of the individual firm, or constituent part of the firm, such as a division or plant (Evans and others 1980). The most important factors which determine acceptability are the technical and economic attributes and institutional barriers.

Waste heat recovery is an example of a field where a significant potential for energy conservation exists through the development of new technologies such as heat recovery based on heat transfer in a fluidizedbed medium.

According to the Drexel study, the waste heat rejected by U.S. industry in 1972 exceeded 10 quadrillion Btus, of which 92 percent came from 10 industries, as defined by two-digit Standard Industrial Classification (SIC) codes (Brown 1977). Of course, this waste heat covers a range of temperatures and is therefore not all equally usable. Dow Chemical estimates that about 40 percent of the waste heat is at temperatures below $100 \mathrm{C}$ and another 20 percent is between $100^{\circ}$ and $250^{\circ} \mathrm{C}$ (Reding and Sheperd 1975).

However, in order to compensate for today's capital investments for the development of new technologies, industry has to expect sufficient increases in energy prices in the future. Although the high interest rates of a few years ago have dropped considerably to current prime rate levels in the vicinity of 11 percent, it is difficult to foresee industry investing in energy-saving equipment if it expects energy prices to be 
only slightly higher than inflation. In other words, if energy prices were kept artificially low by either legislation or government policies, industry would find it impractical to voluntarily invest in energy-saving processes such as the advanced heat-transfer process mentioned above ( $\mathrm{Hu} \mathrm{1983C).} \mathrm{It} \mathrm{would} \mathrm{then} \mathrm{most} \mathrm{likely} \mathrm{use} \mathrm{the} \mathrm{capital} \mathrm{to} \mathrm{invest} \mathrm{in} \mathrm{more}$ profitable facilities such as realty.

One key to further encourage industrial investment in energy conservation is having a cohesive government policy as indicated in Hu's third observation noted earlier in this section. The lack of a consistent policy saw the government's emphasis shift from energy production to environmental protection, to conservation. This shifting of policy was very costly to industry as it forced a change from coal burning to oil or gas burning in the 1960's and then to return to coal burning in the 1980's (Hu 1983C).

A cohesive government energy policy, along with the coordination of conservation efforts at all levels is necessary to help encourage industry to develop new energy technologies. This is essential in order to maintain our industry's competitive position at home and abroad, not to mention its survival.

3. Legislation and the Government's Role. The federal government has to play a major role in stimulating the adoption of energy-conserving technology. Federal policies to encourage industrial conservation may take several approaches to affect technology availability and acceptability, economic acceptability, fuel pricing and end-use priorities, education, and impacting regulations. Evans (1980) identifies major federal policies that have been in force or under consideration. They include: tax policies, fuel-use and pricing policies, utility requlations, design or performance standards, technologv RDED (research, 
development and demonstration), educational programs and an industrial efficiency reporting program.

The government's energy conservation policy must enhance the improvement of the competitiveness of U.S. producers because competition is the key to U.S. economic growth. Any contrary policy would be undesirable.

Government can foster conservation by providing fiscal incentives to replace energy-inefficient facilities that cannot make energy-efficient and high-quality products, by balancing the needs for efficient energy use and by monitoring and collecting data for efficient technologies. Government should not become a regulator in conservation, but should be a catalyst that provides fiscal incentives to foster conservation investments and, at the same time, maintain a safe environment.

4. Industrial Conservation and the Economy. Replacement of old industrial facilities with new and more efficient processes may require years for completion even after the investment decision have been made. The long lead time demands that industry make decisions for conservation early enough that the efficiency of new processes will quickly increase the ability of U.S. producers to compete with imports, in particular, the Japanese products.

On the other hand, industry should make decisions on facility investments in order to improve the energy efficiency of products before the consumer decides to purchase imported energy-efficient equipment and appliances. The consumer will become aware of the energy efficiency of equipment and appliances when the energy cost is sufficiently high. This point is exemplified by consumer attitudes toward the purchase of an automobile. The U.S. automobile industry did not expect the consumer to give up the inefficient big cars so quickly and therefore 
was not prepared for the change; consequently, it has lost large shares of the market to Japanese imports.

Because labor cost in the United States is high, especially when compared with Japanese and other producers, investing in energyefficient processes is urgently needed. Conservation should aid competition because most of these processes also make more energy-efficient and higher-quality products, save labor costs, and reduce pollution. The growth of the U.S. economy depends on the competitiveness of U.S. products, and the U.S. competitive position will largely depend on the efficiency of production processes, and goods and services.

Basically, the progress of industrial energy conservation depends on the relative price and availability of energy (in particular, petroleum products). With the present uncertainty in world oil supply and prices, today's investments in industrial energy conservation measures should assure better control of tomorrow's energy supply and help to keep a stable economy. 


\section{DEVELOPING AN ENERGY CONSERVATION PLAN}

\section{A. A BASIC APPROACH}

1. Purposes and Goals. Most existing buildings were designed and constructed during an era of abundant and inexpensive energy. Initial costs for buildings and their component systems ranked higher in decision making than did the costs of energy or concern over limited fuel supplies. As a result, energy conservation generally was not an important feature of their design.

Huge escalations in energy prices and the reality of fuel shortages now make it economically desirable to redesign, modify and, in general, to retrofit buildings, their operations and their usage to save as much energy as is practical. Practical savings is the key which applies in an energy conservation program.

Many available technical and non-technical options with varying degrees of effectiveness can save energy in buildings. Some modifications can be achieved with little or not cost. Other conservation options can be expensive. Still others may sacrifice occupant comfort or functional use of the building.

Faced with this wide range of possibilities - and also possibly confronted with limited financial resources - a building owner or manager is well advised to first call for a detailed study of many alternatives and then to implement the options which will save the most energy in the shortest time within existing financial constraints.

Dubin and others (1976) have identified three main purposes for the establishment of an energy conservation program for existing buildings. They are as follow: (1) to utilize fuels in the most effective manner to minimize the amount consumed for heating, ventilating, cooling, hot 
water, internal transportation, power, and other processes; (2) to use the particular type of fuel or electricity which is available at the lowest costs (and to switch from one fuel to another if the relative costs change radically in the future): and (3) to carry out these objectives within the financial capability of the owner and in the interests of developing national energy and resources policy.

To establish an energy conservation plan, it is necessary that a basic problem-solving approach be developed to understand a facility's energy consumption patterns and conservation opportunities. The performance of an energy audit and survey of a facility will be integral parts of this process.

2. The Energy Audit. Baron (1978) defines energy auditing as the process whereby the energy cost savings possible through intelligent energy management can be discovered and realized.

A wide range of activities are loosely described as energy audits. At one end of the scale, simply collecting utility bills, calculating energy consumption per square foot, and comparing this consumption to "normal" or "average" values might be termed an audit. At the other end of the scale, the audit by professional engineers and/or architects might include spending several man-days inspecting a building, testing HVAC equipment, measuring lighting levels, computing theoretical performance, determining life-cycle costs, and preparing retrofit recommendations. In general, the audits referred to in this report will be the type where professionals conduct on-site visits and perform technical calculations from which cost-efficient recommendations will later be made.

Energy audits should be done by persons familiar with the characteristics of the energy using systems or processes involved. This 
holds true for the simple fill-in-the-blanks type audit as well as the in-depth audit.

Auditors' knowledge should include how building and/or system characteristics affect energy use under varying load conditions. For example, air infiltration increases under some conditions when a ventilating system is operating even through the system "pressurizes" the building. Also, energy use penalties are inherent in the part load performance of many types of central HVAC systems.

When operations such as heavy manufacturing or chemical processing are the big energy users, individuals familiar with these operations are required. Otherwise the results may be questionable.

The individuals most familiar with energy-using systems are those who design, operate, and maintain buildings and the HVAC, processes, and electrical systems within. This does not mean that everyone who holds an engineering or architectural degree is qualified by experience or temperament to conduct an energy audit. Examples of persons who may be qualified to do energy audits include:

- The consulting engineer who designed the mechanical, electrical, or other type of system involved.

$\circ$ Other outside consulting engineers.

- Engineers on the staffs of contracting firms, either the firm that installed the system or another qualified firm.

- The owner's in-house engineering personnel.

Performance of an energy audit is absolutely fundamental to the successful development and implementation of a energy conservation/management program. It is essential that the audit be made by persons who know exactly what they are looking for and who can 
present findings in an unbiased manner. Whether the audit is conducted in-house or by a consultant, those performing it must be expert enough to recognize a possible source of wasted energy. Contractors or engineers, because of their extensive experience and diversified knowledge, mav recognize that the way in which the specific function is being conducted could be altered to provide significant savings.

\section{B. CONDUCTING THE ENERGY AUDIT}

1. Collecting Background Data. One of the ways to ensure that all energy uses have been subjected to proper scrutiny is to review the energy usage history of the facility to be audited. By establishing an energy inventory by energy use functions, it is possible to later evaluate system performance and identify areas with the most promise of energy reduction.

Although the basic procedure of analyzing fuel and electrical billings before and after implementation of an energy conservation program will be helpful in reviewing retrofit results, it cannot be used exclusively for judging the effect of various conservation efforts. A sample of an energy use form can be found in Appendix $C$.

Energy use may change because of weather deviations from year to year (Kennedy 1979), or changes in hours of occupancy or production programs, or improvements in performance quality, or from one modification rather than another introduced at the same time.

In implementing an energy conservation program it is not uncommon that energy consumption may not change as had been expected. One reason for this occurrence may be that system performance has greatly improved. Obtaining background materials for review, it is necessary to become familiar with the history of the facility including how much of 
what forms of energy are currently being used. To collect energy use data, some businesses keep detailed logs of energy use and know how much fuel they use daily, or they have detailed records of how much steam is generated and from that data one estimate how much fuel is used over a specific time period. Some also relate energy use to production output; i.e., so many Btu per piece or per ton of product. Many organizations, however, do not pay close attention to how much energy they use. They budget for utilities and fuel, pay the bills, and only question usage if expenditures differ substantially from what has been budgeted.

A review of the original construction drawings, if they are available, can also be helpful. Many changes may be made to a building over its life, and sometimes these revisions can drastically affect energy use.

The National Electrical Contractors Association (NECA) (1979) recommends that utility rate schedules be reviewed to determine if the facility is obtaining the best rate possible. Utility representatives should be asked to indicate likely future rate changes or restructuring. Rate analysis comparisons should also be requested to determine if "time-of-use" rates are more favorable (see Appendix D for Florida Power \& Light Co. sample rate schedule).

Other information may be available which will assist in the auditing procedure. For example, in-house personnel may already have initiated certain energy conservation modifications. If so, details should be obtained along with plans for any future modifications. Information should be sought from management on any other changes that they may have planned. 
2. Performing On-Site Survev. After reviewing any available plans and other pertinent data, the survey team should familiarize itself with the building and its operation by the on-site inspection of facilities.

The survey should be conducted with members of the facility's operating staff. This will allow the survey team to discuss operating procedures and gain additional first-hand information on particular systems and processes. It may also provide preliminary data on energy input to certain pieces of equipment in cases where the data are not available in any files. During the inspection, ideas may develop on how some of the equipment, systems, or processes could be operated more efficiently.

If plans do not exist, data should be obtained by inspection of the building. In particular, the physical condition of the building elements, especially apparent deficiencies, i.e. leaks, missing insulation, leaks window, etc. should be recorded.

During the survey it is important to list areas, lighting system details, temperature levels, control systems, equipment and processes, and occupied periods so that these areas can be addressed separately and so that the amount of energy currently used (and then conserved after implementing the individual guidelines in Section $V$ ) can be determined.

It is also necessary to record the number of occupants in the facility. For example, in listing the number of occupants for office buildings, record the average number of employees plus the estimated number of visitors; for retail stores, record the number of employees plus the number of customers; and for religious buildings record the number of people present at one time for various periods during the day and the week (Dubin and others 1976). This is important in that energy 
can be saved by reducing ventilation rates when occupancy is reduced even for portions of the day, and temperature can be reset during unoccupied periods for sections of the building.

The facility's survey should result in the development of lists of possible energy conservation opportunities or other ways in which energy could be managed more wisely.

3. Identifying Retrofit Options. The data obtained from the survey should be organized in an orderly and logical manner. An obvious classification is by system; i.e., building/HVAC/electrical/process/other. Whatever format is selected, a review of the data collected from the walk-through survey plus any other data available, such as from original plans and specifications, will identify obvious and potential sources of energy waste where cost-effective retrofit options can be implemented and point out areas where further information is needed. For example, it may be necessary to consult further with operating, maintenance, or production personnel to fill in gaps in the data collected or to get a clear understanding of certain points.

Once the field data has been collected and analyzed, the next step in the survey procedure is to develop energy savings estimates for each recommendation. In addition, for commercial/industrial analysis, Florida Power \& Light Co.(1982a) suggests that the total energy for lighting and HVAC systems be calculated immediately following the survev while the facility layout is fresh in mind.

Once areas of energy waste are found, recommendations on how to proceed should be submitted to management along with supporting data and cost estimates. One of the recommendations might be to develop an energy use profile for the entire building. This might be done for an office building or other facility where most of the loads -- heating, 
cooling, air handling, and lighting -- usually are significant energy users.

In cases where certain energy intensive loads account for the bulk of the energy used, as in certain industrial operations, the decision might be to concentrate efforts on these areas. These might be specific manufacturing operations and related high energy use systems such as exhaust systems and makeup air heating systems.

The result cost/benefit analysis of each energy conservation opportunity will then produce a prioritized list of those recommendations to be made to the customer or management in the form of a report.

In the commercial survey reports to their customers, Florida Power $\varepsilon$ Light Co. summarizes their recommendations as follows (see Appendix (G):

- Recommendation

- Kilowatt/kilowatt-hour savings

- Dollar savinas

- Installed cost

- Payback

Capital-intensive options should be specifically identified in the report and their costs and savings studied in much more detail than non-capital-intensive options.

C. ECONOMIC EVALUATION AND IMPLEMENTATION OF RETROFIT PROJECTS

1. Simple Payback. Usually, management will want to know the payback period on an investment for an energy conservation measure 
before a decision to implement it is made. Therefore, this is an economic factor that deserves much attention.

Simple payback period is the easiest of all economic factors to calculate. It identifies the amount of time required for the savings generated by an option to equal the cost of implementing the option. Expressed as a formula:

$$
\text { Simple Payback }=\frac{\text { Initial Cost }}{\text { Annual Savings }}
$$

Example:

If it will cost $\$ 10,000$ to install a high-efficiency motor which will save $\$ 4,500$ per year, what is the simple payback period?

Simple Payback Period $=\frac{\$ 10,000}{\$ 4,500}=2.22$ years

Simple payback period analysis should be used primarily to obtain a very general idea about the cost-effectiveness of a given option. For example, assume that one were trying to decide between two types of high-efficiency motors. They cost the same, but motor A pays back in two years and has a usable life of ten years, while motor B pays back in three vears, but has a usable life of 15 years. Simple payback analysis would not provide the answer. It should be used primarily to obtain a very general idea about the cost effectiveness of a given option.

2. Life Cycle Costing. One criticism of simple payback as a criterion for making an investment decision is that it ignores returns after the payback period. For this reason, the client should be given a complete economic picture of the potential investment before and after the payback period. Total "life cycle" costs should be presented in present worth terms so the complete impact of the economic analysis may be realized.

Present worth is the value today, in current dollars, of all future costs and savings associated with an investment. All costs and savings 
associated with an investment decision should be expressed in today's dollars.

Life cycle costing ( $L C C$ ) provides the major benefit of considering all costs of a product, device or system that accumulate over its useful life. Typical costs include those to purchase, install, maintain, and operate, among others. By using LCC techniques, it may be shown that a product which is twice as expensive as another actually may be only half as expensive on a life-cycle basis.

The following are basic data required for the life cycle type of analysis (Yanuck 1981):

- Initial Cost

- Energy Cost

- Operation Cost

- Maintenance Cost

- Taxes

$\circ$ Life

- Terminal Value

- Escalation Rate

- Discount Rate

Specific elements of LCC can be applied for different purposes, as to determine:

- Whether it is better to repair an old item or replace it with a new one:

- Which of two or more similar items is less expensive over the life cycle;

- Which of two similar energy-saving systems, such as different types of insulation, will be the most cost-effective (best buy for the money spent; and

- Which of two dissimilar energy conservation measures is the best investment, gives a limited budget (NECA 1979). 
Successful application of life cycle costing techniques requires an understanding of the basic concepts they entail, as follows: Economic Life: the economic life of equipment or materials is either its expected useful life, or the amount of time for which it will be used -- whichever is shorter. If the building will be torn down in 15 years, however, the boiler's economic life is 15 vears. Initial Capital Investment: Initial capital investment refers to the net amount of your investment, including selling price, sales tax, delivery charges, and installation costs. When the new investment replaces an older one, the old one possible could be sold as used equipment or for scrap. In most cases, however, it will have no value, and you may have to include the cost of carting it away. Tax factors also should be considered. For example, installation of insulation or solar water heating equipment may entitle you to a tax credit. If so, determine how much it will be and deduct it from the capital investment cost. Maintenance Cost: Two kinds of maintenance, such as cleaning, oiling, and tightening. The second involves replacement of components which wear out, such as filters and drive belts. Determine the maintenance requirements of the item being considered. If they are highly technical, will in-house maintenance personnel be able to maintain them, or will a service maintenance contract be needed? In either case, what will be the maintenance costs? Annual Energy Consumption and Saving: Cost and Value: Annual energy consumption is the amount of energy used by equipment or an appliance each year. The annual cost of consumpition and the annual value of savings are determined by multiplying the amount of energy involved by the cost per energy unit: kWH of electricity, 1,000 cubic feet (MCF) of gas, gallon of oil or pounds of steam (Liebman 1985). 
Once the various conservation investment options have been identified, an action plan should be developed for the implementation of the energy-saving measures.

3. Establishing Priorities. There are factors that need to be considered in setting priorities for the implementation of the energy efficient measures that go beyond the identification of the most cost-effective options.

The first step in setting priorities requires evaluation of the retrofit options in terms of interrelationships. Obviously it would be counterproductive to implement a measure at the beginning of the year. For example, there would be no point in relamping to high-efficiency fluorescent lamps if fluorescent luminaires will soon be replaced for conversion to high-pressure sodium lighting.

Another example would be if a new east wing were to be added to a building, it probably would be wasteful to reglaze all existing windows on what is now the east facade. For reasons such as this, management personnel should also be involved in setting priorities.

Studying interrelationships should include identification of measures that should be implemented at the same time. For example, if there are three ventilation system recommendations it may be best to implement them all at once. To implement them sequentially could mean far greater expense, since systemwide adjustments could be needed after each was complete. Implementing all three together would mean that systemwide adjustments would be performed only once.

Analyzing interrelationships may also indicate that one particular version of a device is better than another. For example, if energy and dollars will be saved through installation of equipment for demand control, remote start/stop, duty cycling, and optimal start/stop, you 
could install devices for each function, one at a time, over a period of two or three years. Alternatively, you could obtain just one device to perform all four functions, and install it now, to increase your savings.

Thumann (1977) ranks the order of completion of projects by the best rate of returns on investment, best payout period, or best ratio of Btu/vear savings to capital cost. Once general priorities are identified, specific priorities can be evaluated in terms of cost and benefits.

3. Implementing Conservation Opportunities. Once the implementation priorities have been set and before financial commitment can be made to go ahead with implementation of measures, a workable schedule must be developed. Frequently this is prepared by the engineering consultant.

A master schedule should be prepared which shows exactly what will be happening with competent personnel being assigned to the various functions. The schedule should be able to absorb possible conflicts, such as having someone scheduled to do something during the week that someone else is on vacation, etc.

The National Science Foundation has identified categories under which implementation tasks normally fall (NSF 1977):

- low cost modifications

- work that can be sent directly to construction contractors

- work where detailed design is required

Operational changes and low cost/no cost options should be initiated by in-house staff as soon as possible. In fact, in-house maintenance staff mav be able to do a substantial portion of the retrofit work itself. One jurisdiction has considered having firemen perform some retrofit work on their stations between calls (NSF 1977). Another portion of the specified work can be sent directly to construction contractors for bids. Some options, however, may require further detailed architectural and 
engineering design development before construction can begin. The implementation plan for each facility will be unique. Before a final decision is made to go ahead, the plan should be well outlined defining: Who is to do what; how much their share of the work will cost; how long it will take; and how the work is to be integrated with existing building operations .

\section{ESTABLISHING EFFECTIVE ENERGY MANAGEMENT}

I. Initial Management Effort. An energy conservation program is not complete once an energy survey is performed and the resulting conservation opportunities begin to get implemented. The program has merely begun, and it is at this point that true energy management comes into true focus.

The term Energy Management is relatively new and is a sign of our time. Until recently the efficient use of energy in all its forms was the tacit responsibility of many people in an organization. Now, in many companies, the responsibility for the overall management of energy in its widest contexts is focused formally on the "Energy Manager" (Murphy and McKay 1982).

The successful approach used by the Huyck Corporation (Johnston 1980) was to appoint one corporate engineer as the central energy figure. This individual was given the responsibility of becoming knowledgeable in all areas of Energy, and then developing a corporate energy management plan. This plan led to an energy audit system whereby each facility evaluated its own energy situation and developed its own energy opportunities. 
The purpose of an energy management program for existing buildings is ( 1 ) to utilize fuels in the most effective manner to minimize the amount consumed for heating, ventilating, cooling, hot water, internal transportation, power, and other processes; (2) to use the particular type of fuel or electricity which is available at the lowest costs (and to switch from one fuel to another if the relative costs change radically in the future); and (3) to carry out these objectives within the financial capability of the owner and in the interests of developing national energy and resources policy (NSF 1977).

The U.S. Department of Energy (1980) identifies the following five basic steps which management must accomplish to ensure that an energy management program is effective:

- Establish the clear commitment of top and subordinate management.

- Establish an energy management team with a single point of contact. This point of contact should be a decision maker, who understands energy management concepts, and who has the direct support of top management.

- Staff the energy management team with people who have access to pertinent energv use and cost data, know how the building (s) are now operated and maintained, and have access to building plans and equipment specifications (assuming they exist). Provide them with both the time necessarv to do the job and access to professional engineering support when technical matters are beyond the teams experience.

- Direct those components that will be affected by the program to appoint a representative to interact with the team and direct the team to keep those representatives informed of their findings.

- Publicize the top management commitment and the results of the energy management teams effort.

Energy management is a team effort. The "team" may consist of the owner of the facility: a professional engineer: service and maintenance 
organizations; operating personnel working for the owner or tenant; and the tenants or occupants.

Although energy management is a team effort, Turner (1979) has expressed that it is important that responsibility and authority ultimately rest in a single person. The person placed in charge should be technically sound, a good manager, and one who responds well to challenges. He should have total responsibility for the program and should somehow be given authority. This can be done through a formalized reporting scheme or through th budgetary process. Naturally, the person should have some type of staff backing (whether part- or full-time) and probably some line or operating personnel.

Also, the coordinator of the energy management program must establish realistic, specific, measurable, and tough goals for energy conservation and stick to them. Beside the conservation goals, the energy manager should have as objectives: (I) the development of a reporting scheme to facilitate monitoring or consumption and evaluation of the program and (2) research and development to try new ideas, products or methods to improve the productivity of energy. It is likely therefore that energy managers will become progressively more involved at the conceptual and design stages of projects.

Undoubtedly, the most important ingredient is committment of management from the very top. Initiation of the idea for the program can start anywhere, but, top management must be committed. Furthermore, they must demonstrate this commitment both publicly and privately. For example, management must kick off the program with a considerable push to ensure the development of momentum.

2. Obtaining Personnel Cooperation. To achieve the full effectiveness of the recommendations made in the energy conservation plan it is very 
important to obtain the cooperation of a facility's managers and tenants (NECA 1979). These are the people who, in large measure, may be implementing many of the required changes. In some cases, the changes will mean altering long-established procedures.

It may be advisable, once cooperation and committment are assured, to call together staff personnel to explain the undertaking of the energy conservation goals and instill the initiative to help achieve the goals.

Building managers must be committed to the energy management program and must believe firmly in its effectiveness. If they do not, then the direction which must come from them will not be what is required. Managers have the difficult responsibility of being between owners, who want results, and operating and maintenance personnel who in many cases will be producing the results. They must strive to develop an overall spirit of cooperation and to take those actions which are necessary to maintain this spirit throughout establishment and operation of the eneray management program. It is probable that when building management, rather than the operating engineer alone, directs a program, far more conservation areas are explored and more actual savings are realized.

3. Monitoring. It has often been recognized that one of the key elements in assuring the continuing success of an energy management program is vigilance. Initially, as such a program is being implemented, the capability to monitor its progress provides an indication of the success of individual program elements. In the longer term, accurate information about energy consumption and costs can detect, and help reverse, any "slips" or increases in consumption that might occur. This is particularly important in areas in which conservation efforts depend 
on a commitment by personnel, or for functions which cannot be automated to remove the "human element".

In today's environment there is generally a wide array of constantly changing parameters which affect energy consumption and costs. Internally, additions to building space, increased hours of operation or adding another work shift, fuel inventories maintained, fluctuating production levels, etc. fall into this category. Externally, changes in the weather from year to year, and in energy rates and fuel surcharges also affect total costs. These changes tend to obscure the true impact of energy programs. From a cost standpoint, reductions in energy consumption may be negated by rising prices, a building addition, or any combination of factors.

Monitoring procedures may consist of anything from the initial check to verify that an energy conservation measure was implemented, to the continuous monitoring/recording of the retrofit measure using highly sophisticated instrumentation such as energy management systems or computers.

Monitoring the implementations will involve two types of effort. The first will be to insure that those carrying out specific functions carry them out in the most effective manner. Typical of simple monitoring activities would be the monthly examination of locked thermostats to insure that none had been tampered with and turning off heating and air conditioning at night and on weekends.

The second type of effort concerns monitoring the effectiveness of the program itself in terms of energy consumption. The most direct way of achieving this is by comparing consumption before and after retrofit measures are carried out. This would involve tracking consumption and 
costs from utility records, fuel delivery receipts, bills and invoices, and reports from the field.

A more complex monitoring undertaking might require a series of chart recorders, used to keep track of energy loads on various systems and components. Such data might be used to equalize load distributions throughout the day, which would: (1) permit the use of equipment of less capacity, and (2) lower cost (if electricity is the energy in use) by lowering demand peaks (see Section V-I, Central Control Systems).

All changes implemented should be noted on an energy conservation log, and any monitoring data acquired should also be recorded. Duplicate copies of operating and maintenance manuals and schedules and related information also should be kept on file should replacement become necessary. The same holds for cost and inspection records. Only such data is of any use in a meaningful evaluation of any energy conservation plan.

It is an energy manager's duty to optimize energy usage not only in individual items of equipment but within the total limits of his specified area. If this area is a net exporter or importer of energy he will have to look beyond the horizons of his own area to investigate the optimization of energy at a company or even inter-company level.

The following outline, taken from Thumann's (1977) Plant Engineers $\varepsilon$ Managers Guide to Energy Conservation, offers an excellent checklist to help the continuity of an energy management program:

Develop Continuing Energy Conservation Efforts

A. Measure results:

1. Chart energy use per unit of production by department

2. Chart energy use per unit of production for the whole plant

3. Monitor and analyze charts of Btu per unit of product, taking into consideration effects of complicating variables, such as 
outdoor ambient air temperature, level of production rate, product mix, etc.

a. Compare Btu/product unit with past performance and theoretical Btu/product unit

b. Observe the impact of energy saving actions and project implementation on decreasing the BTU/unit of product

c. Investigate, identify, and correct the cause for increases that may occur in BTU/unit of product, if feasible.

B. Continue energy conservation committee activities

1. Hold periodic meetings

2. Each committee member is the communication link between the committee and department supervisors represented

3. Periodically update energy saving project lists

4. Plan and participate in energy saving surveys

5. Communicate energy conservation techniques

6 . Plan and conduct a continuing program of activities and communication to keep up interest in energy conservation

7. Develop cooperation with community organizations promoting energy conservation

C. Involve employees

1. Service on energy conservation committee

2. Energy conservation training course

3. Handbook on energy conservation

4. Suggestion awards plan

5. Recognition for energy saving achievements

6. Technical talks on lighting, insulations, steam traps, and other projects

7. "savEnergy" posters, decals, stickers

8. Publicity in plant news, bulletins

9. Publicity in public news media

10. Letters on conservation to homes

II. Talks to local organizations

D. Evaluate program

1. Review progress in energy saving

2. Evaluate original goals

3. Consider program modifications

4. Revise goals, as necessary 


\section{A. THE MOTIVATIONAL FACTOR}

In order for any conservation measures to be implemented in the residential sector, the primary objective is to persuade, convince, and induce people to implement energy conservation - to motivate individuals to do something. In the industrial and commercial sectors, it is normally assumed that businesses are run to maximize profit and that long-run operating cost and cost-effectiveness are familiar concepts. In other words, it is assumed that the motivation already exists to conserve energy as long as doing so saves money.

Unfortunately, the situation is not so well defined in the residential sector. For one thing, homeowners are not necessarily accustomed to thinking in terms of long-run operating costs; the initial cost of something has a more immediate impact. Additionally, homeowners have no easy method at hand to secure information about the most cost-effective measures or behavior; the acquisition of such information is haphazard and time-consuming. Financing is also more problematic in this sector.

Bailey (1979) of the New Jersey Department of Energy, has identified three classes of assumptions about what motivates homeowners:

- Facts - Considers the motivational potential of factual statements about potential savings such as payback figures or percentages of fuel savings.

- Explanation - Considers if individuals are more likely to act if they understand things such as why caulking increases comfort or why insulation works.

- Delivery Mechanisms - Considers which sort of mechanism may be the most effective - auditors, computer, printouts, etc. - in 
giving facts to the homeowner.

Since individual homeowners do not generally behave as if they were business people, what will motivate them to conserve becomes a very critical question, Therefore, the ultimate effectiveness of any audit or training program hinges on how well the auditor motivates homeowners to take action.

\section{B. RESIDENTIAL CONSERVATION SERVICES}

From assessments of testimony and discussion at the Public Hearings held in 1979 on the Proposed RCS Regulations (see Section C-2), Baker (1981) estimates that as many as one-third of the existing residences in the United States would be classified as energy efficient on the basis of standards that could be met with a cost- effective investment, while an additional $17 \%$ of the households could be motivated to install conservation measures without the help of the utilities. Therefore, on the basis of reasonable standards, $50 \%$ of the existing housing stock has the potential for retrofits. The number of buildings having from one-to-four residences in areas serviced by utilities is approximately 66 million.

With such numbers as listed above, RCS programs have the potential to reach 33 million residences. Enforcement of the RCS programs is a particularly important state responsibility and is addressed in each state's plan. States must ensure program implementation by covered utilities. In Florida, the monitoring of program implementation is accomplished by the Public Service Commission (PSC).

\section{ENERGY CONSERVATION MEASURES}

Other than the all-important human factor, energy consumption in residential structures includes: 1) architectural ones - building orientation, glazing, shading, insulation, etc; 2) cooling and heating equipment - air conditioners, heat pumps, furnaces, etc. 3) water heating equipment; 4) lighting; and 5) electrical appliances.

Aadland (1980) lists the following important conservation measures and practices: 
RCS measures include:

Caulking and weatherstripping:

Replacement of central air conditioner (high efficiency);

Ceiling, wall and floor insulation;

Duct and pipe insulation;

Water heater insulation:

Storm or thermal windows and doors;

Heat-reflective and heat-absorbing window and door material;

Load management devices;

Clock thermostats;

Furnace efficiency modifications;

Solar domestic hot water systems;

Active solar space heating systems;

Combined active solar space heating and solar domestic hot water systems;

Passive solar space heating and cooling systems;

Wind energy devices;

Replacement to solar swimming pool heaters; and

Replacement to higher efficiency heating systems.

RCS practices include:

Furnace efficiency maintenance and adjustments;

Water flow reduction on showers and faucets;

Sealing leaks in pipes and ducts;

Raising thermostat settings in summer and reducing them in winter:

Nighttime temperature setback;

Reducing hot water temperatures; 
Reducing energy use when home is unoccupied;

Plugging leaks in attics, basements and fireplaces; and

Efficient use of shading.

For additional and more elaborate energy-saving guidelines that apply to the residential sector refer to the following sections in the commercial/industrial section of this report:

Structural/page 54: a through $\mathbf{j}$

Heating and Cooling/page 57: b,c,d,g,k,q

Lighting/page $65: a, b, c, e, f, p$

Water Heating/page 69: e,f,i,q,s,t.

\section{ENERGY EFFICIENT APPLIANCES}

1. General. Decisions on the approximately 23 million major domestic applicances purchased in the U.S. in 1981 had a greater cumulative impact on the nation's energy situation than anv decision made about starting new coal mines, oil wells or power plants. For example, the annual output of over 6 large $(1000 \mathrm{MW})$ coal or nuclear plants was required to operate the major electrical appliances sold in 1981 alone (Geller 1983).

All residential equipment consumed one-third of the electricity produced in the U.S. during 1980. Refrigerators utilized the output of about 25 large power plants, nearly $7 \%$ of the nation's total electricity consumption and over $50 \%$ of the nuclear power generation. Oil consumed by residential equipment equalled about two-thirds of the output of the Alaskan oil pipeline, while all of the oil and gas used in residences was equivalent to over half of all U.S. oil imports. 
The cost for operating residential appliances has become a major expense. A typical household paying the average electricity price charged by private utilities $(6.8$ cents per KWH during the first 8 months of 1982) will spend over $\$ 700$ a year operating a refrigerator, freezer, electric water heater, range, clothes washer and dryer, lights and other electrical appliances (Geller 1983). Heating and air-conditioning could add another $\$ 800$ or more in a typical all-electric home. Furthermore, the cost of energy for operating appliances over their useful life is a number of times their first cost.

The energy consumption of the most efficient appliances available today is dramatically lower than that of typical models produced in recent years. If the entire stock of appliances in the year 2005 consisted of the best models now available, residential electricity consumpition would drop $37 \%$ from projections based on historical trends, equivalent to the output from more than 100 large power plants (AHAM 1985). This makes the simple, day-to-day decisions about appliances purchases as important as national decisions on coal or nuclear power, for example.

2. Government/Utility Programs. Some valuable government programs have been established to encourage the purchased of energy efficient appliances. The federal labeling program provides consumers with much of the information necessary to compare life cycle costs (see Section V-C-2). California, Florida and a few other states have instituted minimum efficienty standars, prohibiting the sale of "energy guzzling" appliances.

The private sector has also initiated some potentially effective programs in addition to simply offering more efficient products. Utilities in many parts of the country now provide rebates to purchasers of 
relatively efficient products (see Section VII-C-5). Rebate programs appear to be highly economical for utilities and an effective way to stimulate the purchase of more efficient appliances. A few utilities are also offering incentives to dealers who sell efficient equipment. Regulatory and incentive programs complement each other: one works to eliminate inefficient products while the other stimulates the production, sale and purchase of highly efficient models.

3. Consumer Information and Incentive Programs. Despite this progress, a major increase in the efficiency of domestic appliances will require additional information and incentive programs. Several potentially important steps such as providing estimated life cycle costs for all appliances and names of the most efficient models when buyers are considering a purchase; providing rebates or readily-available financing for efficient appliances via loans from a utility, municipality or state to overcome buyer resistance to products with a significantly greater first cost; and implementing strong efficiency standards, especially to prevent inefficient products from being purchased by "third parties" need to be considered (Ace 1984). Other possible programs include:

$\circ$ taxes on inefficient models;

- promoting or encouraging early retirement of less efficient, older models;

- extending tax credits to a broader range of more efficient appliances;

- standards or incentives/penalities based on the average efficiency of all models produced by each manufacturer;

- further support for and promotion of new appliance technologies.

It is evident that information is playing a major role in the purchase of energy-efficient appliances. Slowly but surely, consumers 
are becoming aware of the wide range of efficiencies available and the cost effectiveness of the more efficient models.

\section{E. LANDSCAPING}

1. General. A very effective way of helping to lower the energy consumption in a home is through the application of landscaping techniques. The right trees and shrubs when properly planted, can help in reducing the direct solar gain on the structure while enhancing the appearance of the house.

Trees and shrubs can be used to provide shade and enhance ventilation. Deciduous trees or vines can be used to protect the dwelling from summer sun while allowing some winter direct gain. Plants can provide a cooling effect in their understory micro-climate.

Non-photosynthetic landscape features such as paving, decking and walks can be designed to absorb heat from around the structure or reflect light into the structure.

Fruiting plants can deliver a tangible return. For example, in South Florida, banana, papaya, loquat, mango, citrus, avacado, lychee and macadamia trees can be planted along the east and west property lines tor shade protection (FPL 1983c). However, their arrangement should be organized not to block important wind patterns from reaching the house.

2. Application. Espaliered plants and vines, either trained against the wall or on trellises, cool buildings by reflecting and absorbing the sun's rays before they reach the wall itself. Air movement through the leaves further dissipates the heat. In winter, the vines form an insulating layer, helping to retain heat; deciduous vines can be used on walls to permit warming bv the sun's rays. If more air movement is 
necessary, trellises may be used away from walls, or extended overhead beyound the structure to protect outdoor living spaces such as patios. In their Builder's Manual South Florida 2 (1983), Florida Power and Light recommends the following plants used for espalier:

1. Citrus - dwarf usually used; calamondin, lemon, kumquat, limequat espalier the easiest; need supports, usually pruned to six-lor eight-armed cordon.

2. Fig - large espaliers with natural form, or low horizontal-armed, formal shaped; particularly suited to hot south or west walls that protect them from cold but give them summer sun.

3. Grape - trained to a four-armed kniffen system along wires: south, east and west yard where the sun will sweeten the fruit.

4. Persimmon - the Oriental Persimmon is one of the best for a large, informal espalier.

5. Pineapple Guava - marvelous, large, informal espalier; this treatment of the plant shows off the handsome bark to good advantage.

Words of caution are to watch for extreme high summer temperatures which will cook the fruit rather than ripen it. $\mathrm{Be}$ aware of shadows. Although we appreciate shade from an overhead tree, the espalier fruits will not.

Shrubs are often grouped and used along driveways, walks, and property lines, as screens, and at the base of buildings where they are usually referred to as foundation plants. The object of these groupings is to create a pleasing interest with the use of shapes, textures and color. It is pleasant to include a few flowering plants for color and some evergreens to give the design more substance in the winter. One 
important factor in organizing and designing the landscape is to try to enhance summer ventilation and to protect the structure from the hot sun. 


\section{ENERGY CONSERVATION OPPORTUNITIES IN THE \\ COMMERCIALIINDUSTRIAL SECTOR}

\section{A. GENERAL}

Before energy can be conserved, the ways in which it is used must be understood. The building structure - i.e. walls, windows, roof and the passive components of the mechanical and electrical systems i.e. ducts, pipes, filters, or lighting fixture louvers - do not directly consume energy but they influence the amount that is finally consumed. The primary energy-conservation equipments, such as coal, oil or gas burners and boilers/furnaces; refrigeration chillers and compressors; motors; and electric lighting bulbs or tubes, consume energy to supply the building load and to compensate for the distribution system load.

Factors that affect energy in structures include: 1) Architectural ones - building orientation; glazing; shading, insulation, infiltration, etc. 2) Mechanical ones - type of HVAC systems and type of HVAC control system; machinery - machine tools, conveyors, process use. 3) Electrical ones - lights, motors, electronic equipment; wiring overloaded circuits and/or unbalanced circuits, etc.

Energy usage depends upon two main factors:

- The magnitude and duration of the loads.

- The seasonal efficiency of the primary energy-conversion equipment

"Building" loads will be reduced if the temperature and relative humidity indoors are maintained at lower levels in the winter and at higher levels in the summer; heat loss, heat gain, and infiltration through the building envelope are decreased; ventilation rates are reduced; domestic hot water temperature and quantity are reduced; the 
level of illumination by electric lighting is lowered; and the number of hours of operation of elevators, business machines, and cooking equipment is reduced.

The "building" load must be considered on a seasonal basis rather than for peak conditions only. Although two buildings may have the same heating load for any particular hour, one of them may have a considerable higher load, on a seasonal basis, than the other, due to the duration of peak conditions. Or, for instance, a religious building, auditorium or warehouse may have a relatively high energy requirement for lighting during a brief period of time, but if the lights are turned off during unoccupied periods, the annual lighting load may be nominal. Generally, the greater the peak loads for any particular system in an individual building, and the longer their duration, the greater will be the seasonal loads. The distribution loads will be decreased by reducing the amount of power required for pumps and fans, reducing heat loss or gain from ducts and pipes, and by eliminating steam, water and air leaks. Distribution loads are often excessive because systems are designed to operate continuously at the maximum capacity required to meet peak "building" loads, even though these peak loads occur for relatively short periods of time.

Nationwide, in existing industrial and commercial buildings, the systems that consume the most energy in order of magnitude are: 1) heating and ventilating; 2) lighting; 3) air conditioning (cooling) and ventilating; 4) equipment and processes; and 5) domestic hot water (Dubin 1976).

However, depending upon the climate; the building construction; use and mode of operation; and the type, control and efficiency of the 
mechanical and electrical equipment; the relative order of magnitude of energy use among the first three systems will change.

The amount of energy required for domestic hot water is significant in hospital, housing, and athletic or cooking facilities in schools and colleges. In many areas of the country the amount of energy to heat water is second only to space heating in the north, and air conditioning in the south in housing. In hospitals the amount of energy to heat hot water may exceed the amount of energy required for lighting (Munk 1980).

Religious buildings and public halls which frequently include meeting rooms, offices, and school facilities, are most likely to consume energy in the same pattern as office buildings in the same geographic location - but in smaller quantities per square foot of floor area.

In those retail stores with high levels of general illumination and display lighting, and/or a large number of commercial refrigeration units, electricity consumes the greatest amount of energy.

Today, there is a great opportunity for engineers, architects, contractors, and others in the construction industry in the area of energy conservation in both old and newer buildings. While solving this problem, they will be simultaneously relieving the building owners of the overall dilemma of controlling mounting operating costs.

Building owners would probably welcome propositions from the design and construction industry in the area of energy conservation that could update some of their building structures. This could be done by offering the amenities tenants have grown accustomed to expect in modern buildings and by providing better heating, cooling, lighting, life safety, etc., with less energy consumption. 
The Board of Trade Building in Chicago is an outstanding example of what can be accomplished through a comprehensive renovation program. The building, which was completed in 1929, has 43 floors above grade and four levels below. It encompasses nearly I million square feet of floor space; originally 590,000 square feet were rentable (Imperatore 1978). During the renovation, most of the existing HVAC equipment was scrapped and substituted with a higher efficiency, central refrigeration plant; lighting was upgraded to modern standards; and all floor spaces were gutted, and new partitions, ceiling systems, floor covering, plumbing fixtures, etc., were installed. The results were impressive: rentable space was increased from about 590,000 square feet to 700,000 square feet; basement areas formerly occupied by an obsolete heating system were turned into 35,000 square feet of modern office space; and in five years income increased from about $\$ 3$ million to $\$ 4.7$ million, Operating costs declined from $\$ 2.35$ to $\$ 2.25$ per square foot. The decrease in operating costs was achieved in the face of inflationary pressures driving up labor, material, and energy costs.

Buildings built within the last 25 years also offer many opportunities for energy conservation, but the feasibility study required to embark on this program is quite different in that there is no major construction required to change the modern existing building architecturally since the core configuration is generally more efficient. This precludes the necessity to cause major improvements in space utilization, however, generally there is a major requirement to effect mechanical and electrical changes. Although these structures were built with year round air conditioning systems that can be classified as modern, in many cases they are inefficient. If a feasibility program is properly established the impact of the mechanical and electrical changes 
on the operating cost should more than offset the cost of these improvements within a relatively short period time.

An excellent example of the benefits derived from an energy conservation effort is the Homestead Air Force Base (HAFB) Energy Survey, performed in 1982 by Florida Power and Light Company (FPL). A team of engineers from FPL's Southern Division Energy Conservation Department surveyed a total of 207 facilities within HAFB - a tactical air command base located south of Miami, Florida (FPL 1982b).

The resulting 1200-page report addressed the potential energy savings to be derived from implementing cost-effective, energy conservation opportunities at the multi-use facility. The joint survey effort and the subsequent implementation of energy saving recommendations earned FPL and HAFB top honors in the Southeastern Electric Exchange (SEE) 1983 Energy Efficiency Competition .

The extensive report contained recommendations on: 1) no cost/low cost items; 2) medium cost items; and 3) high cost or capital intensive items. The recommendations - most of which have since been implemented - represented potential savings to the base of over $25,000,000 \mathrm{kWh} /$ year in energy consumption and $2,100 \mathrm{~kW}$ in demand, savings of $25 \%$ and $12 \%$ in the respective categories. These figures translated into nearly $\$ 650,000$ (1983 dollars) in annual savings to the base. It was also estimated that the energy demand reduction that could result from implementing the recommendations could save FPL as much as $\$ 2.5$ million in generating plan expansions (FPL).

The above is an excellent example of the mutual benefits that can be gained by both the electric utility industry and the private/industrial/commercial sector when joint energy conservation efforts are initiated and followed through (see Section VI-C-3). 
The following sections, B through I, will outline the energy conservation opportunities in the major energy-consuming systems.

\section{B. STRUCTURAL}

1. Background The amount of energy a building loses is affected by the material used in its construction. Heat moves by conduction, convection, and radiation, and moves from objects or substances at higher temperatures to ones at lower temperatures. In each case, heat moves "down" a temperature gradient just as water flows down-hill. If the temperature difference is great, the gradient will be steep and heat will tend to move rapidly from the area of high temperature to the area of low temperature. If the temperature difference is small, the gradient will be gradual and heat will move more slowly.

The building envelope - the exterior components subjected to the outdoor climate - influences the size of the building heating load. Ordinarily, the components which must be considered are the following: 1) Walls exposed to the outside air and walls below grade; 2) partitions separating spaces which are at different temperatures; 3) windows and doors and any other glass surfaces; 4) ceiling below spaces which are at lower temperatures: 5) floors above spaces which are at lower temperatures or are in contact with the ground; and 6) infiltration, which causes an energy loss when outside air leaks into a building by natural forces throughout cracks around doors, windows, etc (NESCA 1975).

The rate of heat transfer or thermal conductance through the envelope is expressed as a "U" value - Btu/hour/sq. ft. of surface per degree of temperature difference between indoors and outdoors. The thin layer of air surrounding the exterior surface of the envelope adds 
to the insulating value of the wall or roof material. A lower $U$ value means greater resistance to the transmission of heat and saves energy by reducing heat loss from the building.

Single panes of glass in still air (less than 15 m.p.h.) have a $U$ value of 1.13. Double glazing reduces the $U$ value to about .55 . The $U$ values of walls and roofs vary from .4 down to .06 depending upon the structural materials and the thickness of any insulation which has been added (Dubin 1976). Effective measures to reduce the $U$ value and heating load include adding a storm sash to existing windows, replacing the windows with double glazing (or triple glazing in severe climates), and adding insulation to the interior or exterior surfaces of roofs and exterior walls.

The thermal resistance of materials, $R$, is the mathematical reciprocal of $U$. The higher the conductance (or the lower the resistance) the faster the flow. The "R-Value" is commonly-used to designate the insulative capacity of various materials (Aadland 1980).

Wind destroys the air film around exterior surfaces and causes the $U$ value of the surfaces to increase. Heat loss, especially through window panes and uninsulated walls, increases accordingly. Shutters, screens, trees or other shielding devices can be used to reduce wind velocity on the windows to limit heat losses.

2. Guidelines to Reduce Energy. The following are proven energy conservation guidelines. They are general and may not always be applicable to all facilities:

a. Check insulation in all exterior walls, ceilings, floors. Also, interior walls or partitions which separate conditioned and non-conditioned spaces. Insulation should meet minimum recommendations for your geographical area. For example, R-11 for walls and R-19 for ceilings or roof decks is recommended in Florida (FPL 1983b). 
b. Upgrade deficient insulation. Thicknesses in inches for various $R$-factors can be found in Appendix $F$.

c. Consider using reflective paint on roof, especially if current roof is dark color, to reduce heat gain and save energy (FPL 1982a).

d. Install solar screens, film, light-colored blinds or reflective drapes on windows with eastern, western or southern exposure (FPL 1982a).

e. Block or screen skylights during cooling season (FPL 1983b).

f. Consider using insulating, tinted, or reflective glass on new construction or retrofit projects (FPL 1982a).

g. Check weatherstripping on doors and windows. Install or repair where necessary (FPL 1983b).

h. Check fitting of doors and windows. Repair where necessary (FPL 1983b).

i. Replace broken or cracked window panes (FPL 1982a).

j. Consider installing storm windows (FPL 1982a).

k. Consider using vestibule or revolving doors for heavily-traveled entrances (Dubin 1976).

1. Install automatic door closers in problem areas. Inspect automatic door closers for proper function. Consider adjustment to enable faster closing (Roose 1978).

m. Repair and caulk cracks and openings in exterior surfaces (FPL (983b).

n. Eliminate unnecessary outside air vents (Thumann 1977).

o. Close operable windows and doors during heating and cooling seasons. Consider posting a small sign by each window or door to remind occupants not to open during heating and cooling seasons (Thumann 1977).

p. Inspect condition of indoor shading devices such as drapes and blinds which can reduce heat gain as much as $50 \%$. Keep indoor shading devices clean and in good repair (Dubin 1976).

q. Consider air or vinyl curtains for loading dock doors (Dubin 1976).

$r$. Consider building wind screens to protect external doors from direct blast of prevailing winds (Thumann 1977).

s. Consider an evaporative roof spray system to reduce heat gain through roof (See Appendix G). 
t. Consider installation of outdoor shading devices, such as sunshades, which reflect solar heat before it has a chance to enter the building, and which dissipate heat outdoors rather than indoors. Adjustable sunshades enable entrance of warming rays during the heating season (Roose 1978).

\section{VENTILATION}

1. Background Ventilation provides for the introduction of outside air into a building under positive control. Ventilation requirements in residences are usually met by infiltration. However, in larger buildings, mechanical ventilation is provided and has a significant impact on a building's total energy consumption. Each cubic foot of air brought in the building must be either heated or cooled and in some cases, humidified and/or dehumidified. It is generally agreed that many building codes demand an amount of ventilation in excess of what actually is required to provide for the safety and comfort of building occupants. Because many building code officials also recognize this, they often are willing to allow changes to ventilation systems which will drop CFM rates below those nominally required, providing that such changes are not irreversible. Of course, the approval of code authorities must be obtained before undertaking any changes which will result in violation of the applicable codes as written.

2. Guidelines to Reduce Energy The following are proven energy conservation guidelines. They are general and may not always be applicable to all facilities:

a. Reduce outdoor air to the minimum required to balance the exhaust requirements and maintain a slight positive pressure to retard infiltration-caused heat losses and heat gains (Thumann 1977).

b. Inspect all outdoor air dampers. They should be as airtight as possible when closed. Check operation of position indicators for accuracy. Install, repair, or replace position indicators as needed (Sneathen 1978). 
c. Reduce or eliminate the need for using outdoor air for odor control by installing chemical or activated charcoal odor-absorbing devices (Sneathen 1978).

d. Inspect filters carefully. If necessary, create a filter replacement schedule. Utilize high-efficiency, low-cost filters (FPL 1983b).

e. Reduce exhaust air quantities as practical (Roose 1978).

f. Close outdoor air dampers during the first and last hour of occupancy when the air must be heated or cooled, except when outdoor air can be used to reduce cooling loads (Claman 1983).

g. Establish a ventilation operation schedule so exhaust system operates only when it is needed most (Imperatore 1978).

h. Add a warm-up cycle to air handling units with outdoor air intake. Keep outdoor air dampers closed during morning building warm-up or cool-down so only air already in the building is conditioned. Cycle can be incorporate using a two-circuit time clock to control air damper and fan operation (Dubin 1976).

i. Use exhaust hoods in food preparation and laboratory areas only while operations are underway. Add control dampers or gravity damper to keep the air path in the exhaust duct closed when fan is not operating (Dubin 1976).

j. If a food preparation area exhaust hood is oversized, adjust it so no more air than necessary is exhausted. This can be done easily by blocking off a portion of the hood, or reducing fan speed, or lowering hood, or by utilizing a combination of these techniques in compliance with applicable health regulations (FPL 1982a).

$k$. Consider adding controls to shut down the ventilation system whenever the building is closed for an extended period of time, as during the evening, weekends, etc., except when the economizer cycle is in use (FPL 1982a).

1. Reduce volume of toilet exhausts in building which have multiple toilet exhaust fans having a total fan capacity in excess of outside air requirements (Claman 1983).

\section{HEATING AND COOLING}

1. Background - Heating. One of the factors which determine the "building" heat load is the average difference between indoor and outdoor temperatures - the larger the temperature difference, the 
greater the load. The load may be reduced by maintaining lower indoor temperatures for as long a period as possible during the heating season. Lowering the temperature to $68^{\circ} \mathrm{F},(\mathrm{FPL} \mathrm{1983b)}$ or less in the major areas of the building when it is occupied, and maintaining even longer temperatures in less critical areas will conserve energy. The amount of heat produced internally by lights, people and business machines (internal heat gains) and the amount of sunlight impinging upon the structure and transmitted through window panes and doors also reduces "building" heating load.

Greater savings are also realized by reducing the indoor temperature at night and during weekends. Outdoor temperatures are generally colder at night, and neither solar heat gain nor internal heat gains help at night to offset heat loss. The amount of outdoor air which is introduced into the building for ventilation or which infiltrates through the building envelope also contributes to the heating load. This air must be heated and humidified to meet indoor conditions. Its ultimate effect on the load depends, as with other heating loads, upon the difference in indoor and outdoor temperatures, and the quantity of outdoor air. In cold climates, shutting off ventilation air at night when no ventilation is required for physiological reasons - may result in the single largest savings of energy.

"Building" heating load also depends upon the amount of moisture maintained in the building. The measure of the moisture content of the air is relative humidity $($ R.H.). When cold outdoor air enters the building - as ventilation or infiltration - the relative humidity of the interior of the building drops and additional moisture, in vaporized form, must be added. Vaporization requires energy in the form of heat. The greater the volume of outdoor air, the greater is the heat demand to 
supply humidification. Lowering the level of humidification conserves energy. A building is more comfortable at lower temperatures if the relative humidity is maintained at a level within a range of from 20 to $40 \%$ (Dubin and others 1976).

2. Background - Cooling. Two components - sensible or dry heat, and latent heat, a function of the heat content of the moisture in the air - determine the "building" cooling load. To maintain comfort, the dry bulb temperature which measures sensible heat, and the wet bulb temperature (or the relative humidity), which measures latent heat, must be controlled. Because, for most comfort cooling installations, air is dehumidified when it is cooled, separate control of the relative humidity is not usually required.

Average temperature difference between indoor and outdoor conditions is one of the factors which defines the sensible heat gain portion of the annual "building" load. This can be reduced by maintaining higher indoor temperatures for as long a period as possible during the cooling season, whenever further operation of the mechanical refrigeration system would be required to maintain a lower one. When the sensible heat gain is decreased, reduce the amount of cool supply air accordingly to realize additional energy savings in fan horsepower (Imperatore 1978).

The cooling load, is in part, due to conductive heat gain from outdoors to indoors, through the building envelope. The average difference in temperature between indoors and the exterior surfaces of the walls and roof depends upon outdoor dry bulb temperatures and the amount of solar radiation striking the outside walls and roof and warming them to a level which is most often above ambient temperatures. 
To conserve energy, during unoccupied periods, the refrigeration system and its auxiliaries (chilled water and condenser water pumps, cooling towers and air cooled condensers) should be shut off. And during occupied periods, a dry bulb temperature of $78^{\circ} \mathrm{F}$ or higher should be maintained (FPL 1983b).

Maintaining even higher temperatures in less critical spaces will conserve more energy. If the relative humidity in the building is permitted to rise to $55 \%$ (the usual level is 45 to $50 \%$ ) (Dubin and others 1976), or to fluctuate within the limits set by the refrigeration system's ability to maintain wet bulb temperatures, considerable energy will be conserved. The system requires power to remove moisture which originates from internal loads - people and cooking - and from outdoor air as it infiltrates and/or ventilates the building.

Just as ventilation and infiltration add to the heating load in the winter, they also increase the cooling load in the summer. Outside air must be cooled and dehumidified. Maintaining higher indoor temperatures and relative humidity reduce the cooling load contributed by infiltration and ventilation as well as conductive heat gains. However, whenever outdoor air is cool enough to lower the indoor temperatures, it may be advantageous and energy conserving, to cool or pre-cool the building at night, using an economizer cycle, without mechanical refrigeration. When the wet bulb (W.B.) temperature of the outdoor air is lower than the W.B. temperature of the return air from the interior spaces, an enthalpy controller will open the outside air dampers and close the return air dampers to take in $100 \%$ outdoor air: the controller saves power for the refrigeration system. Internal heat gains - heat emitted from electric lighting fixtures, business machines, 
motors, cooking equipment and people form a large part of the total cooling load (Baron 1978).

Reducing the "building" cooling load by a fixed percentage allows further savings of energy since distribution loads can be decreased accordingly. A reduction in the flow of cool air or chilled water to meet the reduced load and an increase in the suction temperatures at which the refrigeration chillers or compressors operate - improving their Coefficient of Performance (C.O.P), See Appendix A - will result in significant savings; less horsepower per ton of refrigeration as well as less tons to be produced.

3. Guidelines to Reduce Energy-Cooling and Heating. The following are proven enerqy conservation guidelines. They are general and may not always be applicable to all facilities:

a. Reduce the size of heating and cooling capacity where possible (Claman 1983).

b. Set thermostats and enclose them in locking cases (FPL 1982a).

c. Maintain efficient temperatures: for example, for residential/commercial applications in winter, $68^{\circ} \mathrm{F}$ and in summer, $78^{\circ} \mathrm{F}$ (FPL 1982a).

d. Discontinue or reduce building cooling and heating when building is unoccupied (FPL 1982a).

e. When tasks are performed at other than normal hours, consider auxiliary heating and cooling units for occupied areas (Claman 1983).

f. Lower heating or raise cooling setting of unoccupied areas (e.g. lobbies and storage rooms) (FPL 1983b).

g. Eliminate simultaneous heating and cooling where possible. Permanently shut off heating elements during cooling season (FPL 1983b).

h. Consider selective switching of air handlers to minimize use during unoccupied periods (Sneathen 1978).

i. Install or upgrade insulation on all steam, hot or chilled water lines, and air handling ducts (Sneathen 1978). 
i. Adjust hot and cold deck temperatures to minimum acceptable limits (Sneathen 1978).

k. Look for leaks in the air distribution system. Repair all leaks (Claman 1983).

1. Consider using heat recovery devices to capture heat from processes, exhaust air and compressor units (Dubin 1976).

m. Reduce "chimney" effect in multi-story buildings by closing stairwell openings and roof hatches (Dubin 1976).

$n$. Develop an after-hours equipment operation checklist for use by custodial and other building personnel as well as occupants who may use various spaces after normal periods of occupancy (Thumann 1977).

o. Schedule operating and maintenance work during the daytime, if possible (FPL 1982a).

p. Consider thermal storage for air conditioning requirements (Dubin 1976).

q. Reduce fresh air to minimum state or local code levels (FPL 1982a).

$r$. Use timers for positive on/off operations (FPL 1983b).

s. Consider using automatic controls to match equipment output to load requirements (i.e., an energy management system) (Honeywell 1979).

t. Check miscellaneous items:

- Regularly adjust and inspect all belts and pulleys.

- Insure free air flow from all supply and return grills.

- Check and replenish refrigeration levels as needed.

- Periodically clean refrigeration condensers and check system for proper operation.

- Replace filters as needed.

- Perform water treatment at proper intervals.

- Regularly lubricate/calibrate all dampers (Dubin 1976).

u. Periodically calibrate space conditioning controls (FPL 1983b).

v. Maintain and operate boilers at maximum efficiency (FPL 1983b).

w. Upgrade control valves and dampers for improved control and to eliminate leakage (Thumann 1977).

$x$. Consider separate cooling units for special zone requirements during unoccupied hours (i.e., for a computer room) (FPL 1983b).

$y$. Consider room motion detectors for positive control of equipment in hotels and motels (FPL 1983b). 
z. Consider painting roof white or spraying with water during peak heat of day to reduce heat gain (FPL 1983b).

\section{E. LIGHTING}

1. Background. Except in buildings that are electrically heated, electric lighting is one of the major uses of electrical energy and accounts for a significant portion of total energy usage in offices and retail stores. When lights are left on in areas which are unoccupied or unused for lengthy periods of the week - in religious buildings and outdoor parking lots, for example, the inadvertent waste of energy often approaches or exceeds the amount of energy used by other building systems much of the week; the cost of this waste for one year may equal the initial cost of installing automatic controls to eliminate it.

Electric lighting is also the major contributor to internal heat gain in stores and core areas of office buildings. Because it increases the cooling load, electric lighting induces additional expenditure of energy to sperate the refrigeration system, including air handling units, chilled water, and cooling tower or condenser fans.

In the past twenty years, lighting design standards have changed and our buildings reflect the trend toward increased lighting levels. The Honeywell Corp. (1979), reports that presently, average annual electrical usage amounts to from 22,000 to 35,000 Btus per square foot per year (based on 2.5 to 4 watts per square foot, occupied 10 hours a day, 5 days per week), representing $40-70 \%$ of the targeted 55,000 Btus/year/ft2 energy load recommended for new construction.

Although conservation of energy is important, it must be achieved in a manner consistent with other requirements, including those of 
productivity and visual comfort; aesthetics; and federal, state and local codes and ordinances.

Lighting energy is wasted in several ways (NECA 1979):

- Inefficient sources - the lamp or fixture is inefficient in converting electricity to light, using more watts (units of electric power) than necessary to produce the lumens (units of light output);

- Transmission losses - when the light source is too far away from what has to be illuminated, or when dirt or some other obstruction blocks off some of the light;

- Overlighting - when using more lighting than is needed; when natural substitutes are not used (e.g., daylight) or reflectors (e.g., light color paint); or when using lights for no reason (for example, no one there).

In addition, unnecessary heat from lights may add to the cooling load. And although lights may contribute needed heat during the heating season, much of that heat escapes without heating the occupied space.

Some light sources produce fewer lumens per watt than others. Incandescent lighting is the least efficient. It's inefficiency may be compounded by indirect lighting designs which further detract from the usable light. Fluorescent lights are more efficient, though mercury vapor, metal halide, and high pressure sodium offer the highest lumens per watt levels. For example, incandescent lighting offers 15 lumens per watt while high pressure sodium compares at 130 lumens per watt (Baron 1978) .

There usually are least several levels of illumination required within any building. These levels can be separated into three general 
categories: specific task lighting, general lighting around tasks, and general lighting for circulation or support areas.

While it is commonly understood that different visual tasks require different levels of illumination, the interiors of many office buildings provide only uniform illumination levels which have little relationship to the amount of illumination required in specific areas.

Because the lighting systems of many existing buildings were designed within the restrictions of initial cost economies, without knowledge about final space use and subdivision, and without benefit of relatively recent developments and research findings in the field, there exists significant potential for lighting system modification. These modifications can reduce substantially the energy consumed by the lighting system (and associated costs) while still providing building occupants with the quality and quantity of illumination required to perform their various tasks and functions.

2. Guidelines to Reduce Energy. The following are proven energy conservation guidelines. They are general and may not always be applicable to all facilities:

a. Consider replacing present lamps with those of lower wattage which provide the same amount of illumination or (if acceptable in light of tasks involved) a lower level of illumination. This method is particularly applicable where current lighting levels are higher than recommended or where uniform lighting is the most practical due to occupant density, as discussed above. This also is a simple way to provide flexibility should higher levels of illumination be required at some future time (See Appendix H) (NECA 1979). 
b. Remove unnecessary lamps if removal will still enable provision of illumination levels required. When lamps are removed from a fluorescent luminaire, all lamps controlled by a given ballast should be removed to prevent ballast failure or reduced lamp life. Except in the case of instant start lamps or luminaires with circuit-interrupting lamp-holders, also consider disconnecting ballasts which otherwise would continue to consume energy (NECA 1979).

c. Replace existing lamps with more efficient versions of the same type of lamp. Numerous different approaches are available. For example, elliptically-shaped reflector lamps have been designed for installation in stack-baffled downlights. A $75 \mathrm{~W}$ version of this new lamp will provide just as much illumination as a $150 \mathrm{~W}$ R40 flood, thus cutting energy consumption by $50 \%$ High efficiency fluorescent lamps can provide almost as much light output as less efficient standard fluorescent lamps, and cut energy consumption by $14 \%$ (NECA 1979).

d. Replace existing mercury vapor lamps with more efficient metal halide or high pressure sodium lamps designed specifically for the purpose. The retrofit lamps consume less energy and provide far more light. As such, fewer lamps may be needed. Note, however, that there are different types of mercury vapor luminaires. The replacement lamps are designed for one type of mercury vapor ballast only (NECA 1979).

e. Consider use of light-reducing fluorescent lamps. When one of these new fluorescents is installed in a two-lamp fixture, the light output and energy consumption of both lamps is equivalent 
to $33 \%$ or $50 \%$ of original. These lamps should be used only when reduced light output is consistent with needs in the space.

f. Consider replacing existing lamps with more efficient lamps of a different type. Use of different lamps will in most cases require replacement of existing luminaires (FPL 1983b).

g. Relocate luminaires to provide light on task areas at an angle outside the zone which causes veiling reflections if relocation of work station is impractical (Dubin 1976).

h. Replace outdated or damaged luminaires with modern luminaires which can be easily cleaned and which use lamps with higher efficiencies and good lumen maintenance characteristics (NECA 1979).

i. Consider installing fluorescent luminaires with two-level ballasts or adding dimming controls in multiple-purpose spaces which require more than one level of illumination (NECA 1979).

j. Consider lowering luminaires so they will provide recommended illumination levels on the task area at reduced wattage (Claman 1983).

k. Where appropriate, consider installation of lenses which provide special light distribution patterns to increase lighting effectiveness. As examples, linear batwing, radial batwing, parabolic louvers or polarizing lenses may provide better visibility with the same or even reduced wattage. It is suggested that competent technical advice be obtained to evaluate where such lenses can be used most effectively (Claman 1983).

1. When existing circuitry makes it impossible to utilize less than $25 \%$ of the light in a given large space whenever light is needed, and when persons consider development of a desk lamp issuance 
program which enables persons working during unoccupied period to use a simple desk lamp or two instead of a large bank of luminaires (Claman 1983).

$\mathrm{m}$. When natural light is available in a building, consider the use of photocell switching to turn off banks of lighting in areas where the natural light is sufficient for the task (Claman 1983).

n. Use photocell and/or time clock controls for outdoor lighting whenever feasible. Parking areas, building exteriors, identification signs, etc., usually require lighting for only a part of the period of darkness. Such lighting should be turned off automatically during late evening and early morning hours except for security and safety lighting (Claman 1983).

o. Use time controls for those areas of a building which are used infrequently and only for brief periods. These controls turn off lights automatically after being activated for a set period of time (NECA 1979).

p. Use alternate switching or dimmer controls when spaces are used for multiple purposes and require different amounts of illumination for the various activities. It is possible to provide multiple levels by providing switching for alternate fixtures, alternate sets of lamps in fluorescent fixtures, etc. Dimmer controls can be effective when it is impractical to use selective switching to obtain multiple lighting levels. This is especially true (and relatively low in cost) when incandescent lighting is involved (NECA 1979).

q. Provide selective switching. Initial cost economies and lack of knowledge about final space subdivision often lead to the use of central panel-boards as the only means of controlling large 
blocks of lighting. This design approach precludes the potential for turning on only the amount of lighting that is actually needed after the space has been subdivided (Dubin 1976).

$r$. Investigate ways to provide local control of lighting. Localized switches can be provided near doorways. Remotely controlled switches can be located near panelboards to control groups of lights. Low voltage switches located in remote locations (these controls usually are relatively inexpensive). When properly used, localized switching usually will save enough energy to provide a pay-back on the investment within a short period of time (Dubin 1976).

s. Lighting use in remote areas can be monitored by providing neon indicator lights at central stations. Personnel will be alerted to investigate and turn off lights not being used (Dubin 1976).

\section{F. DOMESTIC HOT AND COLD WATER}

1. Background. The heating of water can be responsible for approximately $15 \%$ of typical family residential energy consumption (FPL 1982b). Hot water requirements for laundry, bathing and food preparation cannot be eliminated, but they can be reduced in a number of ways.

A temperature setting of $120^{\circ} \mathrm{F}$ is adequate for most families, while some dishwashers require $140^{\circ} \mathrm{F}$ (Aadland 1980). Settings in excess of this not only use more energy but also will shorten the life of the hot water heater. By checking the dial on most water heaters it is impossible to determine the temperature. Instead, water should be drawn and a thermometer used. 
Domestic hot water often consumes from $2 \%$ to $4 \frac{\circ}{0}$ of the total energy used in large office buildings (Roose 1978). In retail stores and smaller buildings, the amount usually is smaller. Cold water, provided in drinking fountains, also is a factor in total building energy consumption.

If domestic hot water is heated by the same boiler which heats the building, and if the load is only 10 or $20 \%$ (Dubin and others 1976) of the total boiler load in those months when the building is heated, the energy used in the fall and in summer months for domestic hot water may be considerably higher than in the winter as the boiler will be operating at low part load efficiency.

2. Guidelines to Reduce Energy. The following are proven energy conservation guidelines. They are general and may not always be applicable to all facilities:

a. Where possible, use cold water only for hand washing in lavatories when cold water temperature is $75^{\circ} \mathrm{F}$ or above. This is most readily accepted in retail stores, religious buildings, owner-occupied small office buildings and in washrooms used primarily by the public on an infrequent basis (Dubin 1976).

b. Where tenants insist upon hot water for hand washing, heat tap water to $90^{\circ} \mathrm{F}$ (Sneathen 1978).

c. Do not maintain an entire hot water system at the same temperature required for the most critical use (Sneathen 1978).

d. If the space heating boiler is also used to supply domestic hot water, lower the aquastat setting in the summer time to $100^{\circ} \mathrm{F}$. The same setting should be used for storage tank temperature control, summer and winter (Roose 1978).

e. Where higher temperatures are required, at a dishwasher, for example, a small gas or electric booster used only as needed 
saves more energy than a large storage tank, piping and distribution system which heats all domestic hot water in the building to the most critical temperature (Roose 1978).

f. Use cold water detergents for laundries and laundromats and set water temperature to $65^{\circ} \mathrm{F}-70^{\circ} \mathrm{F}$ (FPL 1983b).

g. Refer to Health or Food Handling Codes, if applicable, for minimum temperature specifications (FPL 1983b).

h. Insert orifices in the hot water pipes to reduce flows (Aadland 1980)

i. Install spray type faucets that use only $\frac{1}{4}$ gallons per minute (GPM) instead of 2 or $3 \mathrm{gpm}$, at a cost of about $\$ 50$ a unit (Aadland 1980)

j. Install self-closing faucets on hot water taps (Aadland 1980).

k. In buildings with cooking facilities that are used only periodically, such as meeting rooms in religious buildings, shut off the hot water heating system, including gas pilots where installed, when the facilities are not in use (NECA 1979).

1. Re-examine the need to heat entire tank of water when only a small quantity or no hot water is needed (FPL 1983b).

m. Simplify menus to reduce the need for large pots and pans that require large amounts of hot water for cleaning. Where practical, use short dishwashing cycles and fill machine fully before use (FPL 1983b).

n. Reduce the number of meals served and/or serve more cold meals to reduce the hot water requirements for dishwashing (FPL 1983b)

o. In areas where water pressure is higher than a normal 40 to 50 lbs., restrict the amount of water that flows from the tap by 
installing pressure reducing valves on the main service. Do not reduce pressure below that required for fire protection or for maintaining adequate pressure on the top floor for flushing (Roose 1978).

p. Refer to Plumbing Codes, if applicable, for hot water supply requirements (FPL 1983b).

q. Repair insulation of hot water piping and tanks or install it where missing (unless piping and tanks are located in areas which require space heating or are air-cooled) (FPL 1983b).

$r$. Where forced circulation of hot water is used, shut off the pump when the building is unoccupied; when hot water usage is light consider using gravity circulation without the pump (Dubin 1976).

s. Flush water heater during seasonal maintenance of heating systems (Dubin 1976).

t. Repair leakv faucets (FPL 1983b).

u. Repack pump packing glands of recirculation hot water heaters to reduce leaking of hot water (Dubin 1976).

$v$. For boilers with immersion tankless domestic hot water coils, make sure boiler water covers coils (Dubin 1976).

\section{G. COMMERCIAL REFRIGERATION}

1. Background. Commercial refrigeration systems account for as much as $50 \%$ of the total annual energy consumption in some supermarkets, and a significant amount of the energy consumed in cafeterias and restaurants (Evans and others 1980). The actual energy usage is analogous to usage by air conditioning systems; total quantity depends upon the "produce" load, (the equivalent to the cooling system's 
"building" load), the distribution or "parasitic" load, and the seasonal efficiency of the primary conversion equipment, such as compressors.

The "produce" load is a function of the mass of the materials to be cooled, the temperature difference between the refrigerated materials and the ambient conditions and the period of time that the conditions are maintained.

The "distribution" load is a function of the performance of the refrigeration distribution system (refrigeration, piping, valves, controls, cold air ducts and diffusers) and the performance (seasonal efficiency) of the refrigerators, cold display cases, and other cold storage boxes. 2. Guidelines to Reduce Energy. The following are proven energy conservation guidelines. They are general and may not always be applicable to all facilities:

a. If possible, raise storage area temperature (FPL 1983b).

b. Investigate cooling below normal levels during non-peak periods and allowing temperature to rise during peak periods (FPL 1983b).

c. Eliminate unnecessary use of doors in refrigerated areas (FPL (983b).

d. Determine most efficient defrosting of all coils (FPL 1983b).

e. Keep blower fans clear of obstructions (FPL 1983b).

f. Arrange products for best use of space. Avoid operating partially-filled room (FPL 1983b).

g. Check for proper insulation in refrigerated areas as recommended by manufacturer (FPL 1983b).

h. Evaluate effects of controlling air handlers to discontinue operation when refrigerant flow is stopped (Dubin 1976). 
i. Operate blast freezer only when needed and move product to holding room to maintain temperature (Dubin 1976).

j. Investigate using water to cool the compressor to reduce temperature and improve efficiency (Imperatore 1978).

k. Increase condenser size to reduce head pressure and improve efficiency (Imperatore 1978).

1. Investigate recovering heat from condensers for heating water (Roose 1978).

m. Establish a regular preventive maintenance program for refrigeration equipment (FPL 1983b)

n. Make sure refrigeration lines are insulated adequately and charged properly (FPL 1983b).

o. Cover open freezer and display units when not in use. This preserves the cold temperatures from the ambient air. Note: Check with manufacturer hefore installation to verify that this recommendation is applicable (FPL 1983b).

p. When excess capacity exists, consolidate items into fewer cooling units (FPL 1983b).

q. Minimize warehousing items that need refrigeration. Take advantage of more frequent deliveries if possible (FPL 1983b).

$r$. Utilize vinvl strip doors in high traffic areas (FPL 1983b).

\section{H. POWER}

1. Background. The opportunities to reduce "building" and "distribution" loads have been covered in other sections. As an example, when the quantity of water or air circulated in a HVAC system is reduced, less power is needed to drive fans and pumps and, accordingly, it is possible to reduce annual energy consumption even 
further. Improper distribution voltage, low power factor, transformers at inefficient loading points, losses from standby transformers, excessive operation of motors and equipment, improper control and low load factors of motors, and excessive voltage drop in undersized conductors or wiring are the major causes of the waste of electric energy ( $\mathrm{Hu} \mathrm{1983b}$ ).

Because original load calculation estimates are usually conservative, when loads have been reduced through conservation measures, most motors are oversized for the equipment load they are serving. If the ratio of the motor loading to the motor's horsepower rating is small, the power factor will be low and the motor will operate inefficiently.

When evaluating the potential for larger savings, the cost of replacing inefficient motors with the savings in electrical operating cost which would be achieved with newer, more efficient motors should be compared.

There are many loads, such as elevators and escalators, transformers, water coolers, etc. that are often energized $24 \mathrm{hrs} / \mathrm{day}, 7$ days/week - even though they may be required only for 50 hours or less per week. Due to their storage capacity, other loads, such as electric water heaters, can be deenergized for periods of time, even when their function is required. Automatic devices which de-energize loads on a programmed basis are available.

Load leveling, or load shedding, to reduce peak power demands provides an opportunity to conserve energy and reduce consumption costs, as well as to reduce drastically electrical energy costs where the utility rates include demand charges (McClure 1978). For instance, large electrical air conditioning refrigeration equipment can be unloaded during periods when all elevators are in use. Demand limiters and computer programs for load leveling are commercially available. 
Reduction of electric energy consumption can also be achieved through the establishment of a thorough preventive maintenance program combined with cost-effective operational measures.

2. Guidelines to Reduce Energy. The following are proven energy conservation guidelines. They are general and may not always be applicable to all facilities:

a. Keep motors and related equipment clean to reduce operating temperatures and energy loss (FPL 1983b).

b. Inspect drive mechanisms (belts, gears, etc.) to insure proper operation and reduce energy loss. Adjust as needed. Insure proper alignment of motors (FPL 1983b).

c. Maintain and lubricate all motors and motor-driven equipment for optimum efficiency. Replace worn bearings (FPL 1983b).

d. Investigate motor loading to insure that motor matches load and is operating at or near maximum efficiency (FPL 1983b).

e. Correct motor power factors to 90 percent using capacitors switched with the motor(s) either individually or in groups (See Appendix A) (Dubin 1976).

f. Maintain supply voltage to all motors within manufacturer's recommendations to guarantee efficient operation (Dubin 1976).

g. Select high efficiency models when purchasing new motors to reduce energy requirements (Dubin 1976).

h. Provide controls so that motors may be shut off when not in use. Timers may help (NECA 1979).

i. Inspect all compressed air lines and valves and correct any leaks (NECA 1979). 
j. Establish a preventive maintenance program for distribution equipment to reduce losses from poor connections. Tighten or replace connectors as needed (NECA 1979).

k. Disconnect transformers during non-operating periods to reduce losses. When replacement is necessary, select high efficiency transformers (NECA 1979).

1. Use power factor correction to reduce line losses and improve voltage regulation (NECA 1979).

$m$. Consider power factor correction to relieve system and branch loading as alternative to installing larger capacity service equipment (NECA 1979).

$n$. Identify peak energy use (demand) periods and reschedule some operations to lower demand requirements (FPL 1983b).

o. Identify energy-intensive products and processes and find ways to reduce the energy used (NECA 1979).

p. Consider time-controlled switches for water heaters, battery chargers and other deferrable loads to assure they are off during peak demand periods (NECA 1979).

q. Reschedule janitorial services, if possible, to regular business/operating hours (NECA 1979).

r. Evaluate use of automatic load control equipment to lower demand requirements (NECA 1979).

s. Combine electrical services whenever possible to eliminate unnecessary meters (NECA 1979).

t. Evaluate need for each piece of electrical equipment. Where equipment is unnecessary, disconnect it. Timers can help here (NECA 1979). 
u. Evaluate benefits of replacing inefficient equipment with more efficient and less energy-consuming equipment (NECA 1979).

v. Note length of time air compressors operate. If excessive, could indicate pressure loss. Check and correct as needed (NECA 1979).

w. Explore possibility of reducing compressed air requirements by investigating all uses - clean-up, cooling (NECA 1979).

$x$. Shut off air compressor during non-operating periods (NECA 1979)

y. Inspect air compressor intake filter pads regularly. Clean or replace as needed (NECA 1979).

z. Consider installation of demand-type elevator controls on elevators having through trip or collective type of controls so elevators may be adjusted to ensure that the fewest number of cabs travel the shortest distance which demand on the system allows (NECA 1979).

\section{CENTRAL CONTROL SYSTEMS}

1. Background. The purpose of a central control system is to provide the physical plant chief engineer and an energy management team with a management tool to give constant surveillance of the building and to make the most efficient and effective use of physical plan systems and personnel.

Central control systems are applicable only to the larger more complex buildings or groups of buildings. They should be considered where net floor area exceeds 100,000 square feet (Dubin and others 1976) and where energy use is high due to extended occupancy or use of special equipment. 
Central control systems vary from the relatively simple type designed to perform a few functions to the progressively more complex type performing more and more complicated functions.

According to Guntermann (1982), a central control system should be selected to:

a. Monitor all systems for off-normal conditions.

b. Monitor all fire alarm and security devices.

c. Monitor operating conditions of all systems and reschedule set points to optimize energy use.

d. Monitor on a continuous basis selected portions of any system and store this information in bulk memory for later retrieval and use in updating software. This information would also be used to determine the effectiveness of the energv management program to indicate changes or modifications in approach that should be made.

e. Limit peak electrical demand values by predicting trends of loads and shedding non-essential services according to programmed priorities.

f. Optimize the operation of all systems to obtain the maximum effect for the minimum expenditure of energy.

g. Optimize maintenance tasks to effect maximum equipment life for minimum manpower labor and costs.

h. Provide inventorv control of spare parts, materials, and tools used for maintenance.

BV judicious use of these functions, the staff can be able to operate all systems from the central console and have minute-by-minute control of their operation. Any physical plant critical alarm would be reported automatically at the console and the operator would then be able 
to scan the system in alarm, analyze the fault and dispatch the correct maintenance man to effect repairs.

2. Basic Functions. Basic functions of central control systems are generally applicable to a broad range of systems and equipment. Some of these functions include the following identified by NECA (1979):

a. Timed Operation - Consist of starting and stopping a system based on the time. Provides the greatest potential for energy conservation if systems are currently being operated during unoccupied hours. It is also the simplest function to install, maintain, and operate.

b. Duty Cycling - Consists of shutting down a system for predetermined short periods of time during normal operating hours, such as 15 minutes of each hour of operation. The off period time length normally is increased during moderate seasons and reduced during peak seasons.

c. Temperature-Compensated Duty Cycling - With temperature -compensated duty cycling, each load has a related space temperature data point assigned to it. Each load serving interior zones (cooling only) is cycled off for its assigned maximum period as temperature in the space drops to its assigned minimum value. Likewise, the interior load is cycled off for its assigned minimum period as space temperature rises to its assigned maximum value.

d. Demand Control - Demand control functions stop electrical loads to prevent a predetermined maximum electrical demand from being exceeded. Most of the systems employ logic which monitors the base electrical demand continuously and predicts whether or not the preset limit will be exceeded. If it will be, certain 
scheduled electrical loads (secondary loads) are shut off. Additional secondary loads are turned off on a priority basis if the initial load shed action does not reduce the predicted demand enough to satisfy the function requirements.

e. Outside Air Temperature Cutoff - With an outside air temperature cutoff, heating systems, except for direct-fired warm air systems smaller than 500,000 BTU per hour design input capacity, are provided with an outdoor temperature-sensing control which cuts off the heating system for all types of spaces when the outdoor temperature rises to within $5^{\circ} \mathrm{F}$ of the indoor design temperature, or to a minimum of $40^{\circ} \mathrm{F}$.

f. Warm-up/Night Cycle - The thermal load imposed by outside air used for ventilation may constitute a substantial percentage of the total heating and cooling requirements. The warm-up/night cycle function controls the outside air dampers when the introduction of outside air would impose a thermal load and the building is unoccupied.

g. Space Temperature Night Setback - The energy required to maintain space conditions during the unoccupied hours can be reduced by lowering the temperature set point for the space, depending on the climatic conditions. 


\section{A. GENERAL}

Although State and National legislation have been covered in Section III-C-2 and II-D-3, provisions of three key acts - NECPA, PURPA and ECPA will be covered in more detail in this section.

Most of the provisions of NECPA relate to residential, commercial, and governmental buildings in addition to industrial facilities. The following provisions of NECPA affect industrial energy conservation $\mathrm{CHu}$ (983d) :

- Energy-efficiency labeling of industrial equipment.

- Industrial recycling targets and reporting requirements.

- Mandatory minimum energy-efficiency standards for major home appliances, such as refrigerators and air conditioning units (See Appendix $\mathrm{H}$ )

- Authority for the secretary of transportation to increase the civil penalties on automobile manufacturers from $\$ 5$ to $\$ 10$ per car for each one-tenth of a mile a manufacturer's average fleet mileage fails to meet the EPCA automobile fleet average fuel economy standards.

PURPA has three broad purposes:

- Conservation of energy supply be electric utilities.

- Optimization of efficient use of facilities and resources by electric utilities.

- Equitable rates to electric customers.

ECPA is the basic legislation for state energy conservation programs (See $111-C-3$ ). It provides supplemental industrial energy conservation plans for states. Under this act, increased funds were provided to the 
states to support conservation programs (e.g., energy audits and public education)

\section{B. METROPOLITAN DADE COUNTY ENERGY CONSERVATION PROGRAMS}

Metropolitan Dade County, located in southeast Florida, which includes the city of Miami, currently offers five energy-related programs to residents of the County. The programs fall under three major agencies: Community Action Agency (CAA); Community and Economic Development (CED); and Housing and Urban Development (HUD) (Metropolitan Dade County - O.E.M. 1984)

Services furnished under these agencies are as follows:

Community Action Agency (CAA)

- low-income weatherization

Community and Economic Development (CED) and Housing and Urban Development (HUD)

- Section 312 rehab loans

- Community Development Block Grant (CDBG) multi-family rehab loans

- Documentary Surtax single-family rehab loans

- Solar Energy and Energy Conservation Bank (Solar Bank) energy conservation grants (proposed)

Only two of these five programs focus primarily on energy conservation: weatherization and solar bank. The other three are primarily housing rehabilitation programs. All five target low-income persons as the maior population segment receiving financial assistance.

CAA weatherization is a federally-funded program for energy conservation grants to low-income persons. Th funds originate with the U.S. Department of Energy who awards block grants to states. The 
Florida Department of Community and Veterans Affairs receives the federal funds and in turn awards grants to local agencies. By law, preference is given to local community action agencies for managing weatherization programs.

Homeowners and renters with incomes at or below 125 percent of the poverty level are eligible for a grant award of up to $\$ 1000$ for CAA weatherization activities, including materials and labor.

The proposed Solar Bank program is a federal program funded by U.S. HUD through Florida's Governor's Energy Office (GEO). While the Solar Bank has money for both loans and grants, the county's application requests funds for only energy conservation grants to low-income persons. These grants may only be used to match 50 percent of the cost of energy conservation measures up to $\$ 1,250$ for one unit, $\$ 2,000$ for two units, $\$ 2,750$ for three, $\$ 3,500$ for four and 20 percent of the energy conservation cost up to $\$ 400$ per unit for five or more units. The county did not apply for loan funds from the Bank because the loan part of the program would greatly increase the country's administrative costs for operating the program.

The grant program will be integrated with the county's Documentary Surtax and CDBC rehab programs, using the same procedures and staff for implementation.

Metro-Dade County has also identified cost-effective measures to use energy resources more productively and thus help control rising energy costs for its own facilities. To demonstrate one practical, internal solution to the financing problem, the county developed and applied a revolving loan fund for energy-related capital improvements that increase operating efficiencies and reduce energy expenditures. 
Dade County's Comprehensive Energy Management Strategy already places responsibility for energy use and cost management with individual municipal departments and treats energy through the budget process as a manageable, accountable resource. The revolving Energy Investment Fund (EIF) was designed to complement this current energy management program by providing financial support for energy conservation projects identified by department managers. With an initial pool of $\$ 150,000$, the Energy Investment Fund is designed as an internal, renewable source of financing for energy-related capital projects with paybacks ranging from one to five years. During its first year of operation, the Fund supported twelve projects with a total cost of about $\$ 100,000$ and first year savings estimated at over $\$ 70,000$ (Metropolitan Dade County O.E.M. 1983).

One of the most successful efforts by Dade County has been with its Library Department. Through effective energy management training and the implementation of cost-effective measures, dramatic reductions in both $\mathrm{KWH}$ consumption and $\mathrm{KW}$ demand were achieved at most of the libraries.

Focusing on one facility - the South Dade Regional Library - will illustrate the effect of implementing an energy conservation strategy on energy consumption. In June of 1982, the South Dade Library received a full energy audit. This audit was the basic information bank for developing energy management training, performance planning, and EIF application for this facility. The report from the audit contained five Energy Management Recommendations (EMR's) whose eventual implementation, at an initial cost of $\$ 15,550$, would result in an estimated reduction of 191,400 $\mathrm{KWH} /$ year with a payback period of 1 year, 3 months (Metropolitan Dade County OEM 1983). 
Monitoring the actual results of the five EMR's yielded the following data:

$\begin{array}{lll} & \frac{\text { Total Consumption* }}{1980-1981} & 1,300,080 \mathrm{KWH} \\ 1981-1982 & 1,195,920 \mathrm{KWH} & 243,480 \mathrm{KWH} / \text { year } \\ 1982-1983 & 1,056,600 \mathrm{KWH} & (18.7 \% \text { Reduction })\end{array}$

The impressive results are a strong point in favor of the need to truly invest in effective energy conservation and management. In the case of Dade County and its Office of Energy Management, the results have gained national recognition and already saved the local taxpayers hundreds of thousands of dollars.

C. FLORIDA POWER AND LIGHT CO. ENERGY CONSERVATION PROGRAMS

Energy conservation is also a major priority with most utilities in the electric industry. It is especially true in the State of Florida, where forecasts reported by The Miami Herald (1985) indicate that the population will increase by 50 percent by the year 2000 . Such growth translates into hundreds of thousands of new customers for the electric utilities.

As a result, utilities such as Florida Power and Light Company (FPL) have become committed to minimizing fuel costs and reducing dependency on costly fuel oil. FPL has been able to reduce oil usage from 56\% of all fuels used in 1981, to 25\% used in 1984; a $30 \%$ reduction (FPL 1985). This was achieved primarily by increasing the use of nuclear power and purchased coal-fired power, along with expanded conservation efforts. 
In accordance with the provisions of the previously-mentioned energy conservation legislation and the rules of the Florida Public Service Commission, FPL offers five programs for residential energy conservation. These programs include rebates for more efficient home energy appliances and a 50 percent match up to $\$ 75$ for low-cost conservation. These programs are the following:

I. Conservation Cooling and Heating

FPL will provide cash up to $\$ 600$ to those purchasing and installing a high efficiency air conditioner or heat pump. To be eligible for this rebate, the individual's residence must have been served by FPL for at least one year: the existing equipment must cool and/or heat the entire residence; the new equipment must be a central air conditioning system with a minimum SEER of 8.5 or a central heat pump system with a minimum SEER of 8.0 and a minimum COP of 2.5 ; and the new system must be directed to all major rooms of the house.

2. Conservation Water Heating

FPL will pay to help a customer install a solar water heater (from $\$ 164$ to $\$ 400$ ); a water heating heat pump ( $\$ 78$ to $\$ 186$ ); or a heat recovery unit (\$177). To be eligible for this rebate, one's house has to have been served by FPL for at least one year; the hot water must be from a conventional electric water heater; and the new water heater must be permanent. In addition, the house must have an FPL audit, and the system must be purchased from an FPL approved dealer/contractor. After installation, the system must also pass an FPL inspection. FPL pays the rebate to the dealer/contractor.

3. Conservation Insulation 
FPL will pay up to $\$ 400$ toward the cost of installing ceiling insulation. Again, one must have an FPL energy audit; the whole house must be cooled and/or heated either by a central system or individual room air conditioners; and the existing house has inadequate or no insulation. After installation, the ceiling insulation must rate at least $\mathrm{R}-19$, and the material and installation must meet FPL specifications. FPL pays the rebate directly to the contractor.

4. Conservation Window Treatments

FPL will rebate up to $\$ 150$ toward the cost of installing solar reflective film, solar screens and certain types of awnings and shutters. The requirements for the rebate are: the residence must have unshaded, single-pane, clear class with eastern, western or southern exposure. The entire residence must be cooled by central or room air conditioners; and materials and installation must meet FPL specifications. FPL pays the rebate directly to the contractor.

5. HELP (Home Energy Loss Prevention)

FPL's newest program, HELP, will pay up to $\$ 75$ for low-cost conservation measures as a match to an equivalent expenditure by the customer. This program is targeted at low-income customers and could possibly work in conjunction with the Solar Bank and weatherization grant programs (See Appendix J).

FPL hopes to save the power equivalent of two nuclear plants by the 1990's through its ambitious energy efficiency programs. In the residential sector, the utility has already audited 300,000 homes, encouraged the replacement of over 50,000 inefficient central air 
conditioners, and weatherized over 30,000 homes (National Society of Professional Engineers 1985).

3. Commercial/Industrial Program For the commercial/industrial sector, FPL offers energy surveys through its Commercial/Industrial Energy Analysis Program. The survey includes a careful review of a facility's energy-usage for the previous 24 months to help detect any trends in consumption. This is followed by a thorough on-site examination of the facility's energy-using systems: building envelope, including doors, windows, roofs, ceiling and wall insulation; heating, ventilation and air conditioning use; lighting and water heating efficiency; and special systems - such as elevators, escalators, food preparation equipment, compressed air systems, refrigeration equipment and computer facilities.

As part of the Commercial/Industrial Program, FPL sponsors a Lighting Incentive Program under which a qualifying customer can receive refunds of $\$ 1.00$ and $\$ 1.50$ for each 40 -watt and 75-watt fluorescent lamp, respectively, that is replaced with a lower wattage, energy-efficient lamp that maintains the same lighting level.

Numerous facilities within FPL's service territory, from small retail businesses to large industries, have benefitted from the Commercial/Industrial Program surveys. They include Miami International Airport, Omni International Complex, the Orange Bowl Stadium, Four Ambassadors, Sears Roebuck Inc., Calder Race Course, Key Pharmaceuticals Inc., Miami-Dade Community College - North Campus; and the Homestead Air Force Base (Source: FPL Marketing and Energy Conservation Department). A sample of a commercial survey can be found in Appendix G. 
To date, the results have been impressive. FPL reports that, from 1981 to 1984, over 4,600 commercial/industrial facilities have been surveyed, representing potential identified reductions of over $234,000,000 \mathrm{KWH} /$ year and $123,000 \mathrm{KW}$ of demand. Many of the recommendations have been implemented, including actual reductions of nearly $22,000 \mathrm{KW}$ of demand achieved in 1984 alone through the Lighting Incentive Program. The reductions in demand help to lower dependency on the less efficient fossil fuel back-up generating facilities and favorably impact the cost of electricity.

The success of the program is perhaps best illustrated by Colonel Harold G. Hermes, Homestead Air Force Base (HAFB) Vice-Commander's words when the Base and FPL co-shared a national energy award: "The FPL audit was a tremendous help. I feel really good about it. You did something we would like to have done a long time ago, but just aren't staffed to do. Where funding will allow, we intend to use the results as a roadmap to help us reach our energy conservation goals" (FPL 1982b). 4. Passive Construction Program. A formal definition of passive solar design is the following: Passive solar designs are methods for heating or cooling buildings or for heating domestic water in which thermal energy flows by natural means (i.e., without pumps or fans) (U.S. DOE 1980b). A fan added to a passive system may improve the energy transfer or provide an additional level of control over the amount and time of such transfer. Because it doesn't exactly fit the above definition, such a system may be called a hybrid as it has both passive and "active" (fan) systems.

Although not part of any of the previously-mentioned energy conservation programs having incentives, FPL commissioned award-winning architects to design two "passive" homes for each of three 
climate regions in Florida (See Appendix $K$ ). Using extensive test results from The Florida Solar Energy Center - a leading solar research institute - the architectural interpretation of the six designs take advantage of cool summer breezes and warm winter sunshine to cool and heat naturally, and as comfortable as possible without mechanical help. The design principles of passive solar systems including properly spaced storage masses, overhangs, fenestration, the use of vegetation, proper building materials and building orientation, have been used since the beginning of time.

A set of blueprints for each of the designs, along with owner and builder's manuals are available from FPL, with the first set costing $\$ 50$ and additional sets costing $\$ 5$ each (See Appendix G). FPL's Passive Home Program Coordinator has indicated that hundreds of requests for blueprints - prompted by a recent newspaper article - show the growing public revival for this energy saving approach to residential construction.

5. Appliance Efficiency Program In conjunction with hundreds of appliance dealers within its service territory, FPEL Co. promotes a highly successful program - "Select and Save"- that encourages the sale of energy efficient appliances (See Appendix 1).

The impact of energy-efficient appliances could be very significant. Bakke (1980) points out that appliances and water heating in buildings account for one-fifth of the total national energy expenditure, almost as much as the entire industrial sector.

Already appliance efficiency gains have been impressive. In a presentation to the Florida Public Services Commission, the Association of Home Appliance Manufacturers (AHAM) points out that over the last 10 to 12 years manufacturer design changes have improved appliance 
efficiencies as follows: refrigerators - 67\%; freezers - 56\%; and room air conditioners - $22 \%$.

A proposed bill on appliance efficiencies is currently awaiting voting in the Florida Legislature. If passed, minimum appliance efficiency standards will be imposed on all new residential construction in the state. 


\section{FUTURE FRAMEWORK}

There exists an imbalance in the distribution of the world's non-renewable energy resources that will undoubtedly worsen with time. The less developed nations, teeming with most of the world's population and with little chance to house, feed, and educate their people, may find it difficult to survive as the cost of energy continues to rise.

We are fortunate to live in a "have" society, one with the resources to heavily invest in the further development of existing and new energy technologies. But even with the available economic resources, should large new oil and gas fields be discovered, their development would still take years. Similarly, technical limitations also exist in the areas of utilization of renewable forms of energy, such as the problems of area requirements and storage system development for large-scale solar energy applications.

A developing technology with potential importance mav be cogeneration. Cogeneration - the co-production of electrical or mechanical energy and thermal energy - has received significant, encouraging federal and state legislation in recent years. The Public Utility Regulatory Policy Act of 1978 (PURPA - See Sections III-D-3 and $\mathrm{VI}-\mathrm{A})$ requires electric utilities to purchase electric power from, and sell electric power to qualifying cogenerators or to qualifying small power producers (EBASCO 1984). This buyback provision requires utilities to purchase electric energy at a rate equal to the utility's "full avoided cost). The avoided cost is the cost to the utility which, except for the purchase from the qualifying facility, would be incurred by the utility in generating the electricity itself or purchasing the electricity from another source. 
Cogeneration mav offer an advantage to the user if it's operating costs are kept below the combined cost of a conventional system, and to the utility if it can help drop the peak demand on its generating facilities. (Swim and others 1984) point out that the disadvantages of cogeneration to an industrial user would include: increased fuel consumption (at costs that mav remain uncertain since they would be producing their own electricity; increased pollution emissions resulting from increased fuel consumption; and the threatening possibility of increased regulatory controls being imposed.

Nevertheless, irrespective of how promising cogeneration or wind, or solar energy, or other developing technologies may promise to be, the least vulnerable energy option today is to use less by being more efficient. If it now takes ten barrels of imported oil to heat a house for a year, and if that house is retrofitted such that it only uses half the amount of oil, Bakke (1980) asks if it wouldn't be more cost effective to insulate fully one-quarter of all the homes in America than to spend the $\$ 20$ billion now earmarked for synfuels.

Experience has shown that the greatest economic benefit of conservation results from the avoidance of future additions to generation capacity. Toward this objective, national legislation (PURPA) has spurred energy legislation at the state level such as the Florida Energy Efficiency and Conservation Act (FEECA) which is used to establish cost-effective conservation plans and programs with utilities. According to Florida's Public Service Commission (FPSC), the results are significant. Prior to the FEECA goals, growth rates of peak demand and energy sales exceeded that the present and projected rate of energy sales is not less than 75 percent of the growth rate in residential customers. 
It is this type of approach to conservation, one that promotes energy audits at a large scale effort and pushes for stricter energy efficiency codes for building, that should be continued and improved upon.

Legislation alone, however, will not be enough. The initiative of private industry along with more interest from the private sector will have to play a major role in stimulating the adoption of energy-conserving laws, technologies, measures, and practices. We will need to better understand how we use and misuse energy and how all internal and external factors interact.

To achieve this, we will have to rely on the quick implementation of proper energy conservation and management. Only then will we be able to have a substantial effect on our energy predicament. 
IX. APPENDECES 
AEI - Annual Energy Index. The ratio of the total annual energy consumption of a building or plant in millions of Btus divided by the total building area in thousands of square feet. Used as a way of characterizing energy usage in a building.

Air Infiltration

- Air leakage into or out of a building through cracks and around windows and doors.

Barrel - A liquid measure of oil, usually crude oil, equal to 42 gallons or about 306 pounds.

Base Load - The energy requirements of a facility which are unaffected by weather changes.

British Thermal Unit (Btu) - The amount of heat necessary to raise the temperature of one pound of water one degree Fahrenheit. About a quarter of a Calorie.

Building Envelope - All external building surfaces, such as walls, doors, windows, roof, and floors in contact with the ground, which are affected by weather.

Chiller (Centrifugal) - A refrigeration machine using mechanical energy input to drive a centrifugal compressor to generate chilled water.

Coal-Direct Utilization in Utilities/Industry - The design, construction, and operation of advanced components, systems, and processes involved in the industrial and utility combustion of various types of coal; the transfer of the heat produced or steam or other working fluids for process or power use; and the systems and methods employed to reduce or control the generation of pollutants during combustion. Included are new combustion methods such as fluidized bed combustion, more efficient boilers, and the use of additives during combustion.

Coefficient of Performance (COP) - The ratio of the rate of heat removal to the rate of energy input, in consistent units, for a complete refrigeration plant, under designated operating conditions.

Cogeneration - The production of two useful forms of energy from the same process. In a factory, for instance, steam needed for industrial processes or space heating is first run through turbines to generate electricity.

Coil - The area of an evaporator where heat transfer occurs.

Compressor - That component of a refrigeration system that increases the pressure of a compressible refrigerant fluid and simultaneously reduces its volume while moving the fluid through the device. 
Condensate - Water obtained by changing the state of water vapor (i.e., steam or moisture in air) from a gas to a liquid, usually by cooling.

Condenser - A heat exchanger which removes heat from a vapor, changing it to its liquid state. In refrigeration systems, the components which rejects heat.

Connected Load - The uses to which an input energy stream is feeding, i.e., fan motor, lights, heat, hot water, etc.

Cooling Tower - A device that cools water directly by evaporation.

Damper - A device used to vary the volume of air passing through an air outlet, inlet, or duct.

Degree-day - The difference between $65^{\circ} \mathrm{F}$ and the outdoor mean daily temperature.

Demand Charge - The charge to an individual customer for the utility's provision of sufficient capacity to meet the maximum demand of that customer's class on an "as-needed" basis. In principle, this class should reflect the contribution of the customer class to the utility's system peak demand.

Distillate Fuel - Those light and middle fuel oil derivatives from petroleum, such as kerosene, home heating oil, range oil, stove oil, diesel fuel, kerosene-type jet fuel, including Numbers 1,2,3, and 4 fuel oils.

DOE - Department of Energy. Replaces FEA, ERDA and other designations for Federal Energy Offices.

Dry Bulb Temperature - The measure of the sensible temperature of air.

Duct Work - The conduit or piping system through which ventilated warm or cool air is conveyed from the source of supply to the premises or outlet. Ducts are usually made of galvanized metal or fiberglass; they may be lined or covered with insulating materials.

Economizer Cycle - A method of operating a ventilation system to reduce refrigeration load. Whenever the outdoor air conditions are more favorable (lower heat content) than return air conditions, outdoor air quantity is increased.

ECPA - the Energy Conservation and Production Act. Public Law 94-385, 90 Stat. 1125,42 U.S.C. 6801 .

Efficiency - The ratio of useful work or energy output to total work or energy input.

Electricity - Energy consumption is usually reported as kilowatt-hours ( $\mathrm{kWh}$ ). For the purpose of energy accounting, the theoretical heating power of a $\mathrm{kWh}$ of electricity is $3412 \mathrm{Btu}$ and this factor should be used to convert all electrical energy in the various building and industrial plant categories to a common useful energy basis. A more complete picture on a national economy 
basis is obtained if purchased electricity is measured in terms of the average amount of fossil fuel that is required to make a kilowatt of electricity by a public utility. This "gross energy" consumed is not relevant to the energy accountability problem within the scope of a Class A or Class C information audit but as a point of interest, this figure is about $10,500 \mathrm{Btu}$ of fossil fuel to generate $1 \mathrm{kWh}$ of electricity.

Energy - The capacity for doing work; taking a number of forms which may be transformed from one into another, such as thermal (heat), mechanical (work), electrical and chemical; in customary units, measured in kilowatt-hours (kWh) or British thermal units (Btu); in SI units, measured in joules $(\mathrm{J})$, where 1 joule $=1$ watt-second.

Energy Efficiency Ratio - The amount of energy in Btu's consumed per unit of production (Btu/Watt). Used for rating efficiency of air conditioning equipment.

Energy Audit - This means any process which identifies and specifies the energy and cost savings which are likely to be realized through the purchase and installation of particular energy conservation measures or renewable-resource energy measures.

Evaporator - A device in which a liquid becomes a gas while absorbing heat.

Fenestration - An opening in a building, such as a door or window, through which light infiltrates.

Foot-candle - Intensity of light at a distance of one foot from a standard candle.

Fossil Fuel - Coal, oil, natural gas, propane, and other petroleum-based fuels, all derived from previously living things and high in carbon content, are sometimes grouped for purpose of analysis.

Heat Gain - As applied to HVAC calculations, it is that amount of heat gained by a space from all sources, including people, lights, machines, sunshine, etc. The total heat gain represents the amount of heat that must be removed from a space to maintain indoor comfort conditions.

Heat Pump - A refrigeration system, which, when the evaporator and condenser effects are reversed, may be used as a heating system.

Heat Recovery - The capture and use of heat generated by lighting, cooling, and refrigeration systems for purposes requiring heat. Also, the removal of such heat from a conditioned space to reduce cooling or refrigeration requirements.

Heat Sensible - Heat that results in a temperature change but no change in state.

Humidistat - A switch for activating any of several components of an air conditioning system to control the relative humidity of a conditioned space, which responds automatically to changes in relative humidity. 
Humidity - The amount of water vapor in the air. Absolute humidity is expressed in grains of moisture per cubic foot of air. Relative humidity is expressed as the percentage that this amount of moisture represents of the total amount of moisture that a cubic foot of air could hold at the ambient temperature of its condensation point. At $100 \%$ relative humidity outdoors, rain is likely. At $100 \%$ relative humidity indoors, it may not rain, but everything is going to get wet.

Kilowatt $(\mathrm{kW})$ - One thousand watts.

Kilowatt Hour $(\mathrm{kWh})$ - Wattage consumed in thousands per hour.

Load Factor - This is a ratio expressing a customer's average actual use of the utility's capacity provided or built to meet his maximum demand on an as needed basis. A customer whose maximum demand is $450 \mathrm{~kW}$ and who consumes that amount every hour of each day of the month has a perfect or $100 \%$ load factor for that month. A customer who consumes or places that demand of a few hours on each day of the month will have an exceedingly low load factor.

Load Profile - Time distribution of building heating, cooling and electrical load.

Lumen - Unit of light output from a source.

Luminaire - Complete lighting unit consisting of a lamp or lamps and the parts designed to distribute the light, position, and protect the lamps and connect the lamps to the power supply.

Make-up Air - Outdoor air supplied to a building to compensate for air exhausted from the building.

Megawatt - A unit of power equal to 1,000 kilowatts, or one million watts. A gigawatt is a billion watts.

Oil Shale - The extraction of hydrocarbon products from shale and the conversion of the product to liquid or gaseous fuels or other chemical commodities. Included in the program is the development of in-situ methods for product extraction.

Payback - The time required for the cost of energy saved to equal purchase and installation costs.

Photovoltaics - The process by which radiant (solar) energy is converted directly into electrical energy using a solar cell.

Power - In connection with machines, power is the time rate of doing work. In connection with the transmission of energy of all types, power refers to the rate at which energy is transmitted; in customary units, it is measured in watts (W) or British thermal units per hour (Btu/hr), and in SI units is measured in watts $(W)$.

Power Factor - Relationship between $\mathrm{kVA}$ and $\mathrm{kW}$. When the power factor is unity, kVA equals $\mathrm{kW}$. 
Public Service Commission - A state regulatory body established by statute in virtually every state to regulate the private and public electric utilities. Publicly owned electric utilities are regulated in only about one third of the states.

Quad - A quadrillion Btu or Btu $\times 10^{15}$. One Quad equals 180 million barrels of petroleum*; 42 million tons of bituminous coal*; 0.98 trillion cubic feet of natural gas*; or 293 billion kilowatt hours of electricity.

* These values vary with the quality of fuel actually extracted and represent an average or recent production.

$R$-Value - The resistance to heat flow expressed in units of square feet-hour-degree F/Btu.

Refrigerant - The fluid used for heat transfer in a refrigerating system, which absorbs heat at a low temperature and a low pressure of the fluid and rejects heat at a higher temperature and a higher pressure of the fluid, usually involving changes of state of the fluid.

Renewable Energy Source - One that is constantly or cyclically replenished, including direct solar energy and indirect sources such as biomass and wind power.

Reset - Adjustment of the set point of a control instrument to a higher or lower value automatically or manually to conserve energy.

Sensible Heat - The heat which, when added or subtracted, causes a temperature change.

SIC - The Standard Industrial Classification system, described in the Office of Management and Budget, Standard Industrial Classification Manual (1972). The first two digits of the 4-digit Standard Industrial Classification Code are used to group the 10 most energy-intensive industries and set their conservation goals for 1980 .

Synfuels - Fuels synthesized from sources other than crude oil or natural gas and used in place of them or their derivatives, primarily for transportation and heating boilers.

Thermostat - A device that functions to establish and maintain a desired temperature automatically or signals a change in temperature for manual adjustment.

Ton of Refrigeration - A means of expressing cooling capacity: one ton $12,000 \mathrm{~B}$ tu/hour cooling.

Unitary Cooling and Heating Equipment - One or more factory-made assemblies which normally include an evaporator or cooling coil, a compressor and condenser combination, and may include a heating function as well. Where such equipment is provided in more than one assembly, the separate assemblies will be designed to be used together.

U-Value - A coefficient expressing the thermal conductance of a composit structure in Btu per square foot-hour-degree $F$ temperature difference. The reciprocal of $R$. 
Ventilation - Changing the air in an enclosed space by removing the existing air and replacing it with air introduced from another environment, usually the outdoors.

Waste Heat Utilization - The development, design, construction, and operation of systems to utilize the waste or rejected heat incident to the production of electrical power or industrial products for beneficial purposes. It includes bottoming cycles as well as integrated total energy systems employed in residential, commercial, and industrial complexes.

Watt - Unit of measurement for electric power. One volt $\times$ one ampere $=$ one watt. 1000 watts $=3412 \mathrm{Btu}$.

Wet Bubl Temperature - The lowest temperature attainable by evaporating water in the air without the addition or subtraction of energy. 
The common unit of energy measure is the British thermal unit (Btu) which is the unit used in this handbook to calculate and compare energy costs and savings. To convert between the common energy units, use the factors in this table.

\begin{tabular}{|c|c|c|}
\hline To Convert & Into & Multiply By \\
\hline $\begin{array}{l}\text { Barrels, oll } \\
\text { Cubic feet, natural gas } \\
\text { Cubic feet, natural gas } \\
\text { Gallons, No. } 2 \text { oll } \\
\text { Gallons, No. } 4 \text { oll } \\
\text { Gallons, No. } 5 \text { o1l } \\
\text { Gallons, No. } 6 \text { o1l } \\
\text { Gallons, kerosene } \\
\text { Gallons, gasoline } \\
\text { Gallons, diesel oil } \\
\text { Horsepower-hours } \\
\text { Horsepower-hours } \\
\text { Horsepower } \\
\text { Horsepower (boiler) } \\
\text { K1lowatt-hours } \\
\text { mCF natural gas } \\
\text { Short ton, eastern steam coal } \\
\text { Short tons, western coal } \\
\text { Short tons, anthracite coal } \\
\text { Short tons, bitumimous steam coal } \\
\text { Short tons, lignite, brown coal } \\
\text { Steam, saturated (1bs) } \\
\text { Therms, natural gas } \\
\text { Therms, natural gas } \\
\text { Tons, refrigeration }\end{array}$ & $\begin{array}{l}\text { gallon } \\
\text { therms } \\
\text { Btu } \\
\text { Btu } \\
\text { Btu } \\
\text { Btu } \\
\text { Btu } \\
\text { Btu } \\
\text { Btu } \\
\text { Btu } \\
\text { Btu } \\
\text { kWh's } \\
\text { Btu/min } \\
\text { Btu/hr } \\
\text { Btu } \\
\text { Btu } \\
\text { Btu } \\
\text { Btu } \\
\text { Btu } \\
\text { Btu } \\
\text { Btu } \\
\text { Btu } \\
\text { cubic feet } \\
\text { Btu } \\
\text { Btu/hr }\end{array}$ & $\begin{array}{l}42.0 \\
0.01 \\
1,020 \\
138,700 \star \\
145,000 \star \\
148,000 \star \\
150,00{ }^{*} \\
135,00{ }^{*} \\
125,00{ }^{*} \\
138,700 \star \\
2,544 \\
0.7457 \\
42.4176 \\
33,479 \\
3,413 \star \star \\
1,000,000 \\
23,100,000 \star \\
21,000,000 \star \\
25,400,000 \star \\
21,600,000 \star \\
14,000,000 \star \\
1,000 \\
100 \\
100,000 \\
12,000\end{array}$ \\
\hline
\end{tabular}

* These are average values. Since exact Btu content varles with type and source, contact supplier when extreme accuracy is essential.

** When it is necessary to account for line losses and total Btu of the fuel used to generate electricity use 11,600 .

Source: U.S. Dept. of Energy 
Cofmpare same size units at varying EER levels to see yearly operating savings.*

\begin{tabular}{|c|c|c|c|c|c|c|c|c|c|c|c|c|c|}
\hline \multicolumn{14}{|c|}{$\begin{array}{l}\text { Low to Moderate Energy Use ( } 750 \text { operating hours) } \\
\text { To obtain approximate annual energy cost', find your unit's EER in the left hand column. } \\
\text { Read across to vertical column corresponding to your unit's size (BTU / HR). }\end{array}$} \\
\hline \multirow{2}{*}{$\begin{array}{r}\text { EER } \\
5.0 \\
\end{array}$} & \multicolumn{3}{|c|}{ SLA:(OTU/HR RATING } & 7000 & \multirow{2}{*}{5900} & \multirow{2}{*}{$\begin{array}{l}9000 \\
\$ 108 \\
\end{array}$} & \multirow{2}{*}{$\begin{array}{l}10,000 \\
\$ 120\end{array}$} & \multirow{2}{*}{$\frac{\begin{array}{c}1 \text { ton } \\
12,000\end{array}}{\$ \$ 144}$} & \multirow{2}{*}{$\frac{14,000}{\$ 168}$} & \multirow{2}{*}{$\frac{15,000}{5180}$} & \multirow{2}{*}{$\frac{18,000}{\$ 216}$} & $\begin{array}{c}(2 \text { tons }) \\
24,000 \\
\end{array}$ & 30,000 \\
\hline & $\$ 48$ & $\$ 60$ & $\$ 72$ & $\$ 84$ & & & & & & & & $\$ 288$ & $\$ 360$ \\
\hline 5.5 & 44 & 55 & 65 & 76 & 87 & 98 & 109 & 131 & 153 & 104 & 196 & 262 & 327 \\
\hline 0.0 & 40 & 50 & 60 & 70 & 80 & 90 & 100 & 120 & 140 & 150 & 180 & 240 & 300 \\
\hline 6.5 & 37 & 46 & 55 & 65 & 74 & 83 & 92 & 111 & 129 & 138 & 166 & 222 & 277 \\
\hline 7.0 & 34 & 43 & 51 & 60 & 69 & 77 & 86 & 103 & 120 & 129 & 154 & 206 & 257 \\
\hline 7.5 & 32 & 40 & 48 & 56 & 64 & 72 & 80 & 96 & 112 & 120 & 144 & 192 & 240 \\
\hline 8.0 & 30 & 38 & 45 & 53 & 60 & 68 & 75 & 90 & 105 & 113 & 135 & 180 & 225 \\
\hline 8.5 & & 35 & 42 & 49 & 56 & 64 & 71 & 85 & 99 & 106 & 127 & 169 & $\therefore 12$ \\
\hline 9.0 & & 33 & 40 & 47 & 53 & 60 & 67 & 80 & 93 & 100 & 120 & 160 & 200 \\
\hline 9.5 & & 32 & 38 & 44 & 51 & 57 & 63 & 76 & 88 & 95 & $\mathrm{I14}$ & 152 & 189 \\
\hline 10.0 & & & 36 & 42 & 48 & 54 & 60 & 72 & 84 & 90 & 108 & 144 & 180 \\
\hline 10.5 & & & & 40 & 46 & 51 & 57 & 69 & 80 & 86 & 103 & 137 & 171 \\
\hline 11.0 & & & & & 44 & 49 & 55 & 65 & 76 & 82 & 98 & 131 & 164 \\
\hline 11.5 & & & & & & 47 & 52 & 63 & 73 & 78 & 94 & 125 & 157 \\
\hline 12.0 & & & & & & & 50 & 60 & 70 & 75 & 90 & 120 & 150 \\
\hline \multicolumn{14}{|c|}{ High Energy Use (2,000 operating hours) } \\
\hline & \multicolumn{4}{|c|}{ SLEI (BTU / HRR RATING } & & & & & & & & (2 tons) & \\
\hline EER & 4000 & 5000 & 6000 & 7000 & 8000 & 9000 & 10,000 & 12,000 & 14,000 & 15,000 & 18,000 & 24,000 & 50,000 \\
\hline 5.0 & $\$ 128$ & $\$ 160$ & $\$ 192$ & $\$ 224$ & $\$ 256$ & $\$ 288$ &.$\$ 320$ & $\$ 384$ & $\$ 448$ & $\$ 480$ & $\$ 576$ & $\$ 768$ & $\$ 900$ \\
\hline 5.5 & 116 & 145 & 175 & 204 & 233 & 262 & 291 & 349 & 440 & 436 & 524 & 698 & 873 \\
\hline 6.0 & 107 & 133 & 160 & 187 & 213 & 240 & 267 & 320 & 373 & 400 & 480 & 640 & 800 \\
\hline 0.5 & 98 & 123 & 148 & 172 & 197 & 222 & 246 & 295 & 345 & 369 & 443 & 591 & 738 \\
\hline 7.0 & 91 & 114 & 137 & 160 & 183 & 206 & 229 & 274 & 320 & 343 & 411 & 549 & 086 \\
\hline 7.5 & 85 & 107 & 128 & 149 & 171 & 192 & 213 & 256 & 299 & 320 & 384 & 512 & 640 \\
\hline 8.0 & 80 & 100 & 120 & 140 & 160 & 180 & 200 & 240 & 280 & 300 & 360 & 420 & 000 \\
\hline 8.5 & & 94 & 113 & 132 & 151 & 169 & 188 & 226 & 264 & 282 & 330 & 452 & 505 \\
\hline 9.0 & & 89 & 107 & 124 & 142 & 160 & 178 & 213 & 249 & 267 & 320 & 427 & 533 \\
\hline 9.5 & & 84 & 101 & 118 & 135 & 152 & $\cdot 168$ & 202 & 236 & 253 & 303 & 404 & 505 \\
\hline 10.0 & & & 96 & 112 & 128 & 144 & 160 & 192 & 224 & 240 & 288 & 384 & +80 \\
\hline 10.5 & & & & 107 & 122 & 137 & 152 & 183 & 213 & 229 & 274 & 366 & 457 \\
\hline 11.0 & & & & & 116 & 131 & 145 & 175 & 204 & 218 & 262 & 349 & 436 \\
\hline 11.5 & & & & & & 125 & 139 & 167 & 195 & 209 & 250 & 334 & 417 \\
\hline 12.0 & & & & & & & 133 & 160 & 187 & 200 & 240 & 320 & 400 \\
\hline $\begin{array}{l}\text { +The } \\
\text { Ene }\end{array}$ & 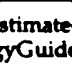 & & & & & & Trad & $\mathrm{mmi}$ & & & - Based & Ion $8 \&$ per & kwh. \\
\hline
\end{tabular}

Source: Florida Power \& Light Co. (FPL) Consumers Guide to Energy Efficient Room Air Conditioners. MEC8404/20M 


\section{ENERGY USE AUDIT FORM}

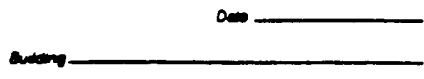

Enenor vat aUor

Grow Anue tow ene Energ conumason

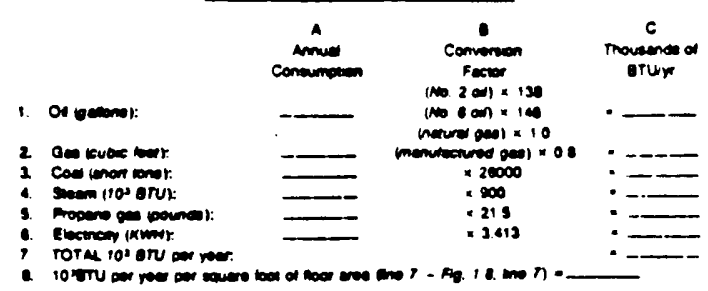

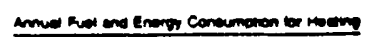

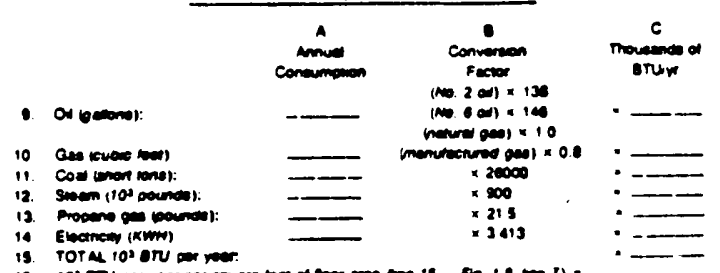

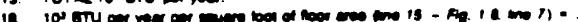

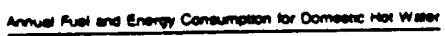
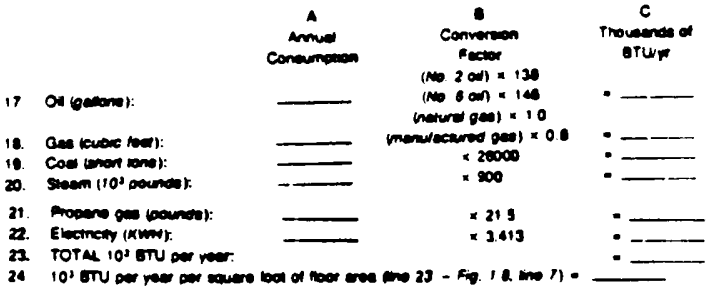

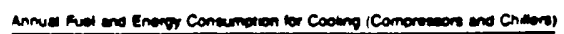

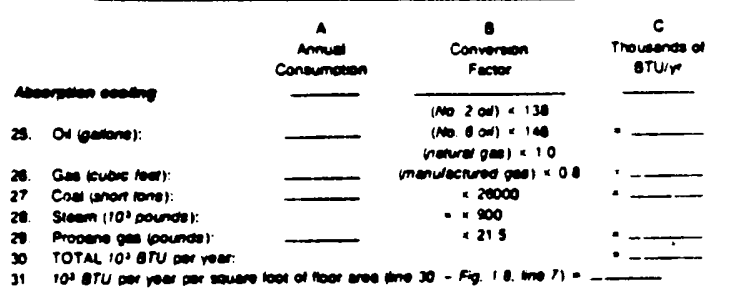

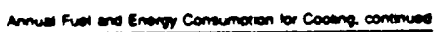

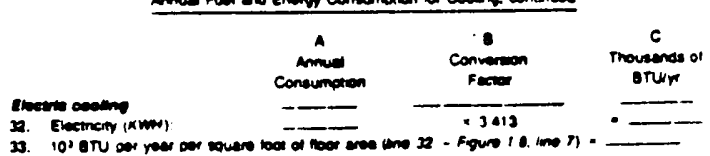

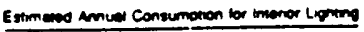

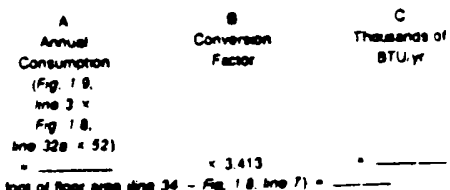

34. Electinen (KWW)

Q 3.413

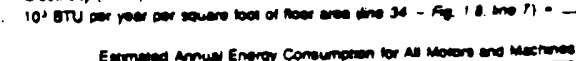

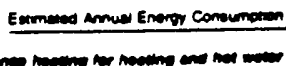

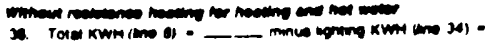

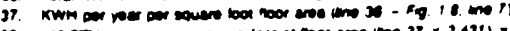

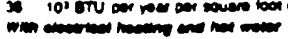

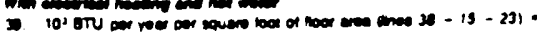


APPENDIX E

UTILITY RATE SHEETS

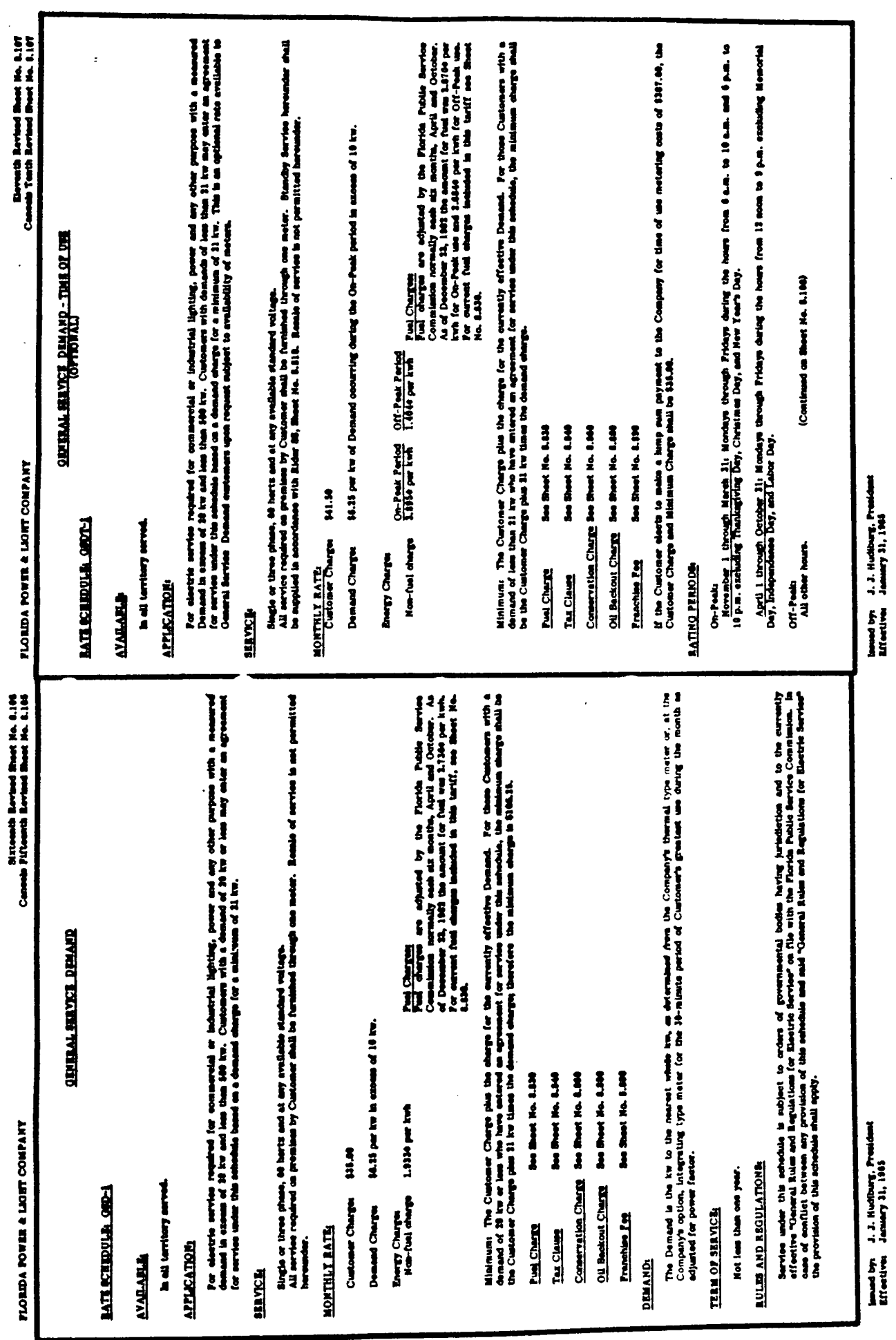

Source: FPL Electric Tariff 
INSULATING MATERIALS AND THEIR R-FACTORS

\begin{tabular}{|l|l|l|}
\hline \multicolumn{1}{|c|}{ Material } & $\begin{array}{c}\text { Inches } \\
\text { of Thickness }\end{array}$ & $\begin{array}{c}\text { Insulating } \\
\text { Values }\end{array}$ \\
\hline Fiberglass Blown & 1 & $\mathrm{R}-2.2$ \\
& 5 & $\mathrm{R}-11$ \\
& 8.75 & $\mathrm{R}-19$ \\
\hline Fiberglass Batts & $2-2.75$ & $\mathrm{R}-7$ \\
& $3-3.5$ & $\mathrm{R}-11$ \\
& $5.25-6.5$ & $\mathrm{R}-19$ \\
& $6.5-7$ & $\mathrm{R}-22$ \\
\hline Expanded Polyurethane & 1 & $\mathrm{R}-6.25$ \\
\hline Expanded Urethane & 1 & $\mathrm{R}-5.88$ \\
\hline Expanded Polystyrene, extended & 1 & $\mathrm{R}-5$ \\
\hline Cellulose Blown & 1 & $\mathrm{R}-3.7$ \\
\hline Sheathing, regular density & 1 & $\mathrm{R}-2.64$ \\
\hline Vermiculite, expanded & 1 & $\mathrm{R}-2.13$ \\
\hline Particleboard, medium density & 1 & $\mathrm{R}-1.06$ \\
\hline Rock Wool & 1 & $\mathrm{R}-2.9$ \\
\hline
\end{tabular}

Source: (FPL 1983b) 


\section{HNTRODUCTION}

This energy survey for

was conducted as part of Florida Power \& Light Company's continuing effort to improve the energy utilization efficiency of our customers' facilities. The survey was conducted on June 16, 1983 by Jorge C. Cano and Richard Crowson of Florida Power \& Light Company with the assistance of. and Manager.

The purpose of an energy survey is to provide a preliminary evalustion of a facility's energy usage and to recommend, where applicable, tuning, operational, and maintenance procedures that will reduce energy consumption.

Preliminary energy surveys point out areas of waste and inefficient operation of current systems and identify areas for improvement. Recommendations can be in the categories of: (1) no cost/low cost items; (2) medium cost items; and (3) high cost or capital intensive items. Although a preliminary eneroy survey deals mostly with those items in the "no cost/low cost" category, items for the remaining categories where potential exists for energy savings are also identified but with recommendations that a professional engineering or contracting firm be acquired for further detailed analysis and design.

The efficiency of energy use is determined by three basic systems which comprise any functioning building. These are: (1) energized systems, such as those required for heating, cooling, lighting, ventilation, and equipment; (2) nonenergized systems, such as floors, ceilings, walls, roofs, windows: and (3) human systems, which includes not only building owners, managers, and maintenance personnel, but all occupants as well.

Each of these "systems" can be modified to achieve significant savings in energy. Effective energy management requires that the entire pattern of energy consumption be analyzed so that changes made will be integrated into each system in full light of the inter-relationships which exist and the various effects which will occur.

Source: FPL Marketing and Energy

Conservation Department

Miami, Florida 
Enclosed is a package which contains general recommendations for saving energy in your facility. These general recommendations, where applicable, should be implemented in addition to the specific recommendations made in this report. Attachment No. 1 summarizes our recommendations, their cost, $K W H$ savings, dollar savings, and simple payback. 


\section{II-UTILITY DATA}

An effective tool to measure the relative efficiency of a building or facility is the Energy Utilization Index (EUI) which is obtained by dividing the annual energy consumption in BTU's by the conditioned floor area.

For this facility:

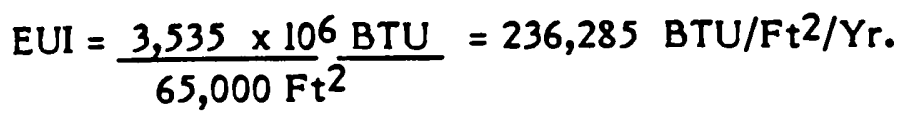

The above calculated energy index for your facility is based on an approximation of total conditioned space and energy consumption for the entire facility. The calculated index compares favorably to those found for similar facilities in the Miami area. Nevertheless, implementation of the recommendations summarized in Attachment No. 1 of this report should help to reduce the EUI to $200,480 \mathrm{BTU} / \mathrm{Ft}^{2} /$ Year, which represents an $18 \%$ reduction in annual energy consumption. In terms of demand (KW) and consumption (KWH), it means that the combined demand could be lowered from its present average of 177 $\mathrm{KW}$ to $145 \mathrm{KW}$, and consumption lowered from its present average of $1,035,840$ $\mathrm{KWH} /$ Year to $851,630 \mathrm{KWH} /$ Year.

Attachments 3, 4, and 5 represent the energy usage pattern over the past 24 months. Attachment No. 3 provides information on billing amount per month, kilowatt hour (KWH) usage per month, number of days in the billing cycle and kilowatt demand (KWD) per month. An extra column was calculated to provide average $K W H$ usage per day. This is to eliminate the effects of varying billing periods. Other calculations include total annual $K W H$ usage, average $K W H$ per month, average KWD for each 12 month period, and the current costs per KWH/KWD. 
Attachments 4 and 5 are graphical representations of the energy usage pattern over the same period. The data from the billing history page is plotted to provide a pictorial view of the usage trend over a long period. It is suggested that this practice be continued in the future by someone in your establishment. The graphs can be very useful to validate the effects of any energy saving measures implemented.

Energy cost is broken into two areas: KWH and KWD. The kilowatt-hour rate for the building is 5 cents per kilowatt-hour. The cost for each $\mathrm{KW}$ is approximately $\$ 6.90$. This is derived from the basic demand charge of $\$ 6.25$ plus the franchise fee and state sales tax.

The following sections of this report will address the building's various systems and identify energy saving measures which can be justified economically. All calculations are conservative and are representative of the most recent billing. 


\section{III - FINDINGS \& RECOMMENDATIONS}

\section{A. Facility Description:}

is an independent supermarket that has served area residents for the past six years. The store is located in a 20 -year old structure that previously housed other chain food stores.

Over 70 percent of the 10,450 square foot store, including the butcher shop and the delicatessen, is air-conditioned. The rest of the building area is used for receiving and storage of goods, packaging of produce, and freezer space. A small second floor area in the rear contains the bookkeeping offices, restrooms, and compressor room.

The store is open for business from 8:00 a.m. to 9:00 p.m., Monday through Saturday, and from 8:00 a.m. to 7:00 p.m. on Sundays. Store personnel start to arrive at 7:00 a.m. and leave by 10:00 p.m. Custodial service is performed twice weekly within working hours.

\section{B. Building Envelope:}

is housed in a one-story building of standard CBS construction. The building shares a common west wall with an adjacent drugstore that is part of a strip shopping center. The front face of the building has a southern exposure with over $70 \%$ glass area. A 10-foot overhang provides shading to the plate glass windows on this side. The remaining walls are windowless.

Of prime concern in improving a building envelope's energy efficiency in South Florida is the prevention of heat transmission through the building's structure.

The effects of heat transmission can be lessened by methods ranging from the installation of insulation, window film, or a roof spray system, to the simple closing 
of a door or window. The criteria for determining the economical feasibility for the implementation of some of these methods will mostly depend on the building's operating hours and the efficiency of its air conditioning systems.

The building's roof consists of tar and gravel over standard roofing felts, 2" of poured gypsum, and particle board. The roof is supported by a framework of steel I-beams and bar trusses. The supports are exposed over the storage areas and are covered by a plaster ceiling over the main store area.

The ability of a material to resist the flow of heat is known as the R-value, or thermal resistance. The higher that value is, the higher is that material's insulating ability. The building's roof R-value was found to be a low R-5. By comparison, FP\&L recommends a value of $R-19$ for roofs. Calculations showed that it would be more cost-effective to reduce the roof's heat transmission by using a roof spray system than by installing insulation to make up the difference to reach an $\mathrm{R}-19$ level.

By sequentially spraying a fine mist of water on the roof's surface, a roof spray system reduces roof temperatures that may normally reach as high as $150^{\circ} \mathrm{F}$ on the hottest days. The high temperatures contribute to the deterioration of the roofing materials and are also transferred through conduction to the building's interior. Using this system as an evaporative cooling process, approximately 1,000 BTU's of heat are absorbed from the roof's surface for every pound of sprayed water that is evaporated. This prevents roof temperatures from going above $90^{\circ} \mathrm{F}$ and thus extends roof life. This measure should achieve a reduction in consumption of $36,320 \mathrm{KWH}$ per year for annual savings of $\$ 1,240$. Installed cost should be $\$ 3,135$, for a 2.5 year payback. 
Other low-cost or no-cost recommendations are maintaining outside door weatherstripping in good condition and keeping doors to conditioned spaces closed.

\section{Recommendations:}

1. Install reflective window film.

2. Install roof spray system.

3. Maintain weatherstripping in good condition.

4. Keep doors to conditioned spaces closed.

\section{Heating, Ventilation and Air Conditioning:}

The main store area was originally conditioned by three air-cooled package units mounted on the roof. Presently, only two of the three rooftop units, AC-1 and $\mathrm{AC}-2$, have working compressors. AC-3's compressors have been burned-out for nearly two years. Their individual capacities and efficiency ratings are as follows:

AC-1 (East Wing) 17.1 ton

AC-2 (Center Unit) 15.5 ton

AC-3 (West Unit) 10 ton
Model, EER - 6.7, one compressor.

Model, EER - 8.5, two compressors.

Model, EER 6.7, two compressors.

The Energy Efficiency Ratio (EER) and equipment condition are usually the main criteria used in recommending a unit's replacement with a higher efficiency model. The EER is a ratio calculated by dividing the unit's cooling capacity in BTUH by its power input in watts at any given set of rating conditions. Expressed in BTUH/watt, the higher the EER value, the less the energy consumed by the unit. For energy efficiency, FP\&L recommends a minimum EER value of 8.5 .

Unit AC-1 serves the front entrance area of the store. Due to the constant opening of the door and the lack of open refrigeration cases in that vicinity, there is more heat gain in this east area of the building than in any other. 
Considering these facts and the unit's low efficiency, it is recommended that AC-1 be replaced on an "as fail" basis with a high efficiency unit similar to the recently installed AC-2, which has an EER of 8.5. This measure should achieve reductions of $8 \mathrm{KW}$ in demand and $40,320 \mathrm{KWH}$ per year in consumption, for annual savings of $\$ 2,715$. Differential cost for this item should be $\$ 2,300$, for a 10 -month payback.

It was noticed that the condenser and supply fans for unit AC-3 were operating. Since this unit's compressors are inoperative, it is recommended that the condenser fans be kept turned off, and if the supply fans are not needed for circulation, that they also be turned off. This should result in reductions of $5.0 \mathrm{KW}$ in demand and $25,200 \mathrm{KWH}$ per year in consumption. Yearly savings for this nocost measure should be $\$ 1,700$.

Each of the $A / C$ units is operated by a thermostat which is located in the vicinity of the return air intake. Thermostat settings for AC-1 and AC-2 were found to be $72^{\circ} \mathrm{F}$ and $70^{\circ} \mathrm{F}$, respectively.

The A/C units are left on during the night to help keep certain products fresh. This also helps the efficiency of the open refrigeration cases which were designed to operate in a cool environment.

The temperature in the store was found to average $70^{\circ} \mathrm{F}$. This value is lower than the $78^{\circ} \mathrm{F}$ temperature normally recommended by FP\&L for energy efficiency. However, considering the nature of the facility, it is recommended that the temperature be raised to only $74^{\circ} \mathrm{F}$. This measure should still maintain the store's comfortable environment while reducing cooling energy requirement by $12 \%$. Savings from this no-cost recommendation should be $27,220 \mathrm{KWH}$ per year, or $\$ 1,390$ per year. 
You should also consider making a provision to stagger, or duty-cycle, the operation of the three rooftop compressors serving the $A C-1$ and $A C-2$ units. Without this feature, the random operation of the units could often result in all of the compressors operating at once. This would maximize peak demand and peak electrical demand charges.

Typically, to meet design cooling demand, an A/C compressor only operates about $60 \%$ of the time. Consequently, with several compressors, it is possible to stagger their relative start/stop cycles. This can achieve a combination of compressors that will operate at a lower kilowatt (KW) demand than if they were operating randomly. Using a timing control device, this scheme could achieve savings in demand without reducing the actual operating time of the compressors.

If compressor operating times permit it, then it is recommended that a fourchannel timing controller be installed. The fourth channel would be available if you decide to replace the single-compressor AC-1 for a more efficient twocompressor unit. This measure could achieve a reduction in demand of $10.7 \mathrm{KW}$ for yearly savings of $\$ 880$. Installed cost for this item would be approximately $\$ 1,600$, for a 1.8 year payback period. Figure 1 , on the following page, illustrates a recommended duty cycling scheme for the existing compressors.

Two wall $A / C$ units serve Mr. office and the bookkeeping office. Their filters were found to be dirty and should be washed to reduce the units' loads. Finally, it is important that miscellaneous maintenance checks and filter replacements be maintained on a periodic basis. It has often been shown that even the most modern facilities can have extensive inefficiencies from faulty equipment maintenance or operation. 


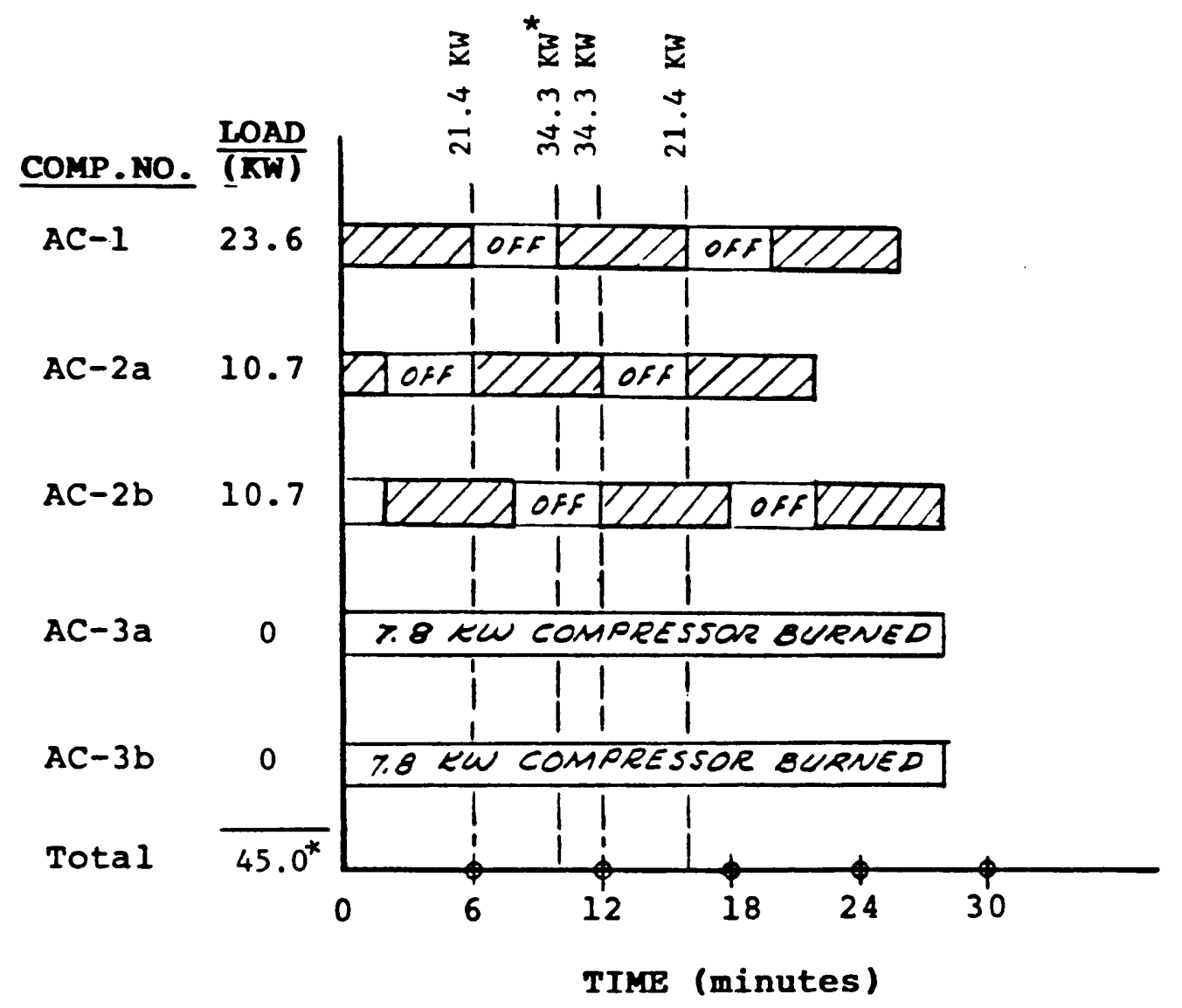

EYZJ = compressor "on" time

PIGURE NO. 1

HIGHEST POSSIBLE DEMAND WITHOUT

TIMING CONTROLLER $\ldots \ldots \ldots \ldots \ldots \ldots \ldots .45 .0 \mathrm{~kW}$ (3 comp on) HIGHEST DEMAND CONDITION USING

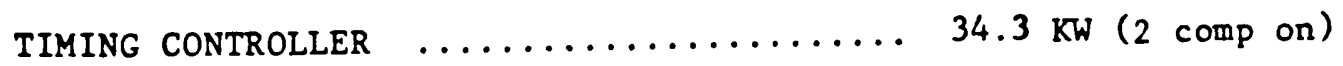

DEMAND SAVINGS USING CONTROLLER $\ldots \ldots \ldots 10.7 \mathrm{KW}$

NOTE: Compressor operating time assumed to be $60 \%$. 


\section{Recommendations:}

1. Replace AC-1 units with high efficiency models

2. Turn off AC-3 fans.

4. Consider installing a four-channel timing controller.

5. Maintain periodic equipment maintenance and filter replacement. 


\section{Lighting:}

The building's lighting systems consist of mostly fluorescent with some incandescent and high intensity discharge lamps. The recorded lighting levels in most areas were comparable to the levels recommended by the Illuminating Engineering Society (IES).

Good energy saving opportunities exist in the lighting system. The savings can be realized by turning off unnecessary lighting systems, using lights only on an "as needed" basis, removing lamps and disconnecting ballasts where lighting exceeds necessity, and relamping with high efficiency, lower wattage lamps.

When replacing standard fluorescent lamps with the high efficiency types, the compatibility of the existing ballasts and the new lamps should be verified to prevent premature ballast burn-out. When replacing ballasts that have failed, high efficiency type replacement ballasts should be installed.

Florida Power \& Light Company is presently sponsoring a Lighting Incentive Program which could be particularly helpful to When you complete all recommended group relamping of fluorescent F40 and F96 lamps with the suggested energy efficient lamps, you will be eligible to receive $\$ 1.00$ and $\$ 1.50$ per lamp, respectively, subject to all rules of the program.

It is recommended that all 40-watt fluorescent lamps be replaced with 34watt lamps. Implementation of this measure should result in savings of $0.6 \mathrm{KWD}$ and 3,047 KWH per year, worth $\$ 201$ per year. After the lighting incentive is paid, the remaining $\$ 137$ investment would result in a nine month payback. 
Approximately $25 \%$ of all 75 -watt fluorescent lamps throughout the store have already been converted to their energy efficient 60-watt replacements. This reflects well on Gardner's energy conservation efforts to this time. Completion of the relamping should reduce demand by 5.1 KWD and decrease yearly consumption by $26,263 \mathrm{KWH}$, worth $\$ 1,738$ per year. The approximate conversion cost of $\$ 1,350$ after the incentive is paid would result in a ten month payback.

There are low-wattage fluorescent screw-in lamps available which can replace existing incandescent bulbs in many locations. Conversion to these lamps in recommended locations would result in a savings of $0.8 \mathrm{KWD}$ and 3,550 KWH per year, worth $\$ 231$ per year. The $\$ 200$ initial investment would reach payback in eleven months.

The six 75-watt incandescent reflector floods located in the Deli container should be changed-out with 50-watt elliptical reflectors (50 ER 30's). This retrofit measure should save $0.1 \mathrm{KWD}$ and $760 \mathrm{KWH}$ per year, worth $\$ 50$ per year. The approximate conversion cost of $\$ 29$ would result in a seven month payback.

In situations where an existing lighting system could be replaced for a more efficient system but the system's operating hours do not make the immediate replacement economically feasible, the replacement will be recommended on an "as fail" basis. This is the case with the existing 400-watt mercury vapor outdoor lights. Upon failure, they should be replaced with the much more efficient 150watt high pressure sodium vapor lights. This would decrease yearly consumption by $3,010 \mathrm{KWH}$ for a savings of $\$ 150$ per year. The approximate $\$ 679$ conversion cost would result in a 4.6 year payback.

Since there are a number of recommendations applicable to the various lighting areas, a table is presented with the suggested energy savings measures (See Attachment 2). 


\section{E. Water Heating:}

Hot water is presently being supplied to the Deli and Meat Processing areas by a single twenty-gallon electric hot water heater. Since the water heater is located in close proximity to refrigeration equipment which operates twenty-four hours per day, this would be an excellent application for a heat recovery system. This type of system works on the principle of heat transfer through convection, using the hot refrigerant from the refrigeration systems to provide all necessary hot water. Installation of a heat recovery system should reduce electric demand by 2 KWD, and decrease annual consumption by $5,260 \mathrm{KWH}$, worth $\$ 430$ per year. The initial cost of approximately $\$ 600$ would reach payback in 1.5 years.

\section{Recommendation:}

1. Install a heat recovery system.

\section{F. Refrigeration Equipment:}

Of all equipment in the store, refrigeration equipment and freezers work more hours than any other systems. Good energy practices in using this equipment can result in substantial savings.

Inspection of freezer door gaskets showed then to fit snugly. This check should be made periodically by placing a sheet of paper between the refrigerator mullion and the door. If the paper is held securely in place by the door gasket, it is considered sealed. If it is not held securely, the door should be adjusted or the gasket replaced.

Walk-in and some reach-in refrigeration equipment use a bank of evaporator coils to pick up heat from inside the refrigerator or freezer. Many of the reach-in units have evaporator coils wrapped around the outside of the interior wall and pick up heat through the walls of the unit.

Some frost was found on some of the ceiling mounted coils inside the meat 
cutting department. Ice or frost collected on the evaporator coils or the walls acts as an insulator for the coils and makes it difficult for the refrigerant to pick up the heat from inside of the refrigerator or freezer. Some units feature automatic defrosting every 24 hours. Others must be defrosted by turning the compressor off periodically. Defrosting should be performed when approximately $K_{\text {-inch }}$ of frost or ice has accumulated on the coils and before circulation of air through the coils is hampered for efficiency operation. It is recommended that your equipment be checked to insure that it is being defrosted only when needed.

Recently, the ice-cream cases have been covered at night to help keep the ice-cream from becoming soft. It is recommended that this energy-saving measure be implemented with all other open top refrigeration cases. Mr. , the store manager, agreed that this measure would not require a substantial amount of time.

Since the walk-in freezers are located in a non-air-conditioned area, care should be taken to not open the doors frequently and to open them only for minimum periods of time. When doors are opened, some cold air escapes from the refrigeration unit and is replaced with warm air. The warm air not only adds heat load but the moisture also increases frosting of the evaporator.

To eliminate frequent opening of doors, all foods that will be needed for packaging or preparation should be removed at the same time when possible and practical. The same applies to placing foods into the units. The foods should be assembled near the door of the refrigeration equipment so that, if possible, the food can be quickly loaded at the same time. The foods should be placed for easy access and quick removal.

It is also good to place refrigerated and frozen foods into the freezers immediately upon arrival from the supplier. If frozen or refrigerated foods are allowed to remain in the receiving area for a period of time, the food will absorb heat and require more energy to cool down to the desired holding 
temperature, as well as increase the possibility of possible spoilage or loss of flavor.

Condenser coils attract dust and lint. Anything that reduces air circulation through the condenser reduces the efficiency of the unit and is wasteful of energy. Fan blades that are dusty are also less efficient in delivering air through the coils. The most effective tool to remove dust is a vacuum cleaner, but a brush or air hose also can be used.

Equipment always works better and more efficiently when kept in good repair. This includes keeping drive belts properly adjusted and replacing the belts when worn. If a unit runs excessively and fails to cool the inside of the refrigerator or freezer to the desired temperature, you should call your service man.

\section{Recommendations:}

1. Maintain freezer door gaskets in good condition.

2. Insure that equipment defrost cycles be performed only when needed.

3. Cover open-top refrigerated cases at night.

4. Limit open time of freezer doors.

5. Store frozen foods immediately upon arrival.

6. Continue periodic maintenance checks of equipment.

\section{G. Miscellaneous:}

The operation of two pieces of equipment located in the Deli are presently being evaluated for cost effectiveness by ner management.

The Barbeque-King revolving oven presently costs approximately $\$ 1.75$ per hour to operate, while the Barbeque-King display case averages approximately $\$ 1.15$ in hourly operation costs at present electrical rates.

Energy efficient units should be considered in any future equipment replacements. 


\section{ATTACHMENT NO. 1}

The following table summarizes the specific recommendations made in this report. It should be noted that simple paybacks shown herein will be reduced as the cost of energy continues to increase.

\begin{tabular}{|c|c|c|c|c|c|}
\hline RECOMMENDATIONS & $\begin{array}{l}\text { FIRST } \\
\text { COSTS }\end{array}$ & KWH/YR & $\begin{array}{l}\text { AVINGS- } \\
\text { KWD/MO }\end{array}$ & $\$ / Y R$ & $\begin{array}{l}\text { PAYBACK } \\
\text { PERIOD }\end{array}$ \\
\hline $\begin{array}{l}\text { Install reflective window } \\
\text { film }\end{array}$ & 1,400 & 6,550 & $\cdots$ & 335 & 4.2 years \\
\hline Install roof spray system & 3,135 & 36,320 & --- & 1,240 & 2.5 years \\
\hline $\begin{array}{l}\text { Replace AC-1 unit with a } \\
\text { high efficiency model }\end{array}$ & 2,300 & 40,320 & 8.0 & 2,715 & 10 months \\
\hline Turn off $A C-3$ fans & $\cdots$ & 25,200 & 5.0 & 1,700 & Immediate \\
\hline $\begin{array}{l}\text { Raise temperature to } \\
74^{\circ} \mathrm{F}\end{array}$ & $\cdots$ & 33,930 & $-\cdots$ & 1,730 & Immediate \\
\hline $\begin{array}{l}\text { Install a four-channel } \\
\text { timing controller }\end{array}$ & 1,600 & --- & 10.7 & 880 & 1.8 years \\
\hline $\begin{array}{l}\text { Lighting recommendations } \\
\text { (See Attachment No. 2) }\end{array}$ & 2,395 & 36,630 & 6.6 & 2,370 & 1.2 years \\
\hline Install a heat recovery system & 600 & 5,260 & 2.0 & 430 & 1.5 years \\
\hline & TOTALS & 184,210 & 32.3 & 11,400 & \\
\hline
\end{tabular}




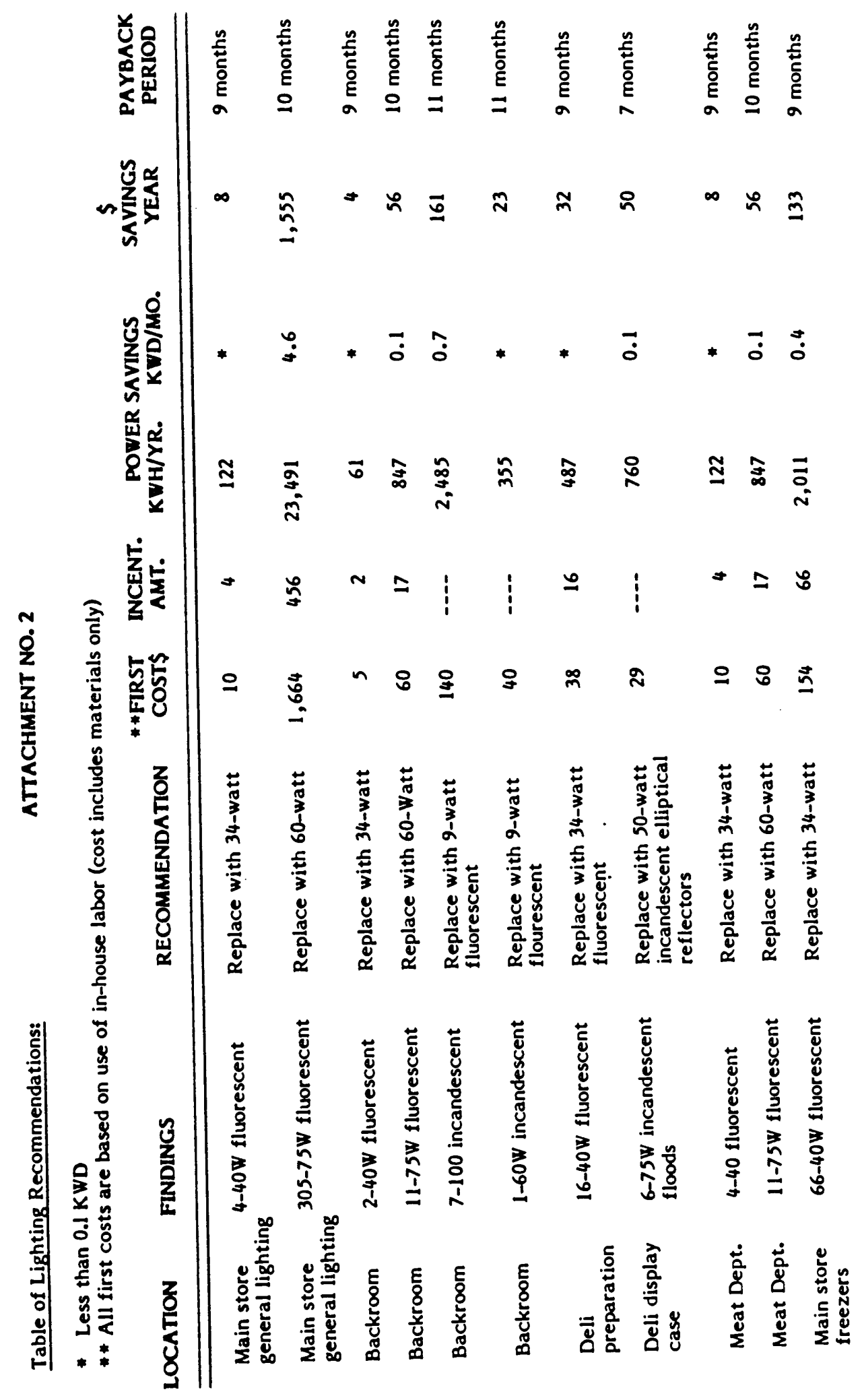




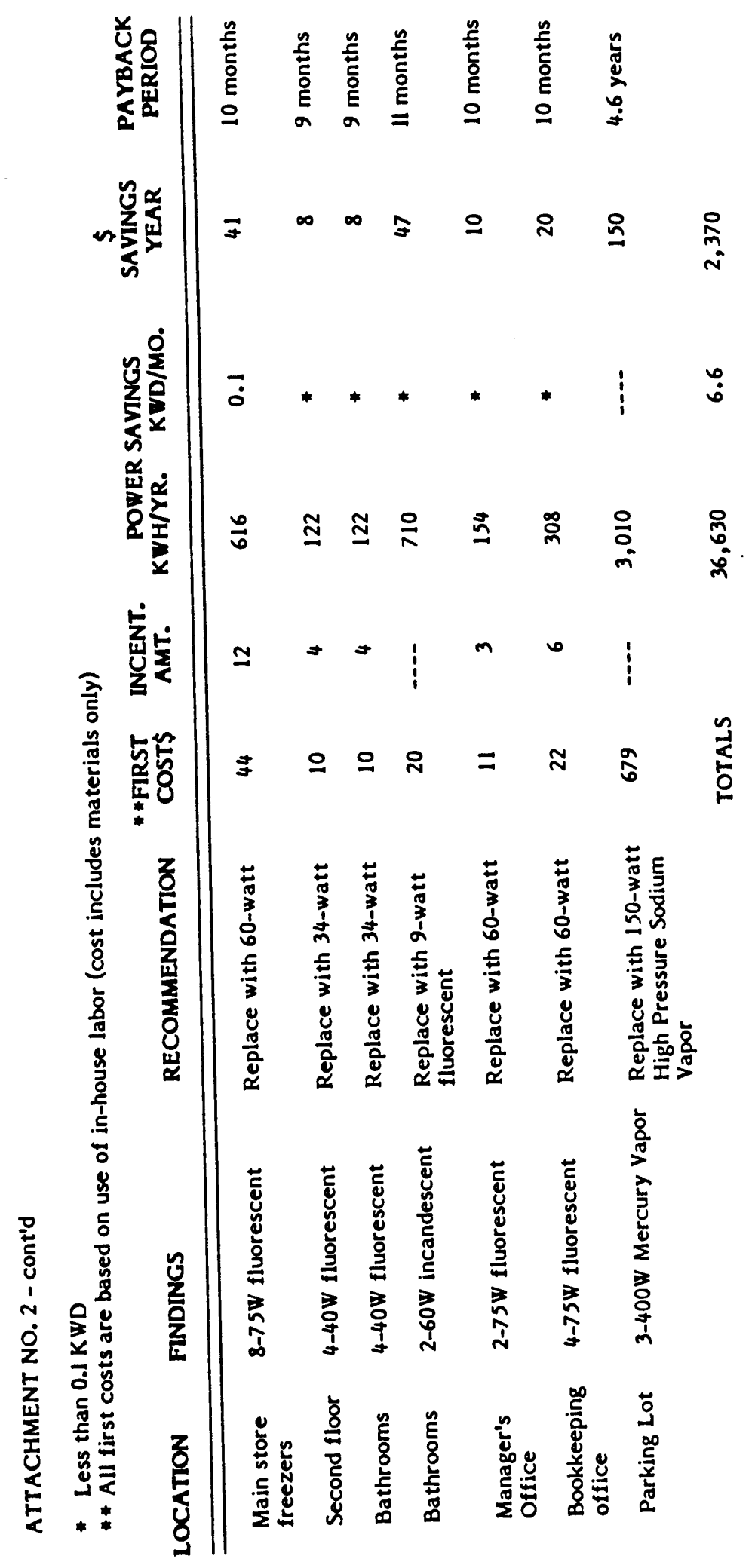


ATTACHMENT NO. 3

ACCT MO-

SER ADD-

STD PO - LOCAL

STATUS- HI ACTIVE

GX

ORIG CONR --

REV/RATE- 21721 CSD-1

CIS ACTI-- MONE PENDING

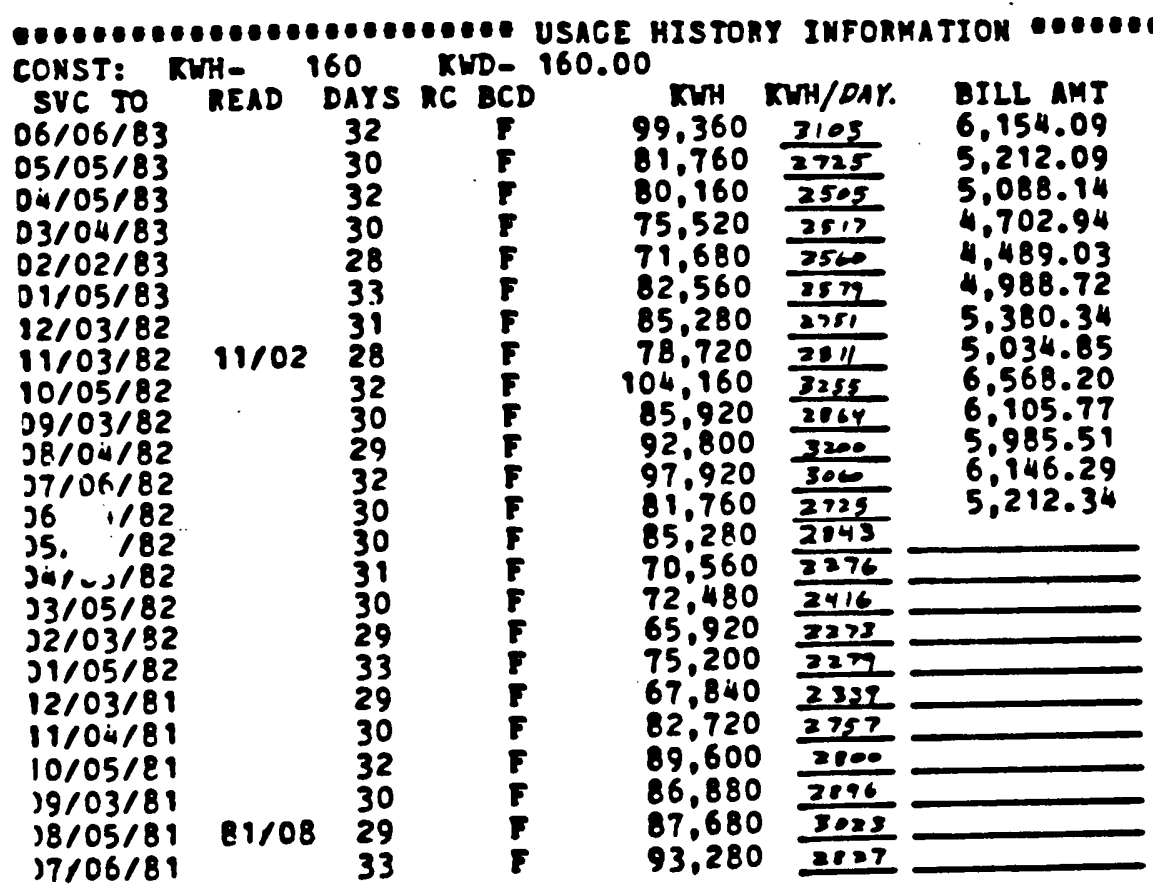

PG 3

CONST:

SVC 10

ST

FL 33165

154.09

5.212 .09

4.702 .94

4.489 .03

.988 .72

5.380 .34

0.568 .05

8.105 .77

5.985 .51

6.146 .29

IXWD

A/KWD

176 176

$166 \quad 166$

160160

$154 \quad 154$

$150 \quad 150$

$147 \quad 147$

160160

160160

192192

$272 \quad 272$

$192 \quad 102$

192192

$176 \quad 176$

$160^{--} 160$

$157 \quad 157$

$154 \quad 154$

$147 \quad 147$

$160 \quad 160$

160. 160

$179 \quad 179$

$166 \quad 166$

$176 \quad 176$

$176 \quad 176$

$176 \quad 176$

TOTALS: $1,035,840 \mathrm{KWH} /$ Year 86,320 Avg. $\mathrm{KWH} /$ Month 177 Avg. KWD/Month 

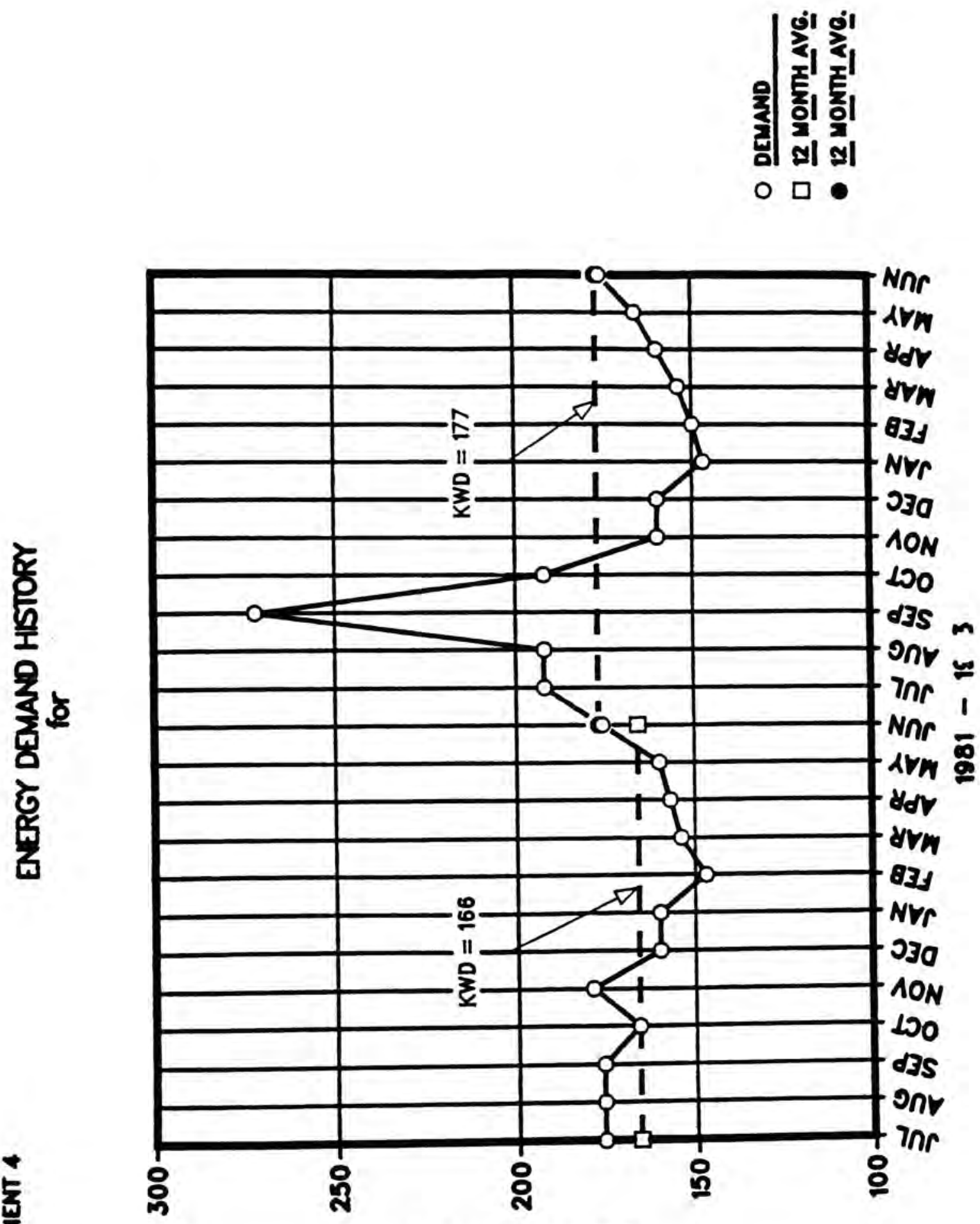

aNYWBO XVZd 

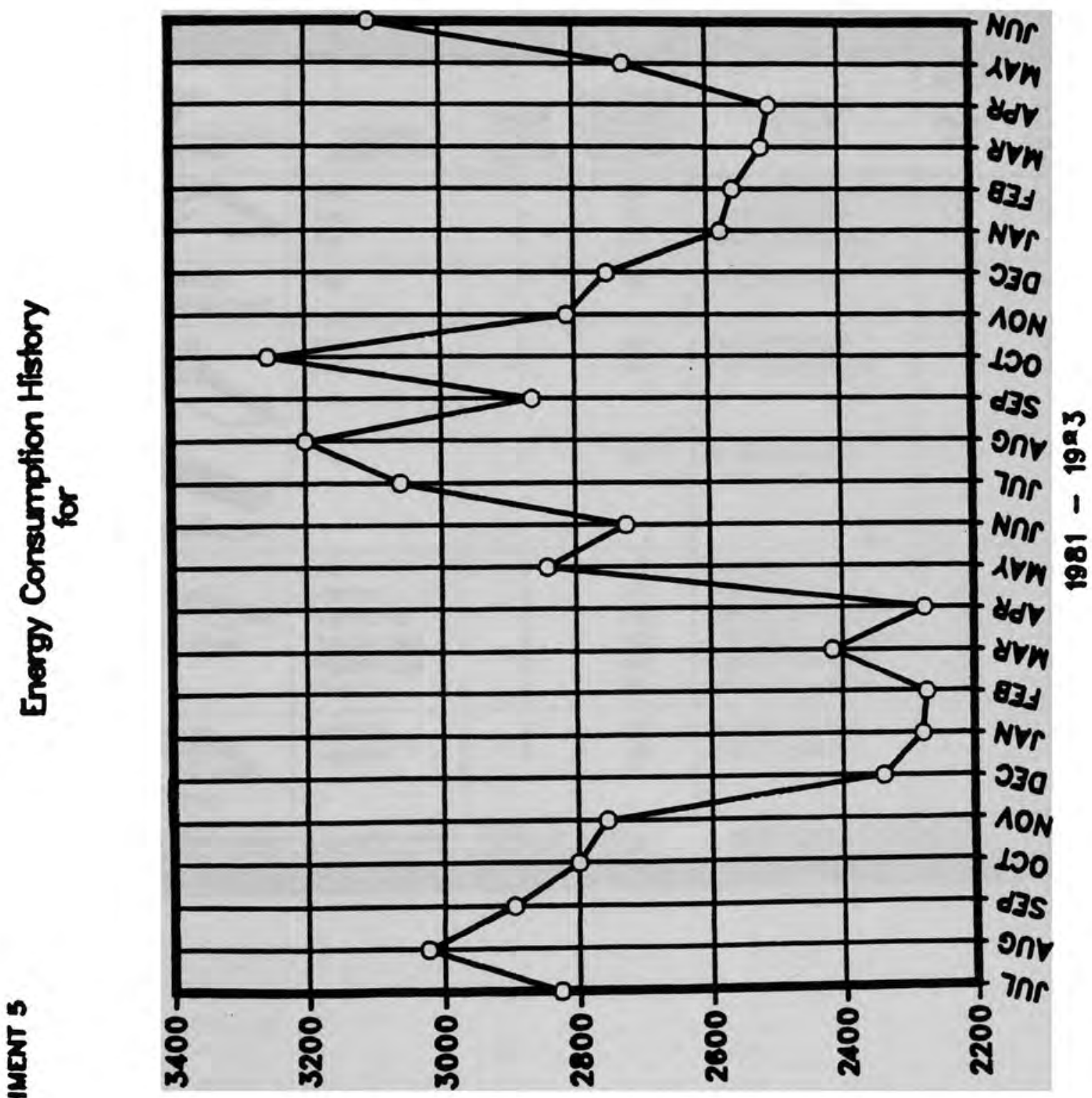

HINOW/HMY RIVO 3OVY3AY 


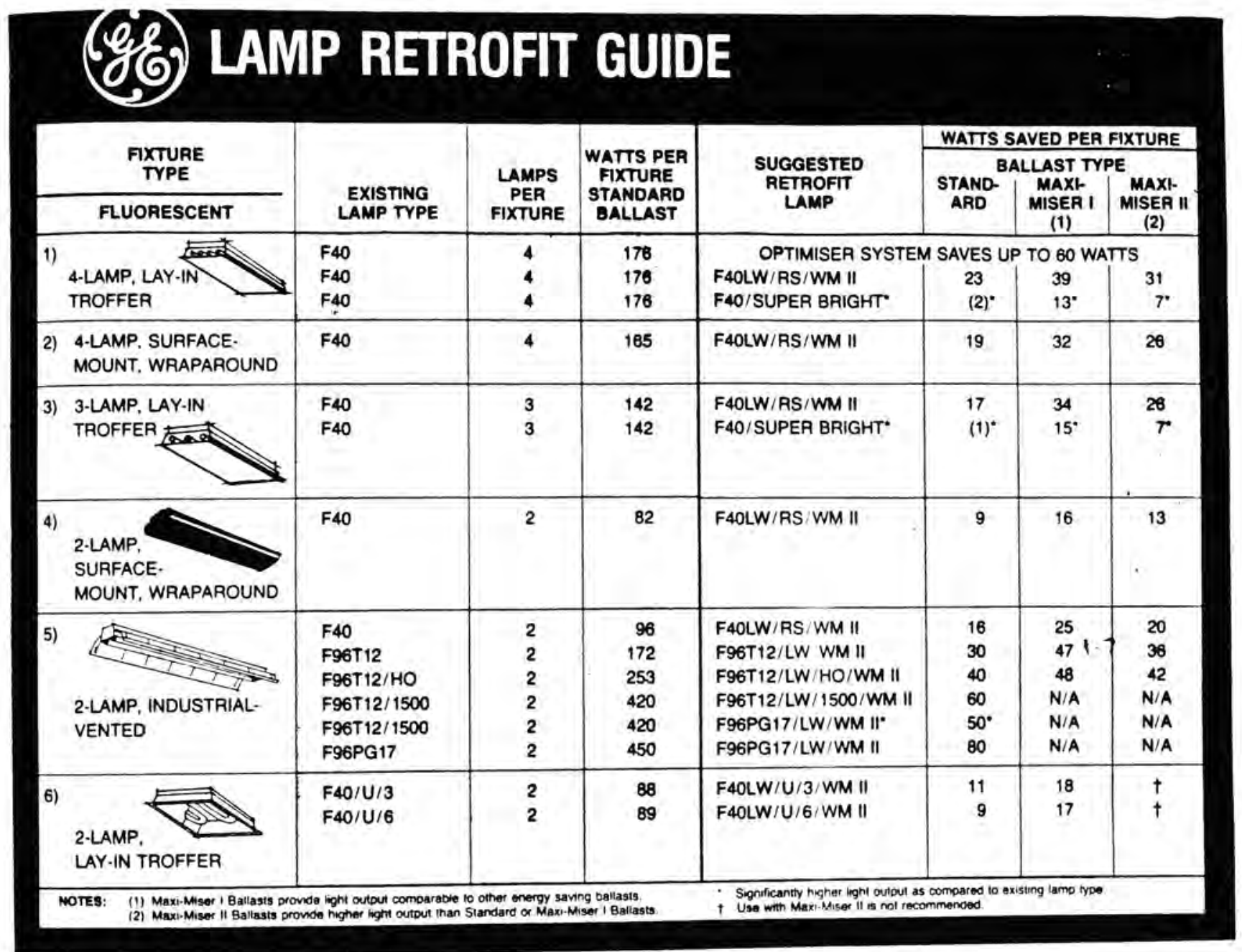

Source: General Electric Co. 


\section{Look for both:}

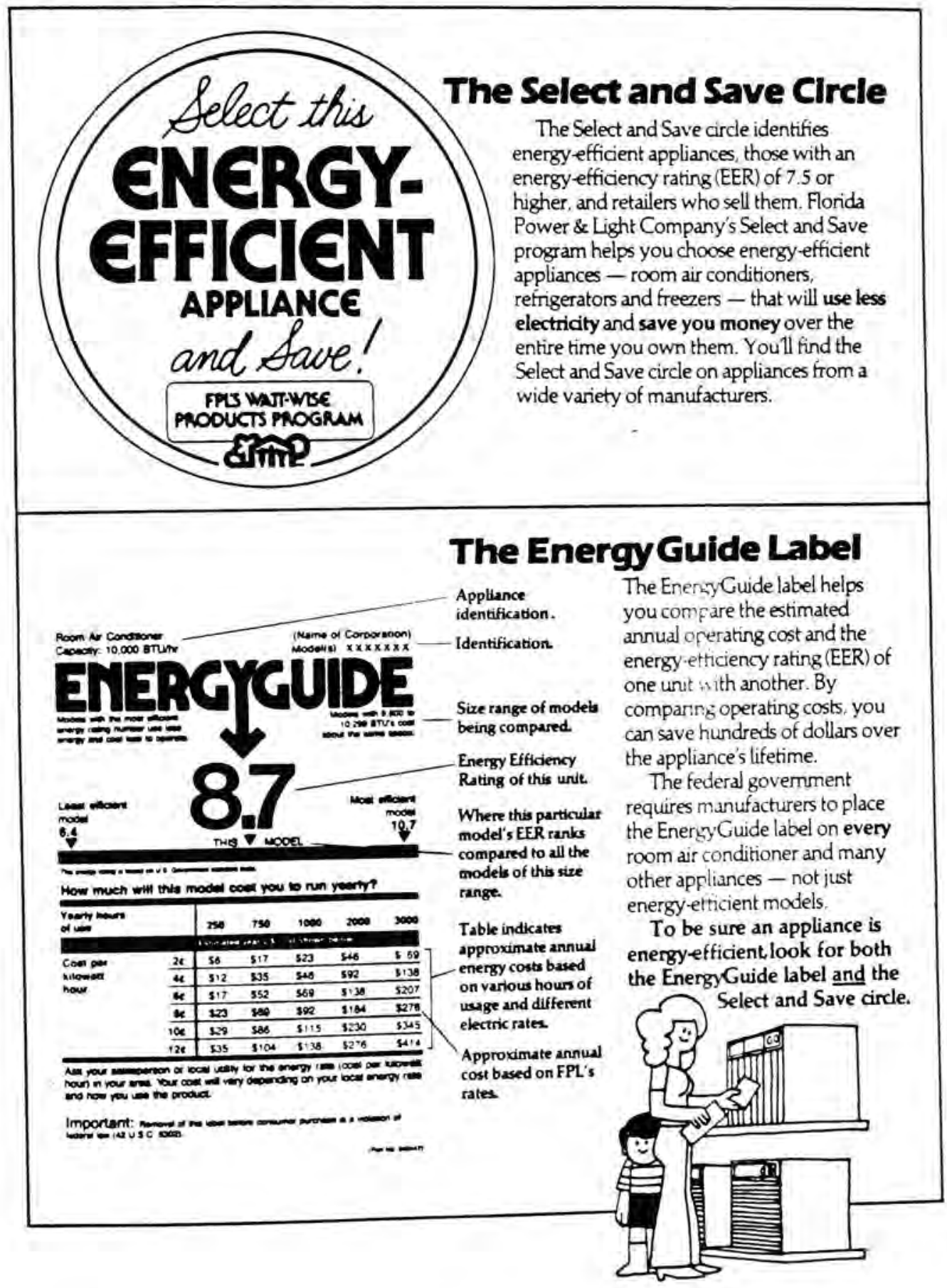

Source: FPL pub. no. MEC8404/20M 


\section{RESIDENTIAL WEATHERIZATION}

There's no need to wait any longer to start saving enerdy dollars! One easy, toll-free phone call to FPL will save you time and guesswork about how to get started on energy-saving home maintenance and minor repairs.

Many homes waste energy dollars every day through small inefficiencies that add up... including air spaces around windows and doors... gaps in air conditioning ducts... faucets and showerheads that use more hot water than really necessary.... water heater tanks and pipes that lose heat to the air.

Eliminating this waste can help chalk up comfortable savings for you. FPL's new home energy loss prevention packageH.E.L.P. - shows you where your home wastes energy - prepares a customized work order for your approval....arranges for a qualified contractor to come to your home and do the work. And, best of all. FPL pays half the cost. up to $\$ 75$.

You'll feel confident knowing that H.E.L.P. contractors are professional. independent business people-qualified. licensed and insured. These contractors guarantee their work - in writingfor one year.

Want some household

H.E.L.P.? It's easy.

Simply dial FPL's toll-free Watt-Wise Line' and ask to have a marketing service representative conduct a H.E.L.P. energy survey of your home, at no charge.

Our representative will examine eight specific areas for H.E.L.P.: caulking. weatherstripping, shower. heads, water heater/ pipe insulation, air conditioning ducts. wall outlets, glass areas and jalousie windows.

Then the representative will prepare a work order for the H.E.L.P. your home needs, including a cost. estimate. FPL will pay onehalf that cost, up to $\$ 75$. For example, if the total were $\$ 90$. FPL would pay $\$ 45$. and you pay the other $\$ 45$.

When you approve the work order. FPL will submit it to a qualified H.E.L.P. contractor, who will contact you to arrange a convenient time to do the work.

When the work is complete, simply pay the contractor your portion of the cost, and receive your written, one-year warranty. For double protection. an FPL representative will visit to verify the work. If anything is amiss, the contractor will make corrections at no extra charge to you!

Don't wait another daycall FPL to get your house started on the H.E.L.P. it needs. If your home has been surveyed in the past. please let us visit you again. Call today!

223-WATT Dade 463-WATT Broward or $1-800-432-6563$

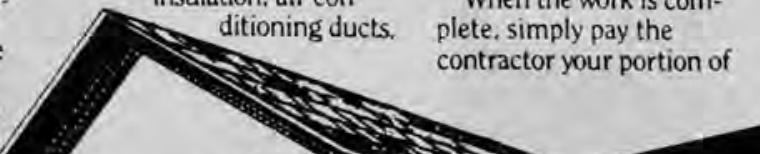




\section{South Florida Design \#2}

\section{Order Plan SF2}

Nostalgic for the Islands? You'll feel right at home with this Polynesian-inspired design. Architectural features include three distinct floor levels, a large wrap-around lanai plus an open-air, second-level deck. Breakfast in style on the lanai off the third-level master bedroom. This design faces south and provides access to a street on the south. For large lots. you also can access a street on the west.

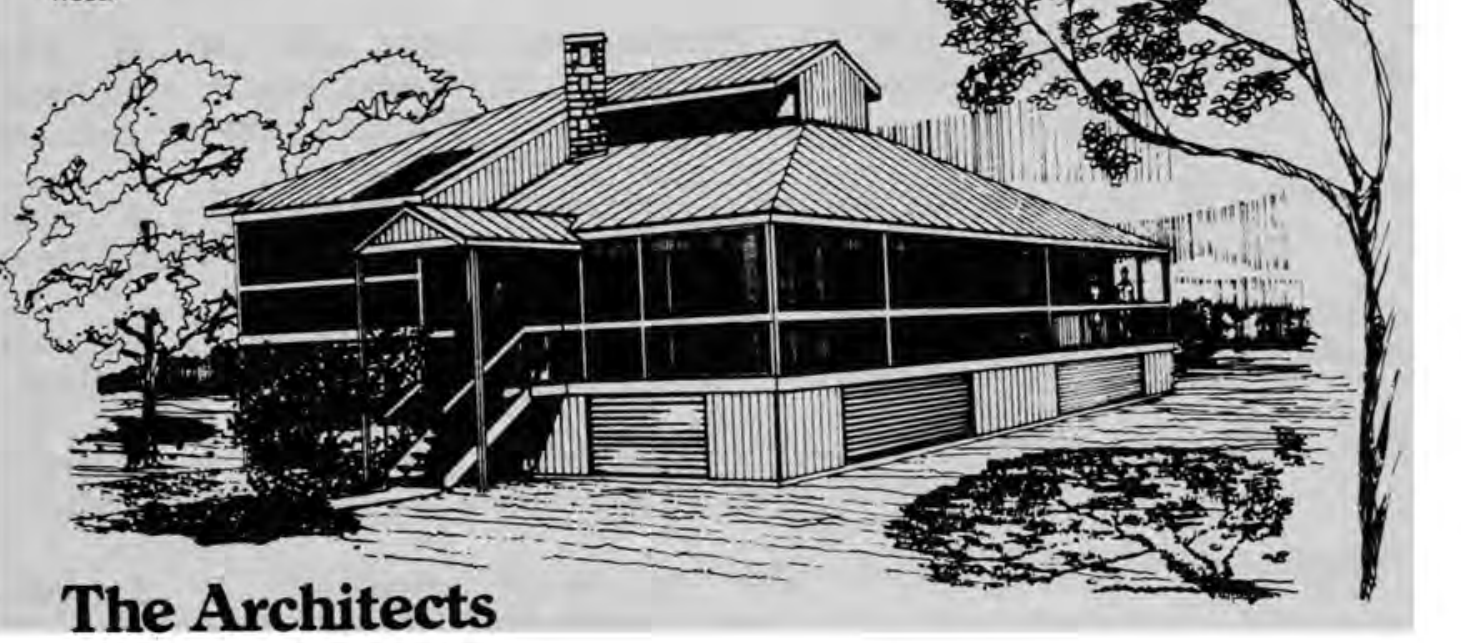

Source: FPL pub. no. $8308-793 / 5 M$ 


\section{LIST OF REFERENCES}

Aadland, D. RCS residential energy auditor training manual. Richfield, Minn. Aadland, Hoffman, Pieri Energy Assoc., Inc.; 1980. 502p.

American Council for an Energy Efficient Economy (ACE). The most energy efficient appliances. Washington, D.C.; 1984 Spring.

Association of Home Appliance Manufacturers (AHAM). Facts on major home appliance energy consumption and efficiency trends. Chicago, Illinois; 1985.

Anderson, J. The state energy conservation program - an overview. Proceedings - state energy audit impact conference; 1979 March 5-7; Dallas, Texas. 5p. [Section]1.

Association of Home Appliance Manufacturers (AHAM). Home appliances and energy conservation - a presentation to the Florida Public Services Commission. Tallahassee, Fla.; 1985. 9p.

Bailey, M. G. Residential energy auditors: data gatherers or motivators? Proceedings - state energy audit impact conference; 1979 march 5-7; Dallas, Texas. 11p. [Section]1.

Baker, M. Training and certification of auditors and inspectors for the residential conservation service program. Payne, F. W. ed. Energy management - a sourcebook of current practices. Atlanta, Ga.: Fairmont Press Inc.;1981: 431-436.

Bakke, D. W. The least cost energy strategy. Thumann, A. ed. Energy utilization - a sourcebook of current technology. Atlanta, Ga.: The Fairmont Press Inc.; 1980: 197-207.

Barker, B.; Lindgren, N. Framework for the future. Electric Power Research Journal. $3: 84-95 ; 1979$.

Baron, S. L. Manual of energy saving in existing buildings and plants - vol. 2, facility modifications. Englewood Cliffs, N.J.: Prentice Hall; 1978. 320p.

Brown, H. L. Industrial waste energy data: executive summary. DOE report no. COO/2862-31. 90 p. Washington, D.C.;1977.

Canby, T. Y. Synfuels: fill'er up! with what?. National Ceographic Special Report (suppl.): 74-95; 1981 Feb.

Claman, V. N. How to reduce costs in your building. Boston, Mass. Center for Information Sharing; 1983. 54p.

De Koker, N. Energy conservation in manufacturing - General Motors Corp. Proceedings - state energy audit impact conference; 1979 March 5-7; Dallas, Texas. 7p. [Section]1.

Dubin, F. S.; Mindell, H. L.; Bloome, S. How to save energy and cut costs in existing industrial and commercial buildings. Park Ridge, N.J.: Noyes Data Corp.; 1976. 725p. 
Ebasco Services Inc. Kilowatts by others. Ebasco's Energy Business. 2d quarter, 1984.

Edison Electric Institute. Coal - answers to your questions. EEI pub. no. 78-33. 48p. Washington, D.C.; 1978.

Edison Electric Institute. Nuclear power - answers to your questions. EEI pub. no. 78-24. 83p. Washington, D.C.: 1979.

Evans, A. R.; Grogan, P. J.; Wyant, F. R. Factors affecting the implementation of energy conserving technology in industry. Thumann, A. ed. Energy utilization - a sourcebook of current technology. Atlanta, Ga.: The Fairmont Press Inc.; 1980: 187-190.

Florida Power and Light Co. Commercial/industrial energy analysis. Conservation Services; 1982a. 12p.

Florida Power and Light Co. The Homestead Air Force Base energy survey. Marketing and Energy Conservation Dept. Miami; 1982b. 1200p. Report.

Florida Power and Light Co. FPL 1982 Energy management report. Miami; 1983a. 13p.

Florida Power and Light Co.: Your guide to commercial and industrial energy savings. Conservation Services; 1983b. $13 p$.

Florida Power and Light Co. Passive design details. pub. no. 8308-793/5M. Miami; 1983c. 10p.

FPL Group Inc. The 1984 annual report. Miami; 1985. 45p.

Geller, H.S. Energy efficient appliances. Energy Conservation Coaltion. Washington, D.C.; 1983 June.

Gore, R. Conservation, can we live better on less?. National Geographic Special Report (suppl.): 34-57; 1981 Feb.

Guntermann, A. E. Energy Management systems: are they cost-effective?. Heating/Piping/Air Conditioning; 1982 Sept.

Honeywell Corporation. Energy management with comfort. 3d ed. New York, N.Y.; 1979. 115p.

Hu, S. D. World energy supply. Handbook of industrial energy conservation. New York, N.Y.: Van Nostrand Reinhold Co.; 1983a: 36-41.

$\mathrm{Hu}, \mathrm{S}$. D. Principles of energy conservation. Handbook of industrial energy conservation. New York, N.Y.: Van Nostrand Reinhold Co.; 1983b: 73-75.

$\mathrm{Hu}, \mathrm{S}$. D. The future of industrial energy conservation. Handbook of industrial energy conservation. New York, N.Y.: Van Nostrand Reinhold Co.: 1983c: 443-447.

Hu, S. D. Legislative, institutional, and environmental impacts on energy conservation. Handbook of industrial energy conservation. New York, N.Y.: Van Nostrand Reinhold Co.; 1983d: 200-231. 
Imperatore, T. Proven ways to save energy in commercial buildings. Roose, R. W. ed. Handbook of energy conservation for mechanical systems in buildings. New York, N.Y.: Van Nostrand Reinhold Co., 1978: 359-367.

Johnston, W. E. The value of the Huyck corporate energy management survey. Thumann A. ed. Energy utilization - a sourcebook of current technology. Atlanta, Ga.: The Fairmont Press Inc.; 1980: 165-186.

Kennedy, W. J. How to perform an energy audit. Proceedings - state energy audit impact conference; 1979 March 5-7; Dallas, Texas. 5p. [Section]3.

Liebman, L. Saving energy. Vol. 9, No. 4; 1985; Bellevue, Washington. 8 p.

Kenton, J. New directions. Electric Power Research Journal. 3:74-83;1979.

McClure, J. R. Judging the results by checking utility bills before and after implementing an energy conservation program is not enough to prove success. Handbook of energy conservation for mechanical systems in buildings. New York, N.Y.: Van Nostrand Reinhold Co.; 1978. 592p.

McKetta, J. J. The 1983 U.S. energy picture - we're still in trouble. 1983; 24p. Available from: NationaL Council for Environmental Balance, Louisville, Ky.

Meloe, T. U.S. energy use to the year 2000. Atlanta, GA.: The Fairmont Press Inc.; 1981. 441-446.

Metropolitan Dade County Office of Energy Management (OEM). Energy economic development - a project report. Energy Task Force; 1982. 103p.

Metropolitan Dade County Office of Energy Management (OEM). Energy financing for local governments - Metropolitan Dade County's Energy Investment Fund. Energy Task Force; 1983. $125 p$.

Metropolitan Dade County Office of Energy Management: Residential programs of Metropolitan Dade County: Miami; 1984.

Miller, J. N. The energy crisis: there is an easy answer. Reader's Digest Reprint. 1980 June. $8 p$.

Miller, J. N. Which path to our energy future?. Reader's Digest Reprint. 1981 Jan. 10p.

Munk, M. Energy auditing neutral band theory and practices. Thumann, A. ed. Energy utilization - a sourcebook of current technology. Atlanta, Ga.: The Fairmont Press Inc.; 1980: 67-94. Murphy, W. R.; McKay, G. M. Energy management. London: Butterworths;
1982. 374p.

National Electrical Contractors Assoc.; National Electrical Manufacturers Assoc. Total energy management - a practical handbook on energy conservation management. 2d ed. Washington, D.C.; 1979. 90p. 
National Environmental Systems Contractors Assoc.(NESCA). Manual j - load calculations for residential winter and summer air conditioning. 4th ed. Arlington, Va.; 1975. 46p.

National Science Foundation (NSF). Energy conservation retrofit for existing public and institutional facilities. Washington, D.C. Public Technology Inc.; 1977. 109p.

National Society of Professional Engineers (NSPE). Utilities and the unselling of electricity. Engineering Times; 1985 Feb.

O'Leary, J. F. What six experts say. National Geographic Special Report (suppl.): 70; 1981 Feb.

Reding, J. T.; Sheperd, B. P. Energy consumption, fuel utilization and conservation in industry. Dow Chemical Co. 65p. New York, N. Y.; 1975.

Roose, R. W. ed. Handbook of energy conservation for mechanical systems in buildings. New York, N.Y.: Van Nostrand Reinhold Co.; 1978. 592p.

Sneathen, J. P. School energy management manual. East Lansing, Mich. School Business Officials; 1978. 192p.

State of Florida Department of Community Affairs. Residential instruction manual - south florida edition; 1984. $45 p$.

Swim, L. K.: Hogsett, G.; Turner, W. C. Future trends in energy management. Strategic Planning and Energy Managemerit. 3(2):55-76; 1984.

The Miami Herald. Challenge: not to cope but control; March 24, 1985.

Thumann, A. Plant engineers and managers guide to energy conservation. New York, N.Y.: Van Nostrand Reinhold Co.; 1977:1-6.

Turner, W. C. Implementing energy management programs. Proceedings state energy audit impact conference; 1979 March 5-7; Dallas, Texas. 5p. [Section]2.

U.S. Department of Energy. Identifying retrofit projects for buildings. Washington, D.C. National Technical Information Service; 1980a. 135p.

144 U.S. Department of Energy. Passive solar design handbook. Washington, D.C. DOE/CS-0127/1; 1980b. $291 \mathrm{p}$.

Weaver, K. F. America's thirst for imported oil - our energy predicament. National Geographic Special Report (suppl.): 2-23; 1981 Feb.

Yanuck, R. R. Heat recovery economics. Journal of the Association of Energy Engineers. 78(2): 51-53; 1981. 